\title{
Lyme Disease Pathogenesis
}

\author{
Jenifer Coburn ${ }^{1 *}$, Brandon Garcia ${ }^{2}$, Linden T. Hu${ }^{3}$, Mollie W. Jewett ${ }^{4}$, Peter Kraiczy ${ }^{5}$, Steven J. Norris ${ }^{6}$ \\ and Jon Skare ${ }^{7}$
}

${ }^{1}$ Center For Infectious Disease Research, Medical College of Wisconsin, 8701 Watertown Plank Rd., TBRC C3980, Milwaukee, WI 53226, USA

2Department of Microbiology and Immunology, East Carolina University, Brody School of Medicine, Greenville, NC 27858, USA 3Department of Molecular Biology and Microbiology, Vice Dean of Research, Tufts University School of Medicine, 136 Harrison Ave., Boston, MA 02111, USA

${ }^{4}$ Immunity and Pathogenesis Division Head, Burnett School of Biomedical Sciences, University of Central Florida College of Medicine, 6900 Lake Nona Blvd. Orlando, FL 32827, USA

5 Institute of Medical Microbiology and Infection Control, University Hospital Frankfurt, Goethe University Frankfurt, Paul-Ehrlich-Str. 40, 60596 Frankfurt, Germany

${ }^{6}$ Department of Pathology and Laboratory Medicine, University of Texas Medical School at Houston, P.O. Box 20708, Houston, TX 77225, USA

${ }^{7}$ Professor and Associate Head, Texas A\&M University, 8447 Riverside Pkwy, Bryan, TX 77807, USA

${ }^{*}$ Corresponding author: jcobum@mcw.edu

DOI: https://doi.org/10.21775/cimb.042.473

\begin{abstract}
Lyme disease Borrelia are obligately parasitic, ticktransmitted, invasive, persistent bacterial pathogens that cause disease in humans and non-reservoir vertebrates primarily through the induction of inflammation. During transmission from the infected tick, the bacteria undergo significant changes in gene expression, resulting in adaptation to the mammalian environment. The organisms multiply and spread locally and induce inflammatory responses that, in humans, result in clinical signs and symptoms. Borrelia virulence involves a multiplicity of mechanisms for dissemination and colonization of multiple tissues and evasion of host immune responses. Most of the tissue damage, which is seen in non-reservoir hosts, appears to result from host inflammatory reactions, despite the low numbers of bacteria in affected sites. This host response to the Lyme disease Borrelia can cause neurologic, cardiovascular, arthritic, and dermatologic manifestations during the disseminated and persistent stages of infection. The mechanisms by which a paucity of organisms (in comparison to many other infectious diseases) can cause varied and in some cases profound inflammation and symptoms remains mysterious but are the subjects of diverse ongoing investigations. In this review, we provide an overview of virulence mechanisms and determinants for which roles have been demonstrated in vivo, primarily in mouse models of infection.
\end{abstract}

\section{Introduction}

Lyme disease was first recognized in 1976 when a cluster of cases of juvenile arthritis was recognized in Old Lyme, CT. Many of these patients also reported cutaneous skin lesions that were similar to those reported in Europe that were previously associated with tick bites. There was a strong suspicion that an infectious agent was the underlying cause of both cases in Old Lyme, CT and in Europe, but it was not until 1982 that a spirochete found in Ixodes ticks was suggested to be the cause (Burgdorfer et al., 1982). The role of this bacterium, named Borrelia (B.) burgdorferi, as the causative agent of Lyme disease was quickly established as the bacterium was recovered from patients as well as from reservoir hosts, such as the white-footed mouse. Although first recognized because of its association with arthritis, it became clear that arthritis was a late stage manifestation and that acute infection manifested with a characteristic erythema migrans rash and, in some cases, with cardiac or neurologic involvement.

Prokaryotes evolved approximately 3.5 billion years ago (Schopf, 2000) and, by definition, were initially free-living. The evolution of microbial communities and symbiotic relationships about 1 billion years ago eventually resulted in the development of multicellular eukaryotic organisms, creating new ecologic niches. Bacteria colonized these 

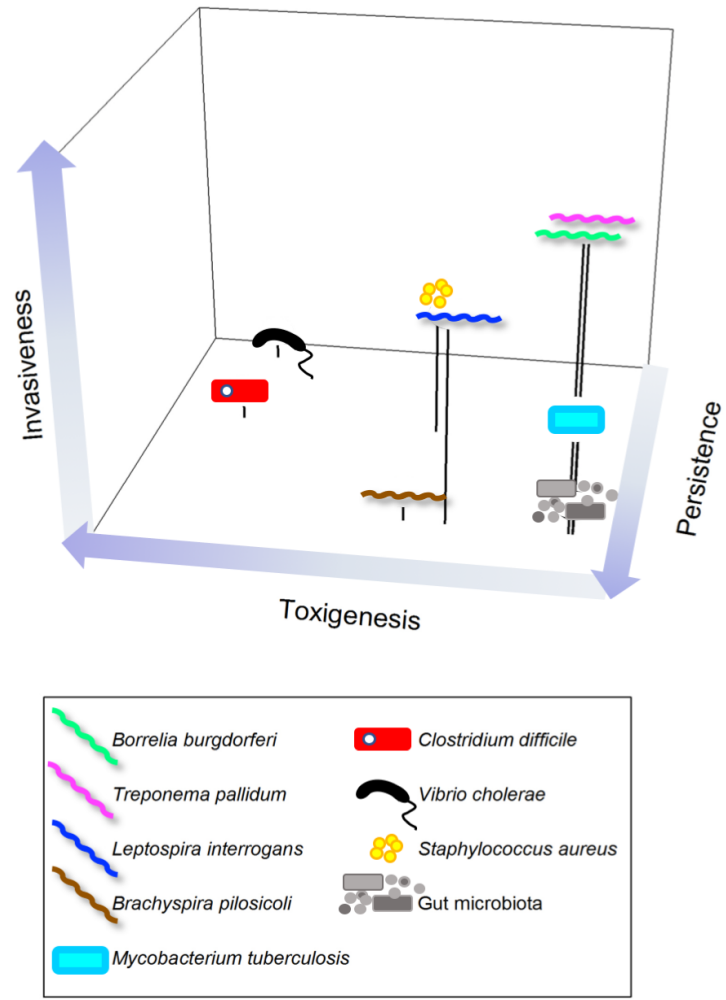

Figure 1. Characteristics of select bacterial pathogens. Schematic depiction of general properties of bacterial pathogens illustrated. Note that for many of the bacteria shown, the outcome of the interaction may depend on the host and even particular sites within the host. B. burgdorferi and T. pallidum are highly invasive and persistent, but non-toxigenic, while $M$. tuberculosis is usually less invasive but persistent and non-toxigenic; gut microbiota are persistent but neither invasive nor toxigenic. $S$. aureus is often a commensal that as opportunity arises can be invasive and toxigenic. $L$. interrogans is invasive and persistent, but unlike B. burgdorferi and T. pallidum, synthesizes lipopolysaccharide (LPS), a highly inflammatory glycolipid. B. pilosicoli causes persistent but not invasive infection, synthesizes LPS and hemolysins. V. cholerae and C. difficile are both toxigenic organisms, which cause disease largely attributable to toxin action; $C$. difficile is more persistent, at least in part, due to spore formation. The authors thank Valery Lozada-Fernandez, PhD candidate at the Medical College of Wisconsin, for generation of the 3D plot in this figure. Concept originally depicted in (Botkin et al., 2006).

ecologic niches as commensal, symbiotic and pathogenic organisms. Development of host-associated pathogens resulted from genetic adaptation to protect themselves, parasitize, and become harmful to other organisms. This adaptation involved modification, acquisition, and loss of a variety of genes, thereby acquiring, creating, and preserving functions that assure survival and losing those that are nonessential.

Lyme disease Borrelia developed an unusual lifestyle in which they must alternate between vertebrate and arthropod hosts; they are never free-living (i.e., they do not "hit the ground"). In addition, they belong to a group of highly invasive organisms, the spirochetes, capable of invading multiple tissues in susceptible vertebrates and causing infection and manifestations for months to years (Figure 1). In this manner, infection with Lyme disease Borrelia in some respects parallels that of another spirochete, Treponema pallidum subsp. pallidum, the causative agent of syphilis. Both diseases exhibit local, disseminated and persistent manifestations, and tissue pathology appears to be due primarily to host inflammatory reactions. However, there are important differences in the mode of transmission (i.e. vectored by an infected tick vs. direct human to human contact). In addition, while Lyme disease and syphilis are both persistent infections with pathology 
predominantly caused by inflammatory reactions, each has distinct manifestations. Overlaid on these differences is the fact that the clinical manifestations of Lyme disease vary in different geographic regions. This is believed to be, at least in part, due to differences in the predominant Lyme disease agents in particular regions. For example, Borrelia garinii, which is found in Eurasia, has been linked to neurologic disease, while B. burgdorferi, the major species found in the U.S. is associated with arthritis. Even among strains of $B$. burgdorferi, there have been differences reported in manifestations and in the severity of inflammation associated with particular strains. The specific differences between species and strains responsible for the varying clinical presentations are only beginning to be identified. Despite a high degree of genetic similarity among pathogenic treponemes, greater clinical distinctions are observed among the diseases they cause (syphilis, bejel, yaws, pinta). The dissimilarities observed in these spirochetal infections reflect important differences in infection patterns, tissue tropisms, and host-pathogen interactions at the molecular level.

In this review, we examine the factors involved in the pathogenesis of Lyme disease in experimentally tractable animal models. In some cases, results obtained in animal models can be directly related to human disease (also see Radolf and Samuels, 2021). It is important to remember that the majority of animal models may not fully reflect $B$. burgdorferi infections of either humans (accidental) or of reservoir hosts in the natural tick-reservoir-tick cycle. Nevertheless, studying the pathogenesis of invasive, nontoxigenic organisms requires animal models for advancing understanding of mechanisms of invasion, dissemination, and persistence. Such investigations are relatively complex, requiring analysis of gene products (e.g. adhesins, or adhesive proteins, and other surface molecules) that are best studied in the context of intact host and pathogen organisms. Only in the setting of an intact animal can the roles of critical interactions be fully evaluated. It is also important to note that low passage, infectious strains of $B$. burgdorferi have low transformation rates, associated with the presence of putative restrictionmodification systems encoded on genomic plasmids frequently lost during in vitro culture (Lawrenz et al., 2002; Kawabata et al., 2004). At least one of these plasmids is required for infection of mice and ticks, making genetic manipulations more challenging than with many other organisms. Thus, our knowledge of the genes important in $B$. burgdorferi pathogenesis is still expanding rapidly and is certainly not complete.

Additional complications in understanding $B$. burgdorferi pathogenesis are the differences in the immune responses between different hosts. In its natural reservoir host, Peromyscus leucopus, the white footed mouse, no inflammatory response is seen with infection. In contrast, different strains of inbred Mus mice manifest varying responses to the organism. With some strains of inbred mice, the manifestations may mimic those seen in human Lyme disease (e.g. carditis, arthritis). However, it is unclear whether the underlying mechanisms for generating these responses are similar. Because of the complexity of host-pathogen interactions, this review can include only a portion of relevant studies; the reader is asked to refer to Radolf and Samuels, (2021) and the primary literature for additional detail regarding gene regulation, motility, interactions with the tick vectors, animal models, host responses, and other factors that contribute to pathogenesis and disease.

\section{The infection process}

Virulence determinants of Borrelia burgdorferi Current knowledge regarding the virulence determinants of Lyme disease Borrelia is summarized in Table 1, which appears at the end of this article. Herein, we define virulence determinants to include all genes that affect the infection process. This designation, therefore, includes genes involved in basic metabolic processes required for survival in a host animal, but that do not necessarily directly or actively engage the host. In Table 1 , we focus on genes that encode functions required for $B$. burgdorferi to (i) survive in, and (ii) invade the mammalian host (disseminate), and (iii) cause disease, as described in greater detail below. The focus on $B$. burgdorferi reflects the volume of work done with this species, although most of the genes and proteins included in Table 1 have orthologs in the other Lyme disease spirochetes. One important consideration is that any virulence determinant should fulfill molecular Koch's postulates (Falkow, 1988), which essentially require that (i) a phenotype or gene be specific to pathogenic members of a genus, (ii) inactivation of a gene results in mutant with reduced infectivity (the ability to cause infection) or pathogenicity (the ability to cause disease), and (iii) complementation of the mutant restores the properties of the wild-type. Note that that all Borrelia isolated from ticks or wildlife could be considered 


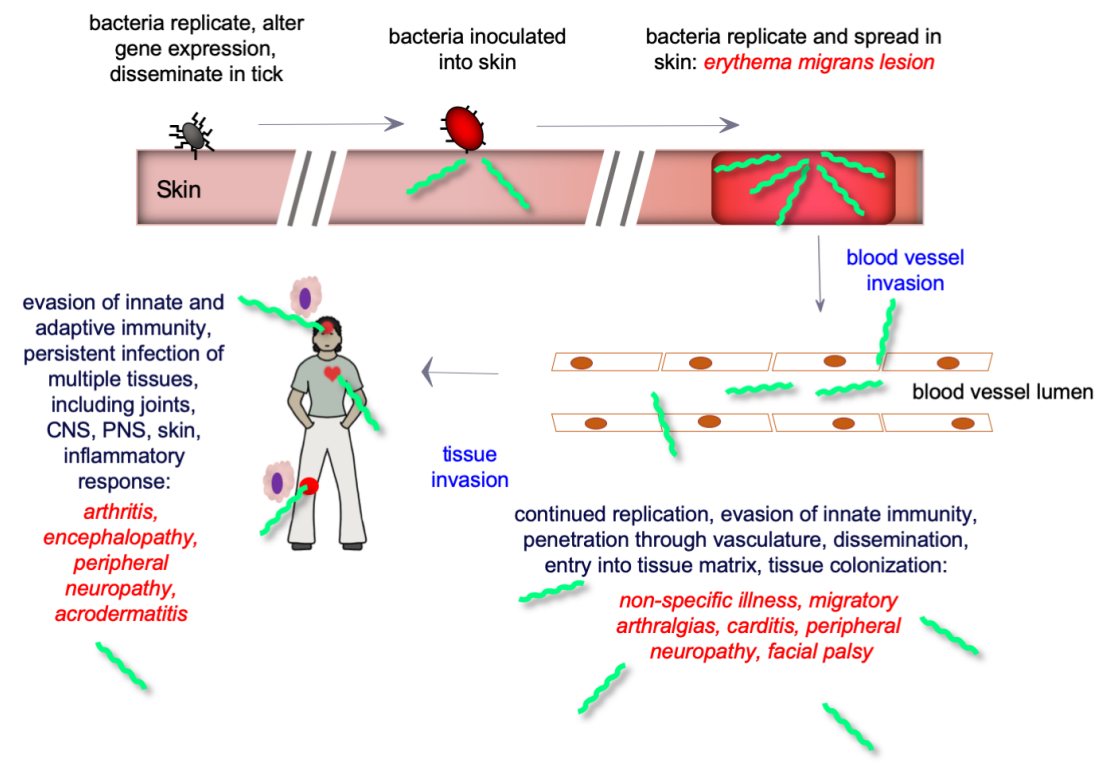

Figure 2. Overview of Borrelia infection and Lyme disease in humans. Schematic representation of the infection process (in black text) and common associated disease manifestations (in red text) in Lyme borreliosis. For detailed descriptions of Lyme disease clinical manifestations, stages, and associations with different Lyme spirochete species, we refer the reader to Radolf and Samuels (2021) and to Steere, A.C. (2001) "Lyme Disease" N Engl J Med; 345:115-125. Adapted from Coburn, J., Leong, J. and Chaconas, G. (2013). "Illuminating the roles of the Borrelia burgdorferi adhesins" Trends Microbiol 21(8): 372-379, with permission from Elsevier.

infectious due to their obligate parasitic their lifecycles but that pathogenicity also depends on the host animal. For example, it is now clear that not all members of the Lyme disease taxonomic clade of Borrelia can cause human infection, so cannot be considered as human pathogens. In Borrelia species, attenuation of infectivity during laboratory culture is frequently associated with loss of genomic plasmids maintained in the natural life cycle.

\section{Overview of the infection process}

An overview of the basic steps of the infection process and host responses in Lyme borreliosis is presented in Figure 2. Table 1 summarizes specific $B$. burgdorferi genes and gene products that have been implicated as virulence determinants or factors in vivo. We recognize that additional Borrelia species cause Lyme borreliosis, but genetic tools that allow testing of hypotheses experimentally have been developed most extensively for use and deployed in, B. burgdorferi (Radolf and Samuels, 2021).

During tick transmission, the bacterium undergoes changes in gene expression that permit it to adapt to the mammalian environment (see Radolf and
Samuels, 2021). Survival and replication in the dermis involve adaptation to the increased temperature, altered $\mathrm{pH}$, and differences in nutrient availability, as well as fending off host innate immune mechanisms. Binding of complement regulators by a number of different $B$. burgdorferi proteins likely plays a key role in survival throughout infection and in diverse vertebrate hosts. Motility and chemotaxis (Radolf and Samuels, 2021) also are important for local and systemic dissemination. Binding to a variety of host tissue components provides activities, such as adherence to the vascular wall and extravasation, while adherence to extravascular tissue components facilitates persistent colonization of diverse tissue sites. The acquisition of host plasmin may aid in the tissue invasion process. Immune responses, both innate and adaptive (Radolf and Samuels, 2021), contribute to control of the numbers of the organisms but also contribute to tissue pathology and disease manifestations. Lyme disease Borrelia have established mechanisms, including antigenic variation, that permit survival for months to years in the mammalian host; indeed, experimentally infected mice appear to be infected for life. This persistence is likely required to maintain the bacteria in the natural 
tick-vertebrate infection cycle. Some of the gene products and mechanisms involved in invasion, dissemination, tissue colonization, and evasion of the host immune system are addressed in the remainder of this review, but other critical aspects (e.g. interactions of $B$. burgdorferi with the tick vector, regulation of gene expression, motility and chemotaxis, and immune responses) are covered in more detail elsewhere (Radolf and Samuels, 2021). Emerging themes regarding the pathogenesis of Lyme disease include (i) $B$. burgdorferi encodes several multi-function proteins, (ii) $B$. burgdorferi encodes several distinct proteins that may inhibit host complement activity at different stages of the cascade, (iii) immune responses to $B$. burgdorferi are not only responsible for controlling bacterial numbers, but also for disease manifestations, and (iv) $B$. burgdorferi encodes multiple adhesins that play distinct roles in the infection process.

\section{Overview of methods used to identify and evaluate candidate virulence determinants in Borrelia}

Evaluation of the roles of candidate virulence determinants in model hosts

While the significance of candidate virulence determinants in many bacterial pathogens can be determined using cell culture and animal models, in the case of $B$. burgdorferi, ticks also must be considered. Each model type can be informative in different ways. Cell culture models can be informative regarding specific and detailed mechanisms of how the bacteria interact with different host cell types, and how individual host cell types respond to the spirochete. The strengths of cell culture models include lower cost and potential for higher throughput, but only in animals can virulence determinants be evaluated in the context of tissue architecture and host responses. Laboratory mice (usually Mus musculus) are the favored model host because of the relatively low cost and the abundance of mutant mice and mouse-specific reagents to facilitate evaluation of damage and pathology. However, a significant caveat to the use of mice is that they are not humans, nor even primates, and so are fundamentally different in terms of the host cells and molecules that are relevant in Borrelia infections. A second significant caveat is the possibility of offtarget effects in mutant mouse lines that are not carefully and completely characterized. The primate (Rhesus macaque, Macaca mulatta) model is more reflective of human disease, but more challenging due to cost, availability of appropriate facilities and expertise, and the lack of genetic tractability. We refer the reader to Radolf and Samuels (2021) for indepth information. The development of the dialysis membrane chamber implant model allowed, for the first time, harvest of sufficient numbers of $B$. burgdorferi cells for further studies on gene expression and protein production while the bacteria are in a host animal (Akins et al., 1998). Tick work requires available hosts for feeding and therefore progression of the ticks through their life stages, and appropriate containment, but is now performed by many laboratories. For further detail on the ticks and the tick phase of the $B$. burgdorferi life cycle, we refer the reader to Radolf and Samuels (2021).

Genetic approaches used to identify virulence determinants of $\mathrm{B}$. burgdorferi

Genome-wide analysis of the $B$. burgdorferi genes that are expressed during mammalian infection was historically challenging because the spirochete loads in blood and tissues are too low to allow use of older technologies. This obstacle has been partially overcome through technological advances, and the transcriptomic and proteomic analysis of $B$. burgdorferi grown under in vitro conditions that mimic certain aspects of the tick and mouse environments (Carroll et al., 1999; Revel et al., 2002; Brooks et al., 2003; Ojaimi et al., 2003; Seshu et al., 2004; Tokarz et al., 2004; Hyde et al., 2007; Angel et al., 2010) and mammalian host adapted spirochetes grown in dialysis membrane chambers implanted in the rat peritoneal cavity (Akins et al., 1998; Revel et al., 2002; Brooks et al., 2003; Caimano, 2005; lyer et al., 2015). More recently, advances in the development of genetic tools for $B$. burgdorferi (see Radolf and Samuels, 2021) and in new technologies have contributed significantly to understanding the importance of particular $B$. burgdorferi genes and likely, their products, during infection.

\section{In Vivo Expression Technology (IVET)}

In Vivo Expression Technology is a gene discovery method that allows for identification of transcriptionally active regions of a microbial genome when the microorganism is in an environment of interest and does not require isolation of microbial RNA (Mahan et al., 1993a; Mahan et al., 1993b). IVET has been applied to $B$. burgdorferi to identify DNA sequences that function as active promoters during murine infection (Ellis et al., 2013; Casselli and Bankhead, 2015). The details of the molecular genetics of $B$. burgdorferi IVET approaches are discussed in Radolf and Samuels (2021). Application of IVET to $B$. burgdorferi has led to the discovery of 
novel genes important for murine infection, as well as previously unannotated sequences that are expressed during an active infection (Ellis et al., 2013; Jain et al., 2015; Showman et al., 2016; Adams et al., 2017).

Signature tagged mutagenesis (STM)

Signature tagged mutagenesis is a transposon-based approach to the generation of mutations on a genomic scale. The transposon ( $\mathrm{Tn}$ ) incorporates short unique DNA sequences, or "signature tags", to help discriminate between genetically identical "siblings" arising from the transformation vs. truly independent transposon insertion mutants. The library of Tn mutants can then be challenged in a number of ways to identify mutants that do not survive the challenge, i.e. mutants that were present in the starting pool but missing after the selection. In a tour de force effort, a large Tn library was generated in an infectious $B$. burgdorferi strain (Botkin et al., 2006; Lin et al., 2012), and used to infect mice. While some mutants were recovered at frequencies reflective of the starting pool, many were recovered at much lower frequencies or not at all. This latter group was considered attenuated. Sequencing of the Tn insertion sites in the clones in the latter group identified candidate virulence determinant-encoding genes at a scale that was unprecedented in the field. Some of these genes had already been shown to encode virulence determinants, validating the approach, but many other genes identified using these strategies opened new avenues of investigation for multiple research groups.

\section{Transposon sequencing (Tn-seq)}

The signature tagged mutagenesis library also has been used in transposon sequencing protocols ( $\mathrm{Tn}$-seq) to identify the fitness of insertional mutants in the STM library under specific conditions. Here, the STM library is placed under a specific selection pressure and the frequency of mutants before and after the selection pressure is compared using quantitative massively parallel sequencing to identify the location of the transposon insertion. This technique has been used to identify genes involved in carbon utilization, evasion of reactive oxygen species, and survival in the tick host (Troy et al., 2013; Troy et al., 2016; Ramsey et al., 2017; Phelan et al., 2019). The technique is highly reproducible when used under in vitro conditions due to the large numbers of mutants that can be tested in a single experiment. When using Tn-seq under in vivo conditions in a mouse or tick host, "bottle-neck" issues must be considered. Bottlenecks occur when there is stochastic loss of mutants for reasons that are unrelated to the specific transposon insertion. During in vivo infections, a large percentage of an inoculum does not survive the initial transition into a new host. Losses in the bottleneck can lead to false discovery of insertions that are not truly related to fitness and survival in the host. Bottleneck issues can be overcome either by studying smaller numbers of mutants or by increasing the sample size (Chao et al., 2016). One of the major advantages of Tn-seq is that it allows the potential for unbiased identification of possible function encoded by genes with unknown function.

\section{Biochemical approaches}

Characterization of the function of a protein or other molecule often requires thorough analyses at the biochemical level. For example, adhesins would have to be localized on the bacterial surface to interact with host substrates, and proof of their localization in or on the Borrelia cell has been approached in multiple ways. Since Borrelia species are diderm (i.e., have outer and inner membranes with a periplasmic space in between), multiple fractionation approaches have been tested (Magnarelli et al., 1989; Bledsoe et al., 1994; Radolf et al., 1995; Jacobs et al., 2005; Nowalk et al., 2006b), although the results have at times been controversial as spirochete components may fractionate incorrectly using protocols developed for Gram-negative enteric organisms. An initial approach is evaluation of whether a secretion signal peptide (Emr et al., 1980a; Emr et al., 1980b; Hall et al., 1980; Beckwith and Silhavy, 1983) is located at the amino terminal end of a predicted protein sequence, although some properties of spirochete lipoprotein secretion signals differ from those found in E. coli (Setubal et al., 2006). Even if there is a signal peptide, the protein is not necessarily localized to the surface in diderm bacteria, so additional biochemical approaches are warranted. Interestingly, it appears that lipoproteins encoded by $B$. burgdorferi are, by default, localized to the outer membrane (Schulze and Zuckert, 2006; Dowdell et al., 2017), but experimental proof of surface localization always is required for any putative surface-exposed protein. One approach is determination of whether the protein is accessible using a protein-specific antibody, with detection of the antibody using a secondary antibody conjugated to a fluorochrome and visualization by fluorescence microscopy. In the case of Borrelia, a control antibody directed against a periplasmic component, e.g. flagellin, is required to demonstrate that the outer membrane is intact (e.g. (Kraiczy et al., 2001b; Hefty 
et al., 2002; Kenedy et al., 2014)). A variation on this technique, designed to help protect the integrity of the outer membrane, is probing with antibodies after suspension of individual bacteria in agarose gel microdroplets (Cox et al., 1996). A second method employs protease (e.g. proteinase $\mathrm{K}$, trypsin) digestion of intact Borrelia cells, followed by gel electrophoresis and immunoblotting to determine whether intact protein or fragments of the protein are present after protease treatment (e.g. (Bunikis et al., 2001; Zuckert et al., 2004; Revel et al., 2005; Jewett et al., 2007a)). Again, controls for the integrity of the outer membrane are essential. For both immunofluorescence and surface proteolysis approaches, a control used frequently in the Borrelia field is flagellin, as the flagella in Borrelia are in the periplasmic space, and not accessible to either antibody or protease if the outer membrane is intact (reviewed in Rosa, 1997; Charon et al., 2012; Zuckert, 2019).

Determination of binding affinities $\left(K_{D} S\right)$ is another approach used to assess the potential physiologic relevance of interactions of Borrelia proteins with DNA or RNA (e.g. regulators or gene expression) or with mammalian substrates (e.g. adhesins). What is considered high vs. low affinity binding is, in part, determined on the basis of physiologically relevant concentrations of the interacting molecules. $K_{\mathrm{D}}$ values for $B$. burgdorferi adhesin-ligand interactions vary considerably ( $\mathrm{nM}$ to $\mu \mathrm{M}$ ranges) (Brissette et al., 2009a; Fortune et al., 2014; Lin et al., 2015; Ristow et al., 2015), but even lower affinity interactions may still be physiologically relevant, as bacterial cell interactions with host cells or extracellular matrix components tend to be multivalent. While the in vitro determination of the cellular locations and the ligand specificities and affinities of adhesins is of value, the ultimate measure of relevance is the assessment of adhesin expression and function in the infection cycle, using mutational analysis and other approaches.

\section{Imaging of Borrelia burgdorferi in murine hosts}

In this section, we provide a very brief overview of live imaging approaches for investigating $B$. burgdorferi-host interactions. More in-depth information is provided elsewhere (Radolf and Samuels, 2021).

In vivo whole animal imaging of $B$. burgdorferi in living mice has illuminated gene expression patterns and roles of several Borrelia proteins in infection (Hyde et al., 2011; Skare et al., 2016). In this biophotonic imaging approach, $B$. burgdorferi strains that do or do not produce a protein of interest are transformed with a Borrelia-codon optimized luciferase gene (Blevins et al., 2007), then injected into mice. A major advantage of this approach is that the Borrelia can be followed over time using the same mice for repeated measurements. Detection requires injection of luciferin, which, upon oxidation by luciferase, emits light. Quantification of the light emitted can be correlated with other methods of Borrelia quantification (e.g., quantitative PCR). Beyond the whole animal approach, Borrelia burdens in tissues/organs also can be quantified after euthanasia of the mice.

Two photon microscopy has been used in the Borrelia field to image the bacteria the feeding tick, and host skin tissue components in living mice (Harman et al., 2012; Bockenstedt et al., 2014). This method takes advantage of near-infrared excitation of fluorescent molecules, which results in reduced scattering of light in mammalian tissues, providing a stronger signal to noise ratio and greater depth of imaging in tissues than is possible with confocal imaging. In addition, second harmonic generation resulting from absorption of photons by certain tissue components allows imaging of Borrelia movement in the context of mammalian tissue in real time.

Spinning disc confocal microscopy provides highresolution live imaging of living, moving, targets of interest. In the world of bacterial pathogenesis, this approach was first used to image Borrelia interactions with the vasculature in living mice (Moriarty et al., 2008). The high resolution images are collected with background fluorescence removed due to filtration of the excitation and emission light through tiny pinholes in a rapidly spinning disc. This increases resolution, particularly for moving targets such as Borrelia and living mouse tissue, because of the high image acquisition rate and the fact that light outside the plane of focus is deflected by the disc unless it passes precisely through the pinholes. Several different types of interactions were discerned, and roles for particular $B$. burgdorferi proteins in each of these types of interactions have been defined (Moriarty et al., 2008; Norman et al., 2008; Lee et al., 2014; Kumar et al., 2015).

\section{Genes and Proteins involved in infection and pathogenesis Adaptation to the mammalian host}

When an Ixodes vector tick begins feeding on a mammalian host, there is a dramatic alteration in the 
tick midgut environment (see Radolf and Samuels, 2021). The blood meal and proximity to the mammal results in changes in temperature, $\mathrm{pH}$, availability of nutrients, and exposure to antibodies, complement and other host protective factors. In response to changing environmental conditions, $B$. burgdorferi replicates rapidly in the midgut during and following tick feeding, with the number of Borrelia increasing from $<500$ prior to feeding to about $1.7 \times 10^{5}$ per tick after 72 hours of feeding, a $>300$-fold increase (De Silva and Fikrig, 1995). Along with this population expansion, $B$. burgdorferi undergoes dramatic changes in gene expression, primarily but not exclusively via the Rrp2-RpoN-RpoS regulatory cascade (Table 1 and Radolf and Samuels, 2021).

Some of these changes are reflected at the mRNA level in vitro with changes in culture temperature and $\mathrm{pH}$, as well as incubation in dialysis membrane chambers or in the presence of blood. These in vitro environmental changes have been used as models to study gene regulation during the tick to mammal transition, and in part reflect the tick to mammal transition, with upregulation of mammalian infectionassociated surface proteins such as OspC, DbpA, DbpB via the Rrp2-RpoN-Rpos sigma factor pathway. However, changes in the in vitro culture conditions do not affect expression of other genes, including $p 66$, or result in downregulation of tickrelated gene products OspA and OspB.

\section{Survival in the mammalian host: Nutrient acquisition and metabolism}

Once the bacteria have been introduced into the dermis of a mammalian host, they must replicate and disseminate in order to facilitate the tick-vertebratetick cycle that maintains the genus in nature. The biosynthetic capabilities of Lyme disease Borrelia are limited, so the bacteria require complex media for growth in the laboratory, and are dependent on acquisition of multiple nutrient classes from the host. Uptake of nutrients by cytoplasmic membrane transporters requires that the nutrients permeate through the outer membrane, likely through porins. Although the in vivo functional roles of $B$. burgdorferi porins have not been addressed experimentally, indirect data suggest that the porin, or some other function, of the adhesin/porin P66 may be required in vivo (Ristow et al., 2015). BB0406, which like P66 potentially may serve as a porin and an adhesin, facilitates $B$. burgdorferi infection (Shrestha et al., 2017; Bista et al., 2020). Several nutrient salvage proteins required for survival in mammalian tissue have been identified (Table 1). PncA, a nicotinamidase that converts nicotinamide (niacin) to nicotinic acid, is needed to provide a precursor for biosynthesis of NAD (Purser et al., 2003). AdeC, an adenine deaminase, which converts adenine to hypoxanthine and, thus, facilitates purine interconversion, and GuaA and GuaB, GMP synthase and IMP dehydrogenase, respectively, are enzymes involved in nucleotide metabolism and are required for infection of mice (Jewett et al., 2007b; Jewett et al., 2009). BBB22 and BBB23 are purine permeases critical for uptake of hypoxanthine, adenine and guanine and also are essential for $B$. burgdorferi infection of mice (Jain et al., 2012; Jain et al., 2015). OppAV, an oligopeptide permease component of the oligopeptide uptake system, is critical for $B$. burgdorferi persistence in the mammalian host (Caimano et al., 2019). BB0318, the ATPase component of a putative riboflavin $A B C$ transport system (Deka et al., 2013), contributes to resistance to oxidative stress and macrophage killing as well as infection in mice (Showman et al., 2016), suggesting an important link between $B$. burgdorferi nutrient acquisition and immune evasion mechanisms. The genes encoding the majority of these proteins are located on genomic plasmids, reinforcing the essential roles of these replicons in the enzootic cycle. The chromosomally-encoded putative glucose specific EIIBC component of a phosphoenolpyruvate phosphotransferase system PtsG is critical for mouse infection (Lin et al., 2012; Khajanchi et al., 2015). The manganese transporter $\mathrm{BmtA}$ is also required for infection of both mice and ticks (Ouyang et al., 2009a). It also is possible that the lipolytic/hemolytic enzyme BB0646 (Shaw et al., 2012) serves a nutrient scavenging function as opposed to an intoxication function, as the pathologies seen in Lyme disease are not consistent with those seen in toxin-mediated diseases. Given that many genes in B. burgdorferi have not yet been assigned a role or function, it is likely that additional factors and their activities remain to be identified in vivo. If, however, their functions also are required for in vitro cultivation, they would not be covered in Tn mutant libraries, as the mutants would be lost from the population.

\section{Survival in the mammalian host: Evasion of innate immune responses}

$B$. burgdorferi components are recognized by multiple members of the toll like receptor (TLR) family of receptors and by Nod-like receptors (NLRs). More extensive descriptions of the functions of these receptors can be found in Radolf and Samuels 
(2021). Upon encountering their cognate ligands, TLRs and NLRs activate signaling pathways that lead to the release of both pro- and anti-inflammatory cytokines and chemokines. Depending upon the host, the initial response typically leads to recruitment of cells of the innate immune system (neutrophils, T cells) that have specific capabilities for killing the organism. B. burgdorferi has evolved mechanisms for evading these host defenses as detailed below and elsewhere (Radolf and Samuels, 2021).

Most pathogenic microorganisms have developed mechanisms for evading the innate and adaptive immune responses, permitting their survival and proliferation in a hostile host environment (reviewed in e.g. (van der Woude and Baumler, 2004; Norris, 2006; Vink et al., 2012; Norris, 2014; Foley, 2015; Knirel et al., 2015; Obergfell and Seifert, 2015; Phillips et al., 2019; Chaconas et al., 2020)). Immune evasion mechanisms are particularly important in pathogens that cause persistent disseminated infection. These infectious agents include Lyme disease and relapsing fever Borrelia, T. pallidum (syphilis and related illnesses), Mycobacterium tuberculosis and $M$. leprae (tuberculosis and leprosy), protozoa such as Plasmodium and Babesia spp. (malaria and related diseases), Leishmania spp. (leishmaniasis), and Trypanosoma (sleeping sickness and Chagas disease), the Herpesvirus family (Herpes Virus I and II, varicella zoster virus, EpsteinBarr virus, and others), and Human Immunodeficiency Virus. Mechanisms of immune evasion are myriad, and several are key contributors to the success of the Lyme disease Borrelia as pathogens in humans and in the natural enzootic cycle.

Borrelia Resistance to Reactive Oxygen Species (ROS) and Reactive Nitrogen Species (RNS)

As a way to neutralize infectious agents, hosts utilize a battery of innate and adaptive immune systems to protect themselves. The great majority of infectious agents that cause infection in immunocompetent hosts are equipped, at least to some extent, to circumvent these host responses through a variety of mechanisms. For an extracellular parasite and pathogen like $B$. burgdorferi, the ability to neutralize innate killing mechanisms is critical. One such protective system that an infected host deploys to protect against infection, be it an arthropod or a mammal, is the induction of reactive oxygen species (ROS) or reactive nitrogen species (RNS). Unlike many bacteria, $B$. burgdorferi does not encode a large collection of obvious detoxification enzymes to combat
ROS or RNS, but independent groups have demonstrated roles for DNA repair enzymes, a ribonuclease, and transport proteins in resistance to ROS and RNS (Bourret et al., 2011; Bourret et al., 2016; Showman et al., 2016; Ramsey et al., 2017). Consistent with these findings, $B$. burgdorferi infection of mice in which either nitric oxide (NO) production was inhibited or inducible nitric oxide synthase (iNOS) was missing had no effect on the disease process, suggesting that the spirochetes have a robust way of combating this potent form of host defense (Seiler et al., 1995; Brown and Reiner, 1999). Other important factors include the role of tick saliva-specific factors that provide antioxidants and other immune modulatory compounds that promote the establishment of $B$. burgdorferi colonization (Ribeiro et al., 1990; Kuthejlova et al., 2001; Narasimhan et al., 2007). Please note that these topics are covered in more depth in Radolf and Samuels (2021).

B. burgdorferi responds differently to oxidative stress relative to most living systems due, in part, to an apparent lack of any requirement for iron (Fe) (Posey and Gherardini, 2000), at least in laboratory culture and as assessed using methodology available at the time. To date, no enzymes have been identified that require $\mathrm{Fe}$ as a cofactor. $B$. burgdorferi uses manganese as a cofactor instead of the iron used by other bacteria (Ouyang et al., 2009a; Troxell et al., 2012; Aguirre et al., 2013; Troxell and Yang, 2013; Troxell et al., 2013; Wagh et al., 2015) and Radolf and Samuels (2021). The lack of $\mathrm{Fe}$ places $B$. burgdorferi at an advantage relative to other Fedependent pathogens (i.e. most) for two reasons. First, DNA damage mediated via Fenton-based chemistry is not likely to occur, particularly following exposure to ROS. Prior studies support this contention given that DNA damage was not detected upon the addition of ROS (Boylan and Gherardini, 2008; Boylan et al., 2008), although as stated above, DNA repair enzymes are important for survival of ROS and RNS challenge. Second, a defense strategy termed nutritional immunity, in which particular nutrients (e.g. $\mathrm{Fe}$ ) are tightly sequestered by the host, is largely irrelevant to $B$. burgdorferi with regard to $\mathrm{Fe}$.

B. burgdorferi do not synthesize their own fatty acids and thus are dependent on the host they infect to provide these essential lipid components (Fraser et al., 1997; Casjens et al., 2000). The incorporation of polyunsaturated fatty acids and lipids from hosts they infect into B. burgdorferi lipids (Crowley et al., 2013) places these structures at risk of oxidative damage 
and the toxicity that occurs as a result. Previous studies demonstrated that the oxidation of lipids occurs when $B$. burgdorferi is exposed to ROS under conditions in which DNA remains recalcitrant to oxidative damage (Boylan and Gherardini, 2008; Boylan et al., 2008). During the blood meal, where tick respiration may generate ROS, or under conditions where the host immune response is elevated, represent times that polyunsaturated lipids would place $B$. burgdorferi at risk of oxidative damage and/or death. As such, it behooves $B$. burgdorferi to neutralize this attack. Exactly how $B$. burgdorferi quells lipid oxidation and the deleterious effects that ensue is not known.

The collection of detoxification enzymes that $B$. burgdorferi encodes would appear to be incomplete based on those found in other pathogenic bacteria. For example, no catalases or peroxidases are encoded in the $B$. burgdorferi genome. A single manganese $(\mathrm{Mn})$-dependent superoxide dismutase $(\operatorname{sod} A)$, a $\mathrm{Mn}$ transporter $(b m t A)$, and a riboflavin transporter (bb0318), all contribute to resistance to added ROS in vitro and $B$. burgdorferi infectivity in mice (Esteve-Gassent et al., 2009; Ouyang et al., 2009a; Showman et al., 2016). A napA homologue (also designated bicA or $d p s$ ) plays a role in metal homeostasis with distinct roles presented in different studies (Li et al., 2007; Wang et al., 2012). A more recent report suggested that mutants in napA/bicA were more resistant to added oxidizing compounds when metals were added, particularly $\mathrm{Fe}$ and $\mathrm{Cu}$, due to the ability of NapA/BicA/Dps to trap these metals and serve as a sink for them within the spirochete (Wang et al., 2012). The latter study, which used a more refined approach to measuring metal contents of $B$. burgdorferi than that used earlier (Posey and Gherardini, 2000), posited that the sequestered metals contribute to damage when ROS is encountered. Consistent with this, bicA mutants, which take up less $\mathrm{Fe}$ and $\mathrm{Cu}$, were more resistant to $\mathrm{H}_{2} \mathrm{O}_{2}$ than their wild-type isogenic parent (Wang et al., 2012).

Other genes whose products are predicted to be associated with resistance to oxidative stress include thioredoxin, thioredoxin reductase, and sulfoxide reductase, although none of these have been functionally characterized. The genome predicts no glutathione or glutathione reductase equivalents to provide redox balance or resistance to oxidizing compounds. However, coenzyme A, in concert with coenzyme A disulphide reductase (denoted as $\mathrm{Cdr}$ and encoded by bb0728), reduces hydrogen peroxide and thus protects $B$. burgdorferi from damaging ROS (Boylan et al., 2006). These studies also determined that reduced coenzyme $A$ was present in high concentrations within $B$. burgdorferi cells and that $\mathrm{Cdr}$ was specific for the thiol-containing coenzyme $A$, with coenzyme A serving as a functional analogue to glutathione in $B$. burgdorferi to maintain homeostatic redox balance within the cytoplasm of the spirochete.

In contrast to the effect of oxidative exposure, the consequence of nitrosative stress, due to NO exposure, results in significant damage to DNA that then requires nucleoside excision repair genes $u v r B$ and $u v r C$ to repair the lesions that accrue (Bourret et al., 2011; Bourret et al., 2016). The production of NO is as likely in the tick vector as it is in mammals (via iNOS) given the presence of Ixodes-specific nitric oxide synthase and nitrophorins. Further, the production of $\mathrm{NO}$ also contributes to vasodilation that seemingly benefits the blood meal process (Yang et al., 2014).

With the goal of identifying novel $B$. burgdorferi proteins involved in resistance to ROS and RNS, an unbiased screen was employed using the existing transposon library (Lin et al., 2012) coupled with Tnseq analysis (Ramsey et al., 2017). From this analysis, 66 genes were identified that contributed to RNS and ROS resistance. Notably, several genes already known to be important for resistance to ROS and RNS were observed in this study. For example, it is known that nucleotide excision repair, mediated by $B$. burgdorferi uvrB and $u v r C$, is needed in response to RNS (Bourret et al., 2011; Bourret et al., 2016), and Tn mutants in uvrC and $u v r D$ were disproportionally lower in abundance in the Tn-seq data following $B$. burgdorferi exposure to RNS (Ramsey et al., 2017). In addition, several genes of unknown function were identified in the RNS as well as the ROS screens (Ramsey et al., 2017). Two distinct ROS compounds were used, hydrogen peroxide and tertiary-butyl hydroperoxide, with several targets overlapping between these samples (Ramsey et al., 2017). In addition, unique targets were found for both reagents, suggesting that $B$. burgdorferi produces proteins with unique mechanisms that specifically combat either hydrogen peroxide or alkyl peroxides.

Several of the novel targets identified encode transmembrane protein transporters, most of which have not been characterized in any context (Ramsey et al., 2017). One of these proteins, designated 
BB0164, appears to transport $\mathrm{Mn}^{2+}$ similar to $\mathrm{BmtA}$ (Ouyang et al., 2009a; Ramsey et al., 2017). The need to accumulate divalent cations, particularly $\mathrm{Mn}^{2+}$, is also seen in Lactobacillus species, which, similar to $B$. burgdorferi, also lack many detoxification enzymes (Archibald and Fridovich, 1981). Prior work suggests that $\mathrm{Mn}$, in complex with other molecules, forms antioxidant compounds that scavenge ROS that protect the cell from damage (Archibald and Fridovich, 1981). It is also noteworthy that the majority of the genes identified in the initial in vitro RNS and ROS screen were also required for experimental infection, suggesting that the proteins they encode are important in the pathogenic capabilities of $B$. burgdorferi (Ramsey et al., 2017). Along these lines, another independent screen designed to track genes essential for survival in the tick identified several genes that were also seen in the RNS/ROS screen, implying that $B$. burgdorferi must negate RNS and ROS exposure in the tick to maintain its ability to survive in order to ultimately transmit to mammalian hosts (Ramsey et al., 2017; Phelan et al., 2019).

\section{Complement evasion by Lyme disease Borrelia}

The complement system is a primary arm of the innate immune system comprised of dozens of soluble and membrane-attached host proteins (Figure 3). Complement activation is initiated by surface-associated molecular recognition events that trigger a proteolytic cascade mediated by the action of specialized serine proteases. Complement activation occurs through one of three canonical pathways known as classical, lectin, or alternative (Figure 3). Regardless of the initiating pathway, complement activation (i) leads to the recruitment of professional phagocytes via release of powerful chemotactic peptides (i.e., C3a and C5a), (ii) opsonizes surfaces near the site of activation via various complement component fragments (i.e., C4b, $\mathrm{C} 3 \mathrm{~b}, \mathrm{iC} 3 \mathrm{~b}, \mathrm{C} 3 \mathrm{dg}$, and $\mathrm{C} 3 \mathrm{~d}$ ), and (iii) results in the formation of a pore-like structure, the membrane attack complex (MAC or C5b-9), that integrates into target membranes, leading to lysis of the invading pathogen. Vector-transmitted microorganisms like Borrelia that traffic in fluids where complement proteins are present at high concentrations (i.e. blood, interstitial fluids, etc.) must overcome destruction by complement.

Lyme disease spirochetes have evolved an arsenal of outer surface proteins with demonstrated anticomplement function in vivo (Figure 4 and Table 1). We also refer the reader to three recent reviews of
Lyme disease Borrelia interactions with the host complement system (Lin et al., 2020a; Lin et al., 2020b; Skare and Garcia, 2020). Each of these Borrelia outer surface proteins exerts its inhibitory activity at proximal (i.e. initiation pathways), central (i.e. C3b amplification loop), or distal (i.e. terminal sequence) positions of the cascade. Complement evasion mechanisms associated with Borrelia outer surface proteins can be broadly characterized by one of three activities: (i) proteins that recruit endogenous complement regulators (CspA, CspZ, ErpP, ErpC, ErpA), (ii) proteins that recruit endogenous proteases and target their proteolytic activities towards complement protein substrates (CspA, CspZ, ErpA, ErpC, ErpP, BBA70), or (iii) proteins that inhibit the activity of a complement protein by directly binding to it (BBK32, BAD16, OspC, BGA66, BGA71). The collective activity of these proteins affords Borrelia one of the most diverse and functionally overlapping complement evasion repertoires known.

Interestingly, Lyme disease spirochetes vary in their susceptibility to killing by nonimmune human and various mammalian sera in vitro, indicating a differential ability of these spirochetes to prevent MAC formation (reviewed by Kurtenbach et al., 2002; Lin et al., 2020a; Lin et al., 2020b). All human-pathogenic species including $B$. burgdorferi, $B$. afzelii, B. spielmanii, $B$. bavariensis (formerly classified as $B$. garinii OspA serotype 4 ), and $B$. mayonii, as well as $B$. japonica and $B$. bissettiae, resist complement-mediated killing in vitro (reviewed by (Kraiczy, 2016b, a; Walter et al., 2019). Although pathogenic to humans, $B$. garinii predominantly displays a susceptible phenotype in vitro like the non-pathogenic genospecies $B$. valaisiana and $B$. Iusitaniae. How $B$. garinii overcomes the cidal activity of human complement remains unresolved, but one possibility is that protein(s) critical for complement evasion are produced in vivo but not in vitro. In addition, recruitment of host-derived (plasminogen) or tickderived proteins during transmission (Tick Salivary Lectin Pathway Inhibitor, TSLPI; Salp15, Salp20) (Schuijt et al., 2008; Schuijt et al., 2011) or specific pathogen-associated factors may protect this particular genospecies from complement attack during natural infection. More recently, complement resistance has been linked to alleles from distinct Borrelia species. The best example is CspA. CspA from B. burgdorferi and $B$. afzelii confers resistance to mammalian complement, whereas CspA from B. garinii provides resistance to avian serum (Hart et al., 2018). 

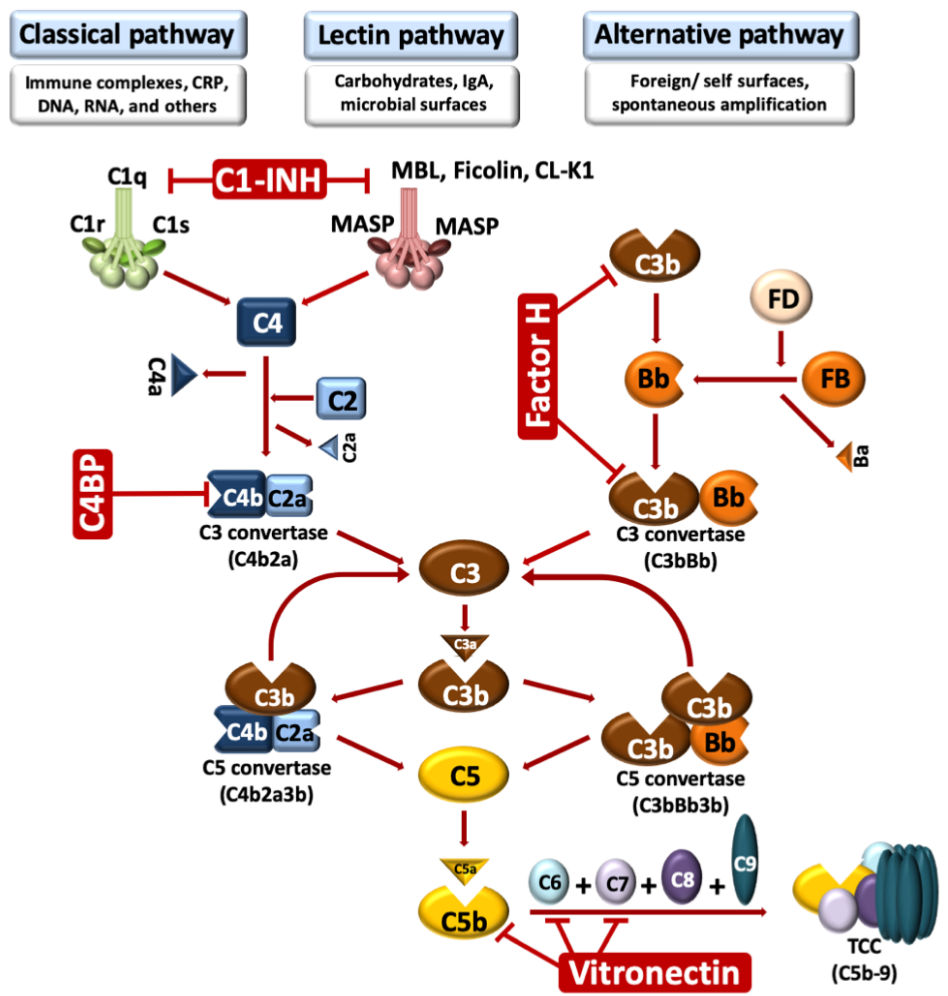

Figure 3. Schematic representation of the human complement cascades. Complement is activated by three pathways: the classical, lectin, and alternative pathway. In each pathway, a series of initial binding steps followed by proteolytic steps ultimately results in activation of the terminal pathway and lysis of the target cells. CRP, C-reactive protein; C1-INH, C1 esterase inhibitor; MBL, Mannose-binding lectin; MASP, MBL-associated serine protease; C4BP, C4b-binding protein; TCC, terminal complement complex. Parts of this figure are adapted from Kraiczy, P. (2016), "Travelling between two worlds: complement as a gatekeeper for an expanded host range of Lyme disease spirochetes" Vet. Sci., 3:12; doi:10.3390/vetsci3020012. Permission to reproduce under CC 4.0 (https://creativecommons.org/licenses/by/4.0).

Borrelia factors affecting activation of the classical and lectin pathways

The classical and lectin pathways of complement are activated by pattern recognition molecules capable of distinguishing specific molecular structures on the surfaces of microbes, including Borrelia. The classical pathway is controlled by the action of a multi-protein complex known as the first component of complement, C1. C1 consists of the pattern recognition subcomponent, $\mathrm{C} 1 \mathrm{q}$, in complex with a heterotetramer of two serine proteases $\left(\mathrm{C}_{1} \mathrm{r}_{2} \mathrm{C} 1 \mathrm{~s}_{2}\right)$. Following binding of $\mathrm{C} 1 \mathrm{q}$ to activating ligands such as $\lg G$ and $\lg M$ immune complexes, $\mathrm{C} 1 \mathrm{r}$ is converted from a zymogen form into an active protease where it then cleaves and activates the C1s zymogen. The classical pathway is, therefore, linked to the adaptive immune response, as specific antibodies are developed in response to a pathogen. Likewise, the lectin pathway is triggered by the pattern recognition molecules mannose-binding lectin (MBL), ficolins, or collectins, which recognize foreign carbohydrates resulting in activation of the MBL-associated proteases (MASPs). Both C1s and MASP-2 cleave C4 and C2 and, thus, the classical and lectin pathways of complement intersect at the formation of the C3 convertases (i.e. C4bC2b).

Relatively few examples of pathogen-derived molecules with specific activity against the upstream activation steps of the classical and lectin pathways have been described. Lyme disease Borrelia spirochetes are outliers in this regard, however, as 


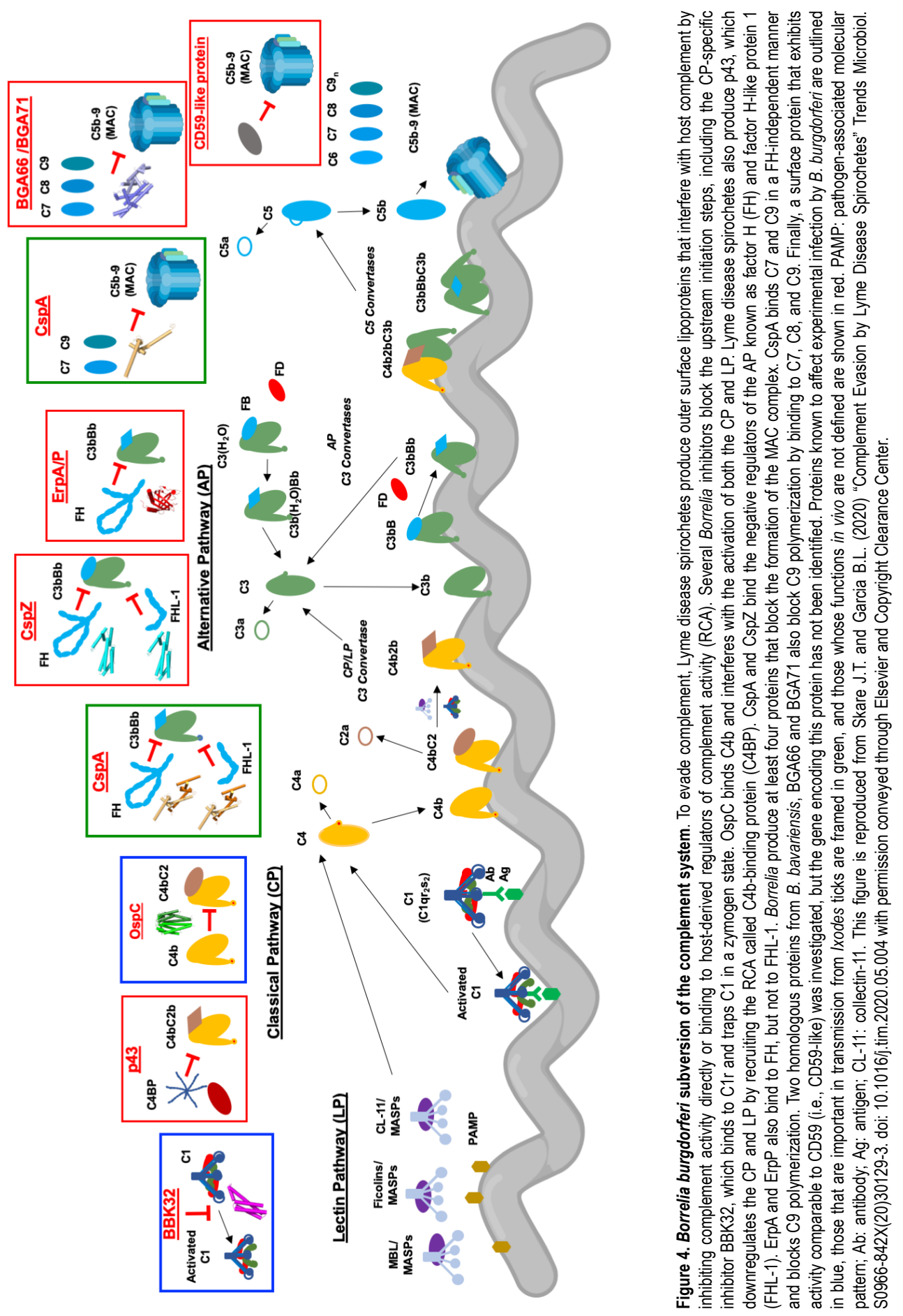


they target both pathways through two unrelated outer surface proteins, OspC and Bbk32. OspC was shown to bind $\mathrm{C} 4 \mathrm{~b}$ and prevent formation of the classical/lectin pathway C3 proconvertase by blocking binding of C2 (Caine et al., 2017). In this manner, OspC inhibits both pathways simultaneously. Consistent with a role in complement evasion, an isogenic ospC mutant of $B$. burgdorferi strain B31-A3 (i.e. B31-A3 $\Delta o s p C$ ) exhibited reduced survival in the blood of intravenously (i.v.) inoculated mice by 30 minutes post-inoculation relative to wild-type. B31-A3 derived strains that constitutively produced OspC from B31-A3 or N40 D10/E9 showed prolonged survival. Yet to be determined is whether this complement-inhibiting activity of OspC is mechanistically tied to its antiphagocytic activity (Carrasco et al., 2015). OspC from B. garinii PBr also was protective in this system albeit to a lesser extent than OspCs of B31-A3 and N40 (Caine et al., 2017).

BBK32 is a multi-functional $B$. burgdorferi outer surface protein with roles in adhesion to fibronectin (Fn) and glycosaminoglycans (GAGs) conferred by distinct domains of the protein (Lin et al., 2015; Xie et al., 2019) (see adhesin section below). More recently, BBK32 was shown to form high-affinity interactions with the human complement $\mathrm{C} 1$ complex by binding specifically to the $\mathrm{C} 1 \mathrm{r}$ protease subcomponent, thereby inhibiting the classical complement pathway. The C1r-binding activity of BBK32 is mediated by a third domain of the protein distinct from those that mediate binding to GAGs and fibronectin (Garcia et al., 2016; Xie et al., 2019). Evidence that BBK32 promotes bloodstream survival of $B$. burgdorferi in mice was reported independently (Caine and Coburn, 2015), supporting the in vivo relevance of its complement-inhibiting activity. Using surface plasmon resonance binding assays and human serum-based assays of complement function, it was shown that the C-terminal region of BBK32 (i.e. BBK32-C) is responsible for all BBK32-mediated C1/C1r interaction and anti-complement activities (Garcia et al., 2016; Xie et al., 2019). Thus, BBK32 possesses a modular architecture whereby its interactions with glycosaminoglycans, fibronectin, and $\mathrm{C} 1 \mathrm{r}$ are mediated by non-overlapping binding sites. Strengthening the case that BBK32 binds $C 1$, a serum-sensitive, high passage strain of $B$. burgdorferi missing linear plasmid-encoded outer surface proteins, including BBK32 (i.e., strain B314), was protected from classical pathway-mediated lysis when transformed with a shuttle vector containing $b b k 32$ (Garcia et al., 2016). However, an isogenic bbk32 mutant in an otherwise infectious strain of $B$. burgdorferi was serum-resistant, pointing to additional factors (e.g., OspC) responsible for evasion of complement by Lyme disease spirochetes.

The complement inhibitory activities of BBK32 homologs in the Lyme spirochetes B. afzelii (i.e., $\mathrm{BAD} 16)$ and $B$. garinii (i.e., BGD19) also were evaluated (Xie et al., 2019). While BAD16 exhibited similar properties to BBK32 in vitro, recombinant $B$. garinii BGD19 failed to inhibit the classical pathway. BGD19 also did not inhibit the classical pathway when expressed on the surface of $B$. burgdorferi B314. The three-dimensional structure of the complement inhibitory region of BBK32, BBK32-C, was solved by $\mathrm{x}$-ray crystallography, and the binding site on $\mathrm{C} 1 \mathrm{r}$ was mapped to the serine protease domain (Xie et al., 2019). A recombinant BBK32 chimeric protein with site-directed changes designed to mimic BDG19 at three surface-exposed residues exhibited BGD19-like activities in all assays, indicating that one or more of these residues in native BBK32 contributes to complement inhibition.

\section{Borrelia factors affecting activation of the alternative} pathway

Unlike the lectin and classical pathways, which rely on pattern recognition molecules to initiate the cascade, alternative pathway complement activation occurs by a mechanism known as tick-over. Tick-over is a process whereby spontaneously hydrolyzed $\mathrm{C} 3$ forms fluid phase C3 convertases of the form $\mathrm{C} 3\left(\mathrm{H}_{2} \mathrm{O}\right) \mathrm{Bb}$, leading to surface-bound alternative pathway C3 convertases $(\mathrm{C} 3 \mathrm{bBb})$. The main negative regulators of $\mathrm{C} 3$ convertase formed by the alternative pathway are Factor $\mathrm{H}(\mathrm{FH})$ and FH-like protein (FHL-1) (Zipfel and Skerka, 2009). FH and $\mathrm{FHL}-1$ bind directly to $\mathrm{C} 3 \mathrm{~b}$ and stimulate the release of the protease fragment (i.e. complement component $\mathrm{Bb}$ ) through a process known as decay accelerating activity. Additionally, $\mathrm{FH}$ and $\mathrm{FHL}-1$ each act as cofactors for factor-I mediated degradation of C3b. These inhibitory activities protect self surfaces from excessive activation and harmful attack by activated effector molecules (Zipfel and Skerka, 2009).

Borrelia produce outer surface proteins collectively called complement regulator-acquiring surface proteins or CRASPs that recruit FH and FHL-1 to the Borrelia surface, thereby hijacking their anticomplement activities. CRASPs are members of at least two surface protein families and bind different proteins of the $\mathrm{FH}$ protein family (see above) (Kraiczy et al., 2001b; Kraiczy et al., 2001c). In this model of 
complement evasion, Borrelia cells usurp the host regulators of the innate immune system by binding $\mathrm{FH}$ and $\mathrm{FHL}-1$ via CRASPs, thereby terminating the accumulation of activated $\mathrm{C} 3 \mathrm{~b}$ molecules on the bacterial cell surface. Resistant spirochetes with less C3b deposited on their surfaces would have decreased opsonization (reducing phagocytosis) and a significantly reduced formation of the complement membrane attack complex (decreasing complementdependent lysis).

Most data accumulated to date support the importance of CspA (also CRASP-1 and BBA68) and its orthologous proteins as inhibitors of the complement cascades in diverse Borrelia species. Disruption of bba68 (encoding CspA) in the complement resistant $B$. burgdorferi strain $\mathrm{B} 31 \mathrm{cF}$ resulted in sensitivity to killing by human complement, while complementation with the shuttle vector pKFSS-1::CRASP-1 restored resistance in vitro (Brooks et al., 2005). Similarly, transformation of the serum-sensitive $B$. garinii strain Bg50 with pKFSS-1::CRASP-1 rendered the strain resistant to killing by human complement (Brooks et al., 2005). Further gain-of-function studies revealed that the $\mathrm{FH}$ and FHL-1 binding CspA proteins from $B$. afzelii, $B$. spielmanii, and $B$. mayonii also promote complement resistance in a serum sensitive $B$. garinii background (Hammerschmidt et al., 2014; Walter et al., 2019). RT-PCR and western blot analysis indicated that CspA is not expressed during experimental infection of mice with different North American B. burgdorferi strains, and that human Lyme disease patients do not produce antibodies against CspA (McDowell et al., 2006), bringing into question whether CspA is expressed during mammalian infection. However, a different group found that antibodies from Lyme disease patients react specifically with nondenatured, recombinant CspA in a line blot assay but not with the denatured protein in western blots (Rossmann et al., 2006). Further studies also provided evidence that CspA is expressed by spirochetes 72 hours post infection at the tick bite site but not at later time points (von Lackum et al., 2005; Hart et al., 2018). The collective results support the notion that CspA-mediated binding of $\mathrm{FH}$ during the blood meal permits survival of Borrelia in the feeding tick and during transit to the host (Hart et al., 2018). Binding of mouse $\mathrm{FH}$ to CspA of $B$. burgdorferi B31 and $B$. afzelii PKo allows the bacterium to survive in ticks fed on mice, while the parental $\triangle c s p A$ or a derivative complemented with $\operatorname{csp} A$ from $B$. garinii ZQ1 are not detectable in infected nymphs. These findings suggested that the Borrelia binding to host-derived $\mathrm{FH}$ determines survival in fed ticks, a key prerequisite for transmission to the mammalian host.

Another member of the CRASP family, CspZ (CRASP-2, BBH06), binds $\mathrm{FH}$ and $\mathrm{FHL}-1$ and also facilitates complement resistance in gain-of-function experiments with non-infectious strains (i.e., $B$. burgdorferi B313 and B. garinii G1) (Hartmann et al., 2006; Siegel et al., 2008). CspZ has been surfacelocalized on intact cells by immunofluorescence microscopy and FACS analyses (Hartmann et al., 2006; Marcinkiewicz et al., 2019), and by trypsin digestion (Hartmann et al., 2006; Coleman et al., 2008; Dowdell et al., 2017). In studies conducted with different infectious clones of $B$. burgdorferi B31 (Bykowski et al., 2007; Coleman et al., 2008), the cspZ gene is expressed by $B$. burgdorferi in all mouse tissues examined but not in unfed or feeding ticks. However, deletion of the cspZ gene did not affect mouse infectivity or disease, and did not reduce resistance to complement-mediated killing in vitro (Coleman et al., 2008). In contrast, it was recently shown that addition of human blood to the culture medium increased hematogenous dissemination and colonization of wildtype B. burgdorferi strain B31-A3 but not B31-A3 $\Delta c s p Z$ in mice and $C$. coturnix quails (Marcinkiewicz et al., 2019). The addition of blood to the medium increased CspZ levels, suggesting that the pre-induction of CspZ might allow $B$. burgdorferi survival immediately after injection, whereas those grown conventionally cannot escape clearance by the host.

Three additional surface lipoproteins encoded on cp32 plasmids, BbCRASP-3, BbCRASP-4, and BbCRASP-5 have been shown to bind $\mathrm{FH}$ and certain factor $\mathrm{H}$ related (FHR) proteins (Kraiczy et al., 2001a; Alitalo et al., 2002; Stevenson et al., 2002; Kraiczy et al., 2003; Metts et al., 2003). In vitro, recombinant versions of these proteins bound $\mathrm{FH}$ in ELISA and surface plasmon resonance analyses, but the same proteins exposed on the Borrelia surface did not bind $\mathrm{FH}$ and gain-of-function strains remained complement sensitive (Siegel et al., 2010). No specific role for any of these proteins in vivo has been demonstrated, but analyses of these genes are complicated by the high degree of redundancy in the $B$. burgdorferi genome.

Borrelia factors affecting activation of the terminal pathway Different Borrelia factors involved in inactivation of the terminal pathway have been described, including 
CspA of $B$. burgdorferi, the CspA orthologs of $B$. afzelii, B. spielmanii, and B. mayonii, and BGA66 and BGA71 of $B$. bavariensis (Hallstrom et al., 2013; Hammerschmidt et al., 2014; Hammerschmidt et al., 2016; Walter et al., 2019). Common to all of these proteins are: (i) binding to the late complement components $\mathrm{C} 7, \mathrm{C} 8$ or $\mathrm{C} 9$, and the terminal complement complex (TCC), (ii) termination of autopolymerization of $\mathrm{C}$, (iii) inhibition of the formation of the TCC and (iv) promotion of complement resistance in gain-of-function strains (Hallstrom et al., 2013; Hammerschmidt et al., 2014; Hammerschmidt et al., 2016; Walter et al., 2019). Despite being members of the PFam54 protein family (the largest paralogous gene family in the Lyme disease spirochete genome), which includes CspA, BGA66 and BGA71 did not bind complement regulators $\mathrm{FH}$ or FHL-1. To date, their possible roles in a mouse infection model have not been investigated.

Role of host complement in control of Borrelia infectivity The involvement of the classical and lectin pathways in Lyme borreliosis recently has been studied in animal models of infection using complement-deficient mice. The lectin pathway was evaluated in $B$. burgdorferi infection of mannose-binding lectin (MBL) deficient mice (Coumou et al., 2019). An early protective role was shown for MBL as MBL-deficient mice exhibited significantly higher bacterial loads in skin tissues of both needle- and I. scapularis infection models (Coumou et al., 2019). However, later infection time points showed similar bacterial loads in heart, joints, and bladder in WT vs. MBL-deficient mice. The role of classical pathway initiation in response to $B$. burgdorferi infection was investigated using $\mathrm{C} 1 \mathrm{q}$ deficient mice (Zhi et al., 2018). As measured using bioluminescent in vivo imaging, $\mathrm{C} 1 \mathrm{q}$ deficient mice harbored higher bacterial loads at 10 days relative to WT mice. Significantly increased bacterial loads also were measured by quantitative PCR in $\mathrm{C} 1 \mathrm{q}$ deficient vs. WT mice at day 21 in the skin, joint, and heart but not lymph nodes. At day 28 , loads were higher in joints and hearts, but not skin and lymph nodes in C1qdeficient mice. Collectively, these studies suggest that the upstream pattern recognition molecules of the complement system play roles in controlling $B$. burgdorferi infections in vivo, although individually, the roles are relatively minor.

The role of the alternative pathway in host response to Lyme borreliosis has been studied using mouse models of disease. No significant differences in $B$. burgdorferi loads could be detected at any time post- infection in mice genetically deficient in complement factor B relative to WT mice (Woodman et al., 2007). In the same study, the use of $\mathrm{FH}$ deficient mice demonstrated that $\mathrm{FH}$ is not required for $B$. burgdorferi to infect mice. However, a confounder in these studies is that $\mathrm{FH}$-deficient mice have extremely low levels of $\mathrm{C} 3$ due to the high rate of spontaneous C3 consumption (Pickering et al., 2002). Infection of C3 deficient mice resulted in significantly increased bacterial loads in the ear tissue during the first two weeks of infection, but not in heart or joint tissue. As C3 activation is central to the complement cascade, C3 deficiency affects all three complement initiation pathways. Thus, while the factor $\mathrm{B}$ and $\mathrm{FH}$ deficient mouse studies suggested a muted role for the alternative pathway in control of $B$. burgdorferi burden in the murine host, the C3-deficient mouse infection experiments may indicate a role for the classical or lectin pathways, even prior to a strong humoral response (Woodman et al., 2007). Indeed, others have noted a role for C3 in experimental Lyme borreliosis. For example, C3 deficient mice showed generally increased bacterial loads compared to wild-type mice when needle infected with B. burgdorferi (Lawrenz et al., 2003). The same study also showed that a complementsensitive strain of $B$. garinii exhibited a lower median infectious dose in C3 deficient mice compared to wild-type. These results indicate that complement is a potential barrier for $B$. garinii infection in mouse models and that $\mathrm{C} 3$ may play an important role in early dissemination of $B$. burgdorferi. In contrast, infections of C3-deficient mice deficient with $B$. burgdorferi, $B$. afzelii, and $B$. bavariensis did not show significant differences compared to WT mice, with the one exception of increased $B$. burgdorferi loads in joints (van Burgel et al., 2011). In the same study, complement-susceptible strains of $B$. burgdorferi remained noninfectious in C3 deficient mice. Finally, the involvement of the host terminal pathway in borreliosis was evaluated in vivo using mice deficient in C5. These studies showed that activation of $\mathrm{C5}$ is not necessary to control murine borreliosis (Bockenstedt et al., 1993). Collectively, these studies suggest that complement regulation does play a modest role in determination of outcome in experimental Lyme borreliosis, but that additional Borrelia virulence determinants contribute to the host-pathogen standoff of persistent infection.

Regulation of expression of complement inhibiting factors Several of the genes that encode complementinhibitory proteins are modulated by both well- 
characterized and novel regulatory systems, as reviewed in (Kraiczy and Stevenson, 2013). CRASPs have different patterns or expression, but all are produced by $B$. burgdorferi in skin at the tick feeding site, and none in the unfed tick (Kraiczy and Stevenson, 2013). Expression of the multifunctional OspC and BBk32, along with that of many other gene products, is transcriptionally regulated by the RpoS/ RpoN/Rrp2 and BosR systems (Hubner et al., 2001; Yang et al., 2003; Fisher et al., 2005; Caimano et al., 2007; Ouyang et al., 2008; Hyde et al., 2009; Ouyang et al., 2009b; Samuels, 2011; Caimano et al., 2019). Both ospC and bbk32 are known to be expressed during the blood meal and early in mammalian infection. This regulatory scheme is well studied and is described in greater detail in Radolf and Samuels, (2021).

\section{Evasion of Adaptive Immunity: Antigenic Variation of VIsE}

The vertebrate host mounts a continually expanding (Craft et al., 1986), yet non-protective, response to $B$. burgdorferi during infection, indicating that immune evasion is a critical virulence determinant in this organism. Antigenic variation as a means to escape clearance by the adaptive immune system has been noted in multiple bacterial, protozoan, and fungal pathogens (reviewed in (Deitsch et al., 2009)). Antigenic variation was known to occur in the relapsing fever Borrelia species (e.g. (Plasterk et al., 1985; Burman et al., 1990; Schwan and Hinnebusch, 1998; Dai et al., 2006)), and accounts for the relapses for which the disease was named. The relapsing fever Borrelia antigenic variation entails a gene conversion type of recombination, copying a complete silent gene encoding a variable membrane protein ( $\mathrm{Vmp}$ ), into a single expression site near the telomere of one of the genomic linear plasmids (Barbour et al., 2000). Multiple vmp genes, which encode two classes of lipoproteins designated large (Vlp) or small (Vsp), are maintained as silent copies elsewhere in the genome. In most recombination events, a v/p or vsp gene recombines randomly via upstream and downstream homology sites into the single expression site (Barbour, 1991; Barbour et al., 2000; Dai et al., 2006; Norris, 2006). In some instances, chimeric genes are formed. The number of possible variants is, thus, largely dependent on the number of $v m p$ genes in the genome. One particular vmp gene, designated vtp or vsp33, has its own expression site and does not undergo recombination. Vsp33 is required for transmission of spirochetes to a new vertebrate host (Raffel et al., 2014; Schwan et al., 2020).
In 1997, the ground-breaking discovery and description of the v/s ( $\underline{v} m p$-like sequence) locus (Zhang et al., 1997) brought the Lyme disease Borrelia into the group of pathogens able to vary a surface protein. This locus as characterized in $B$. burgdorferi strain B31 consists of a single expression site ( $V / S E$ ) near the telomere of a linear genomic plasmid, Ip28-1, plus an adjacent set of 15 silent cassettes in the opposite orientation (v/s2-16). The silent cassettes have a high degree of sequence similarity ( 76.9 to $91.4 \%$ at the amino acid level) to the central cassette region of the expression site (Figure 5). Although the v/s system has been detected in all strains and species of Lyme disease Borrelia examined, the replicon in which the vls locus is contained and the number of silent cassettes vary between isolates (Kawabata et al., 1998; Wang et al., 2001; lyer et al., 2003; Wang et al., 2003; Norris, 2014; Casjens et al., 2017). Notably, the locus is always near a telomere of a linear plasmid, as is true for the vmp system in the relapsing fever Borrelia, but in other ways it is quite distinct. VIs has been calculated to theoretically generate on the order of $10^{40}$ possible variants in B. burgdorferi strain B31 (Verhey et al., 2018a), many orders of magnitude greater than vmp. In contrast to the vmp system, vIsE undergoes random, segmental gene conversion (also termed "switching", or "templated changes") in which portions of any of the silent cassettes are copied into the variable domain of the vlsE expression site, resulting in cellular-level unique mosaics of VIsE due to continuous independent gene conversion events throughout infection (Figure 5) (Zhang and Norris, 1998a, b; Verhey et al., 2018b, a, 2019). Unfortunately for researchers investigating the molecular mechanisms involved in antigenic variation of VIsE, no switching has been detected during in vitro culture, and the in vivo signals that activate this process are currently unknown. Two excellent reviews provide a comparison of the antigenic variation systems of the relapsing fever and Lyme disease Borrelia (Norris, 2014) and a compilation of the unique features of the vls locus (Chaconas et al., 2020).

B. burgdorferi clones lacking Ip28-1 are eliminated from infected immunocompetent mice within 2-3 weeks following inoculation, but survive in the absence of adaptive immune system pressure in SCID mice (Labandeira-Rey et al., 2003; Purser et al., 2003); this result is consistent with a role in protection against adaptive immunity. As expected, transformation of a strain missing Ip28-1 with Ip28-1 restores full infectivity in immunocompetent mice (Grimm et al., 2004a). 


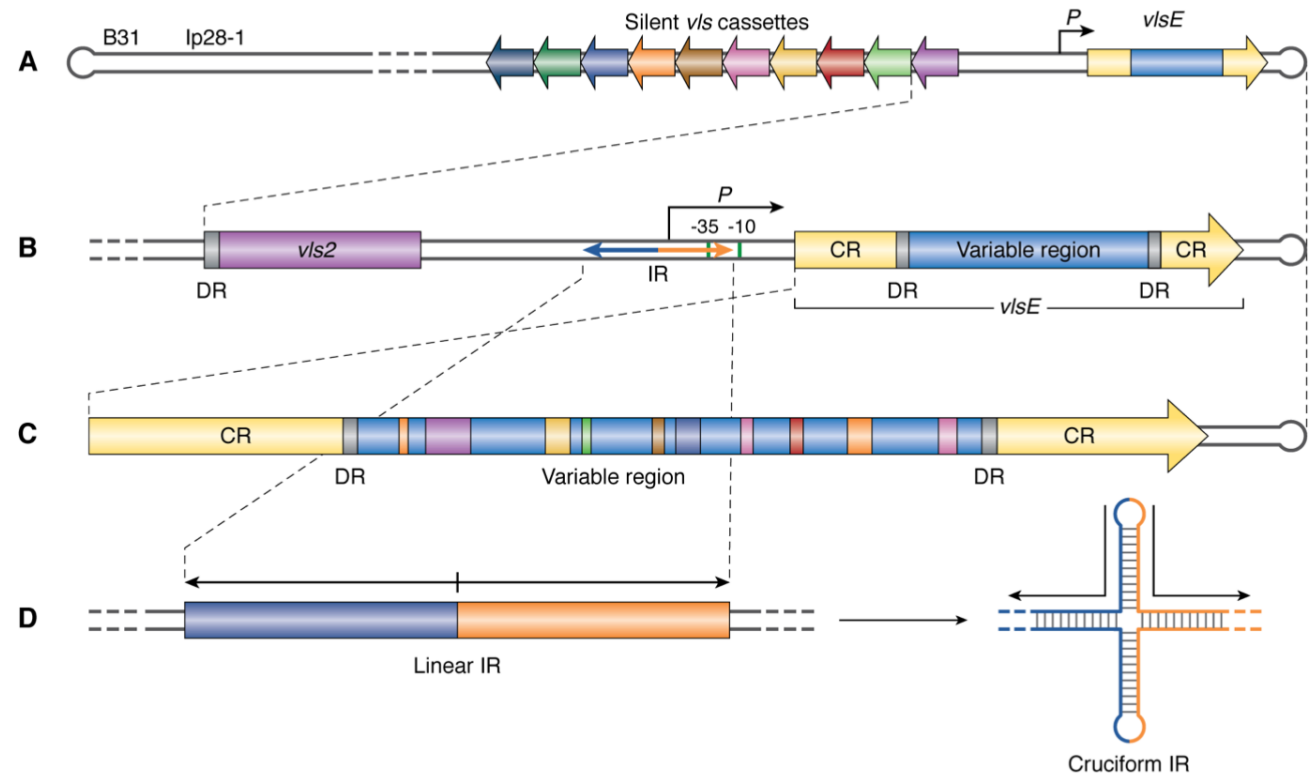

Figure 5. Schematic of the vls antigenic variation locus of $B$. burgdorferi strain B31. A, the vls expression locus (vlsE) with its promoter $(P)$ is located $82 \mathrm{bp}$ from the right covalently closed hairpin end of the linear plasmid Ip28-1. To the left of the promoter and intergenic region (gray) are 15 silent cassettes carrying information corresponding to the variable region of $v l s E$ and situated in the opposite orientation. $\mathrm{B}$, the $v / s E$ region is shown in greater detail, with the constant regions (CR) shown in yellow and the variable region, which corresponds to the information carried in the vls cassettes, shown in blue. The variable region is flanked by 17-bp direct repeats (DR)s. To the left of $v / s E$ is its promoter, with the -10 and -35 sequences shown as green bars. Also shown by the bidirectional arrow is a 100-bp perfect inverted repeat (IR) that partially overlaps the promoter. C, an enlargement of the vlsE gene shows the product of multiple recombinational switching events that result in the copying of genetic information from the silent cassettes into the expression locus, producing a mosaic vlsE carrying information from a number of the silent cassettes. $D$, an IR found in the promoter region of the $v / s E$ gene is shown in its normal linear configuration and as an extruded cruciform promoted by negative supercoiling or DNA unwinding from replication or transcription. This figure is republished from Chaconas, G., Castellanos, M. and Verhey, T. B. (2020). "Changing of the guard: How the Lyme disease spirochete subverts the host immune response" J Biol Chem 295(2): 301-313, with permission of The Journal of Biological Chemistry, (C) the American Society for Biochemistry and Molecular Biology, permission conveyed through Copyright Clearance Center, Inc.

Refined analysis of the specific role of the vls system was achieved using engineered versions of Ip28-1 that lacked either the $v / s$ sequences or the remaining portion of the plasmid (Bankhead and Chaconas, 2007). The $\Delta v / s$ clones exhibited decreased infectivity in WT mice similar to that seen with a Ip28-1 negative clone, with no positive cultures obtained at 21 or 28 days post infection. In contrast, a clone lacking the remainder of Ip28-1 but carrying an intact vls locus was fully infectious in WT mice by needle inoculation. The $\Delta v / s$ clones were recovered from every tissue site tested 28 days after infection of SCID mice; this result paralleled the infectivity of Ip28-1 minus clones in SCID mice observed previously (Labandeira-Rey et al., 2003; Purser et al., 2003; Lawrenz et al., 2004). Since SCID mice cannot elicit an adaptive immune response, but have intact innate immune responses, these results corroborated other evidence that the role of $\mathrm{vls}$ is primarily evasion of adaptive immunity. VIsE also protects (masks) other surface-exposed proteins that do not vary (possibly due to important functional constraints) from host antibodies (Rogovskyy and Bankhead, 2013; Lone and Bankhead, 2020), and this variable protein appears to serve as an immuneevasive barrier critical to maintenance of $B$. burgdorferi in the natural tick-vertebrate infection cycle (Rogovskyy and Bankhead, 2013; Rogovskyy et al., 2015). Of note, the invariable major lipoprotein produced by $B$. burgdorferi in the tick appears to have a role in protecting $B$. burgdorferi from acquired immunity in the tick (which does not have an adaptive immune system), 
which also is relevant to maintenance in the natural cycle (Battisti et al., 2008).

The timing of the requirement for vIsE also is consistent with a role in evasion of adaptive immunity in that antibody responses are first detectable at approximately 2 weeks of $B$. burgdorferi infection. This is also the time frame at which OspC production begins to be detrimental in immunocompetent mice (Tilly et al., 2006; Xu et al., 2006; Tilly et al., 2013), as the ospC sequence of an individual Borrelia cell and its progeny does not vary and so is targeted by the adaptive immune response. VIsE previously was shown to succeed OspC in immunocompetent mice, but in SCID mice infected with a vlsE-deficient strain, ospC expression was maintained (Tilly et al., 2013). Since OspC has been shown to inhibit the innate complement host defense system, while VIsE renders the adaptive immune response essentially irrelevant to clearance of infection, the OspC-VIs succession is consistent with $B$. burgdorferi's requirements for immune evasion to establish and maintain persistence. Intriguingly, both OspC and VIsE were selected for in vivo vascular adhesion using a phage display library of $B$. burgdorferi DNA (Antonara et al., 2007). This has been verified for OspC (Lin et al., 2020c), and hints that VIsE may also have an adhesin function in mice.

Within the vlsE expression site, there are invariant or "constant" regions at the 5' (amino terminal) and 3' (carboxy terminal) ends flanking a central variable region. Additional features of the best-characterized v/s locus, that of the B31 isolate, include direct repeats flanking the variable region of vlsE and the silent copies of $v / s$ genes, but this feature is not conserved among all strains (Chaconas et al., 2020). A 100 base pair inverted repeat upstream of the coding sequence and overlapping with the -35 promoter element is present in all v/s loci sequenced to date (Hudson et al., 2001; Castellanos et al., 2018). The Vls protein is the target of antibody development during infection, with antibody responses targeting both variable and invariable regions (McDowell et al., 2002). Small regions scattered within the variable region are not variable, and one of these segments encodes the "C6" peptide that is a target of serologic testing used for diagnosis of Lyme disease (see, for example, (Branda et al., 2017; Marques, 2018; Wormser et al., 2018; Lipsett et al., 2019)). The variable region largely maps to the membrane-distal protein surface in the crystal structure of VIsE, while the invariant amino and carboxy termini include the major alpha-helices that comprise the framework of the surface-localized protein that is important for dimerization (Eicken et al., 2002; Verhey et al., 2018a, 2019).

Although point mutations may also occur (Sung et al., 2001; Coutte et al., 2009; Verhey et al., 2018b), most sequence changes can be attributed directly to substitution of silent cassette sequences of varying lengths of $\sim 1-140$ base pairs (Verhey et al., 2018b), and so are templated changes. These events can be detected as early as 4 days post infection in mice, and by 28 days each clone re-isolated from mice exhibited a different sequence resulting from separate recombination events (Zhang and Norris, 1998b). Recent advances in DNA sequencing technologies and, more importantly, comprehensive analysis of the enormous volumes of data generated by sequencing reads, have enabled the generation of vast datasets that illuminate $v / s E$ changes to the single nucleotide level in $B$. burgdorferi isolated from multiple tissue sites in independently infected mice at multiple time points (Verhey et al., 2018a, b, 2019).

The use of long-read sequencing combined with multiple reads for each template strand enabled reliable assembly and analyses of the sequence data that had previously been impossible with older technologies, a particularly daunting task in light of the multicopy vls genes arranged in linear fashion on a single genomic replicon. These data revealed that essentially all vlsE sequences isolated from infected mice were unique, i.e. that no single sequence change predominated, or was strongly selected for, in murine infection (Verhey et al., 2018a, b, 2019), similar to earlier findings (Zhang and Norris, 1998b). The deep sequencing used in the more recent studies also suggested that, once disseminated, individual bacterial cells do not frequently re-enter the circulation to seed additional sites (Verhey et al., 2018a).

The data also revealed that gene conversion events (templated changes) were not randomly distributed in the variable region of $v l s E$, but instead occurred more frequently proximal to sites of previous events (Verhey et al., 2018b). Homology does appear to play an important role in segmental gene conversion, as particular silent cassettes flanked by direct repeats with the highest similarity to those in vlsE also have the highest frequency of being used as templates for segmental gene conversion (Verhey et al., 2018b). As noted by the authors, however, it is possible that a physical constraint in generating the recombination structure favors usage of the same silent cassettes. It is possible that maintenance of the similarities in the 
direct repeats is mutually selected for based on the physical restraints placed on the DNA by the recombination structure and/or machinery. Interestingly, however, studies using strain B31, which has direct repeats, and strain JD1, which does not, revealed that the direct repeats are not required for segmental gene conversion to occur (Verhey et al., 2018a, 2019). Nevertheless, even without the direct repeats, the v/s cassettes, by definition, have significant homology, and stretches of highest homology at the base pair level were seen to recombine most frequently (Verhey et al., 2018b). A window of $\geq 20$ homologous base pairs flanking a switch site was found to be optimal.

The frequency of "switch" events was estimated to be on the order of $3.3 \times 10^{-2}$ per cell per generation based on the vast data sets generated in these studies (Verhey et al., 2018b). This rate is one to two logs higher than that estimated for $v m p$ switching in the relapsing fever Borrelia, and it should be noted that this is based on data at the nucleotide, not the amino acid level. Templated changes would be expected to be either silent or missense, while non-templated changes, which occur most frequently in regions in which templated changes are most frequent (Verhey et al., 2018b), could be silent, missense, or nonsense. The cells in which silent or nonsense mutations occur in vlsE would more likely be cleared by the host immune system and not available for analysis after infection of wild-type mice. The clustering of nontemplated changes with regions of templated switches, which were particularly biased to the 5' end of the templated regions, led the authors to speculate that error-prone repairs may participate in the changes at the vIsE locus (Verhey et al., 2018b). It is important to point out that switching of vlsE also occurs in SCID mice, but the elimination of clones expressing the parental $v / s E$ takes longer, presumably because of the lack of immune clearance of invariant clones (Zhang and Norris, 1998b; Coutte et al., 2009; Verhey et al., 2018a). This observation was exploited in the use of SCID mice to characterize and quantify all types of change events in the vls locus, which permits study of vls changes independent of selection by the host adaptive immune response.

The potential roles of both the inverted repeat upstream of $v / s E$ and the telomere-proximal location of the gene were explored using a mini-v/s system that had to be constructed due to the genetic intractability of the full-length v/s locus (Castellanos et al., 2018). In this system, the vIsE locus was cloned with or without an adjacent silent cassette, with or without the inverted repeat, and in plasmids that would be maintained either as circular replicons in B. burgdorferi or would resolve into linear replicons due to the inclusion of telomeric sequences. Multiple steps, some performed by direct transformation of ligation products into $B$. burgdorferi, were required to generate the constructs. The switching frequency assessed after infection of mice was very low (considered background) in strains carrying plasmids with no silent cassette and in those in which the replicon was circular and lacked the inverted repeat. In contrast, with the silent cassette AND the inverted repeat present, the switching frequencies on both circular and linear replicons were all similar and higher, though approximately three logs less than observed with the intact v/s locus. At this point, it is not clear how the inverted repeats and the replicon topology affect v/s variation, but this system will facilitate further investigations of these questions.

Together, all of the results thus far reinforce the concept that antigenic variation is a critical function of VIsE, and that VIsE is a critical virulence determinant of $B$. burgdorferi. Variation in VIsE sequences has not been detected during in vitro culture (Zhang and Norris, 1998b) or in infected ticks (Indest et al., 2001), indicating that as yet unidentified environmental signals in vertebrate hosts (in all of these experiments, mice) regulate the gene conversion process.

The genes critical to the segmental gene conversion at the vls locus were identified independently by two groups (Dresser et al., 2009; Lin et al., 2009). Interestingly, and perhaps surprisingly, RecA expression was shown to be NOT required for vlsE recombination during mouse infection (Liveris et al., 2008; Dresser et al., 2009), indicating that the process is not dependent upon 'standard' homologous recombination. This is somewhat surprising given the overall homology of the locus and the presence of direct repeats flanking the variable region in many isolates. Two different genetic approaches were employed to the gene(s) critical to v/s switching; both found that the process depends on the activity of the RuvA-RuvB Holliday junction helicase/branch migrase. In one study, transposon (Tn) mutants (Lin et al., 2009) in genes involved in DNA repair and recombination were screened in wild-type mice by infection over several time points up to 28 days. Tn mutants in ruvA and ruvB both were attenuated in wild-type mice and had reduced $v / s$ recombination when isolates were analyzed after recovery from infected mice. A targeted 
ruvA mutant showed reduced infection in wild-type, but not SCID, mice (Lin et al., 2009). Sequence analyses of $B$. burgdorferi clones isolated after murine infection again showed that minimal vlsE change had occurred in the ruvA and ruvB mutants during infection of wildtype mice, and that the parental sequence was detected in only a small proportion of clones by 28 days post-inoculation. In contrast, the parental sequence was found in multiple isolates after infection of SCID mice with the ruvA mutant. The recombination events that did occur in the ruvA mutant during infection of wild-type mice were not only less frequent but also used fewer silent loci as templates, indicating that the fine-scale segmental gene conversion that generates multiple changes of few amino acids in the parental bacteria is not active in the mutant.

In the same journal issue, an independent group, using a different approach, also identified RuvA and RuvB as critical to vlsE segmental gene conversion by generating $17 \mathrm{~B}$. burgdorferi strains with targeted mutations that disrupted genes predicted to encode proteins involved in DNA repair, recombination, and replication (Dresser et al., 2009). A strength of this targeted approach was that it facilitated analysis of independent clones. Two individual mutant strains for each targeted locus were tested for their ability to cause infection in mice, again over a time course, and for vls recombination during infection. Again, ruvA and ruvB mutants were the only strains reproducibly attenuated by both measures.

VIsE and the flanking silent cassettes therefore comprise an elegant system required for Lyme disease Borrelia to maintain persistent infection in immunocompetent reservoir animals, an essential element of the natural lifecycle. Although variation in the surface-exposed portions of the protein keeps antibody-mediated clearance in check, invariant domains that are not surface-exposed are targeted by antibody responses that are not effective at clearing the organism, but are useful in diagnosis of infection in accidental hosts including humans. Finally, there is some evidence that additional proteins help $B$. burgdorferi survive in the face of the host adaptive immune response, e.g. BB0210, also known as Lmp1 (Yang et al., 2009). As yet, the specific roles that other such proteins play remain to be determined.

\section{Dissemination and tissue colonization: A plethora of adhesins}

Colonization of the tick is mediated by several $B$. burgdorferi proteins, including OspA, an adhesin that binds to the tick midgut epithelium (also see Radolf and Samuels, 2021). In addition, OspA blocks antibody access to the bacterial cell when $B$. burgdorferi resides in the tick midgut, serving as a shield as well (Battisti et al., 2008). In this review, however, we focus on interactions that contribute to infection of the mammalian host. $B$. burgdorferi has been known for decades to bind to a variety of mammalian cell types in culture and to extracellular matrix components, as reviewed in (Benach et al., 1991; Coburn et al., 2005; Antonara et al., 2011; Coburn et al., 2013; Brissette and Gaultney, 2014), but the relevance of these interactions in vivo has not always been clear. Recent advances in genetic manipulation of the bacterium and in imaging have enabled studies of the roles of individual $B$. burgdorferi-host protein interactions in vivo. Here we focus on $B$. burgdorferi proteins that facilitate survival, dissemination, and tissue colonization in the mouse model of infection and that bind to specific mammalian substrates in vitro. Several adhesins also serve to combat host immune defenses, and, at least in some cases, these activities are mediated by distinct domains. Of note, adhesive activities found only in vitro warrant some caution regarding importance in vivo, as many of the substrate proteins are inherently "sticky". Affinity and specificity are important considerations, but the gold standard regarding any candidate adhesin is the fulfillment of molecular Koch's postulates (Falkow, 1988). We begin with the adhesins that bind to components of the extracellular matrix (ECM), then move on to adhesins that bind to mammalian integral membrane proteins that have transmembrane signaling potential.

Adhesins that bind to extracellular matrix components Laminins constitute a family of widely distributed heterotrimeric extracellular matrix glycoproteins that serve a variety of functions; many bacteria produce lamininbinding adhesins. $B$. burgdorferi encodes at least three laminin-binding adhesins: ErpX, BmpA and BB0406. ErpX was shown to bind laminin (stated to be primarily $\alpha_{1} \beta_{1} \gamma_{1}$ by the vendor) produced by a murine sarcoma cell line (Brissette et al., 2009c), but no assessments of a potential in vivo role have been reported.

Similar in vitro approaches were used to identify the Bmp proteins as candidate laminin-binding adhesins, although only BmpA was investigated in depth (Verma et al., 2009). In vivo, there is evidence that $\mathrm{BmpA}$ and $\mathrm{B}$ contribute to joint colonization and arthritis development (Pal et al., 2008), and BmpD 
was selected in vivo for vascular adhesion (Antonara et al., 2007). More recent structure based predictions suggest a role for Bmp proteins in nutrient uptake (Astrand et al., 2019; Cuellar et al., 2020), although this activity has not been experimentally verified. Furthermore, BmpB, C, and D all are associated with the cytoplasmic membrane, i.e. not available to serve as adhesins (Dowdell et al., 2017). Therefore, potential roles of Bmp proteins as adhesins are in serious doubt, as independent lines of evidence (in silico and experimental) suggest that they are not located on the $B$. burgdorferi surface.

BB0406 is a recent addition to the group of lamininbinding adhesins as well as a putative porin (Shrestha et al., 2017; Bista et al., 2020). Mutants in bb0406 are infectious but attenuated in mice and show reduced bacterial burdens in tissues compared to the parental strain. The data presented support a role for this protein in dissemination and bacterial colonization in mouse tissues (Bista et al., 2020). The precise roles of the laminin-binding proteins in murine infection remain to be determined.

OspC is one case in which a protein known to be required for $B$. burgdorferi to establish infection in mice was subsequently found to have adhesin functions and a role in evasion of innate immunity. It is not yet clear whether the same or distinct domains of the protein are involved in each activity. ospC mutants are unable to initiate infection in either immunocompetent or MyD88-/and SCID mice (Table 1), which are deficient in innate and adaptive immunity, respectively. These results are consistent with the more recent identification of OspC as an antiphagocytic factor (Carrasco et al., 2015), and as having a role in disabling the complement cascade (Caine et al., 2017) (Table 1). Expression is required only during initial infection, as $\triangle o s p C$ organisms complemented with ospC encoded on a plasmid had consistently lost the plasmid 6 weeks post infection (Tilly et al., 2006). Constitutive expression of OspC results in elimination of $B$. burgdorferi in immunocompetent but not SCID mice (Xu et al., 2006), suggesting that appropriate downregulation of this major surface protein is critical to evasion of the adaptive immune response. The documented succession of OspC to VlsE production by $B$. burgdorferi during mammalian infection (Tilly et al., 2013) is interesting in this regard, as OspC contributes to complement resistance in innate and adaptive immunity, while VIsE undergoes continual antigenic variation throughout mammalian infection, protecting the bacteria from the adaptive immune response (Table 1).
OspC also was identified as a candidate adhesin using in vivo phage display (Antonara et al., 2007) and was shown to bind to mammalian cells in culture. Subsequent work has demonstrated that OspC binds to mammalian ECM components fibronectin and/or dermatan sulfate, with binding to each substrate varying with the OspC sequence type (Lin et al., 2020c). OspC also contributes to extravasation of bacteria (Lin et al., 2020c). VIsE also was selected for vascular adhesive activities using in vivo phage display (Antonara et al., 2007) (Table 1), providing hints of possible adhesion-based functional overlap of these proteins in addition to their roles in subverting or evading host immune defenses.

An operon encoding two related adhesins, decorinbinding proteins A and B (DbpA and DbpB; Table 1), also is activated when the bacteria are transiting to the mammalian host. Decorin is a proteoglycan with a core protein modified by addition of a dermatan sulfate (chondroitin sulfate B) glycosaminoglycan, which "decorates" type 1 collagen fibrils. Decorin is known to have several structural and regulatory functions and is widely available as a substrate for bacterial adhesion. DbpA has been shown to bind the proteoglycan decorin, and to dermatan sulfate glycosaminoglycans in the absence of the core protein. In the first genetic study of the role of $B$. burgdorferi attachment to host molecules, decorindeficient mice showed colonization defects by $B$. burgdorferi in heart, bladder, and joint at low doses; at higher inocula, decorin-deficient mice harbored fewer $B$. burgdorferi specifically in joint tissue and exhibited reduced arthritis severity and frequency (Brown et al., 2001). Mutant B. burgdorferi that do not produce DbpA and DbpB have significant attenuations in virulence as measured by bacterial loads in disseminated sites (Hyde et al., 2011; Fortune et al., 2014; Lin et al., 2014), suggesting that a key role for these proteins is in facilitating dissemination and/or colonization of multiple tissue sites. Various DbpA sequences produced in an isogenic strain background showed different levels of binding to decorin and dermatan sulfate in vitro and different levels of colonization in a variety of tissues in vivo (Lin et al., 2014), For example, DbpA sequences from $B$. garinii and $B$. afzelii strains colonized joint tissues in mice at significantly lower levels than did DbpA from a $B$. burgdorferi strain, reflecting the different propensities of the species to cause arthritis in humans (Lin et al., 2014). 
The search for $B$. burgdorferi collagen-binding adhesins began long before the identification of BBA33 as a collagen-binging adhesin (Zhi et al., 2015). The interest in collagen was initially fueled by pathological observations of the bacteria residing primarily in perivascular connective tissues and frequently associated with collagen (Barthold et al., 1988; Barthold et al., 1991; Barthold et al., 1993). Although $B$. burgdorferi was found to bind to and invade biologically intact type 1 collagen (Zambrano et al., 2004), which is the most abundant collagen and is widely distributed, BBA33 was found to bind to types IV and VI collagen (Zhi et al., 2015). Type IV collagen is widely distributed, primarily found in the basement membrane (basal lamina) of endothelial and epithelial cell layers. Type VI collagen is abundant in skeletal muscle and nervous system tissue types and appears to serve as a connection between basal lamina and other ECM components. Since collagens are increasingly appreciated as signaling as well as structural proteins, it is intriguing to contemplate potential effects of $B$. burgdorferi binding to collagen not only in terms of tissue colonization but also in effects on host responses to the bacteria. Considerations of the complexities of $B$. burgdorferi interactions with ECM components are complicated by the complexities of interactions between the ECM components themselves (e.g., binding of decorin to type I collagen). Interestingly, BBA33 does not bind to collagen type I (Zhi et al., 2015), suggesting that additional collagen-binding adhesins await discovery.

$B$. burgdorferi encodes several fibronectin-binding adhesins RevB, RevA (2 genomic copies), BB0347, and BBK32, in order of increasing affinity for fibronectin (decreasing $K_{\mathrm{D}}$ ). All were identified originally using in vitro approaches, but further work has identified roles for some in the mouse model of infection. The fibronectin-binding adhesin with the lowest affinity for fibronectin, RevB (encoded by $b b c 10$ ), does not yet have a known in vivo function. The only test reported thus far is in gain of function studies in which no increases in binding to skin vasculature were seen as compared to the parental strain (Moriarty et al., 2012).

Studies on RevA are inherently complicated by the fact that there are two copies of the gene on different replicons in the genome. Nevertheless, a double knockout strain was generated, and while there was no difference in the ID 50 from the wild-type parental strain, a defect in colonization of heart tissue was identified (Byram et al., 2015). Complementation of the mutant restored heart colonization. A transposon insertion near the 5' end of one of the RevA genes, $b b m 27$, revealed an infectivity defect, while a transposon insertion nearer the 3' end of the other RevA-encoding gene, bbp27, did not have an apparent virulence defect in mice (Lin et al., 2012). This provides a basis for future studies of the precise roles of the RevA proteins during $B$. burgdorferi infection. For example, no role for RevA was found in gain of function $B$. burgdorferi strain interactions with the vasculature in the skin in living mice (Moriarty et al., 2012), and the same gain of function strain showed reduced binding to heart and ear tissues in a different infection model (Caine and Coburn, 2015). BB0347 is a third fibronectin-binding adhesin of $B$. burgdorferi that was not found to have any significant effect on $B$. burgdorferi interactions with the skin vasculature (Moriarty et al., 2012), but in gain of function studies was found to increase $B$. burgdorferi interactions with the vasculature in tibiotarsal joint tissue (Caine and Coburn, 2015).

Finally, although not essential to the ability of $B$. burgdorferi to cause infection in mice, BBK32 is the highest-affinity fibronectin-binding protein produced by $B$. burgdorferi and has separable dermatan sulfate glycosaminoglycan (GAG)-binding activity as well. Both of the extracellular matrix-binding activities contribute to vascular interactions of $B$. burgdorferi in living mice (Moriarty et al., 2012). Initial, more transient, $B$. burgdorferi-endothelium interactions are mediated by fibronectin binding, while the more stable interactions are mediated by GAG binding. The GAG-binding activity of BBK32 also contributes to $B$. burgdorferi tropism for joint tissue during murine infection (Lin et al., 2015). As described earlier, BBK32 also binds C1r, blocking its activation and thereby the classical complement pathway (Garcia et al., 2016). Live imaging of $B$. burgdorferi infection in mice using bioluminescence also supports a role for BBK32 in the full virulence of the bacteria (Hyde et al., 2011).

Several questions remain to be resolved regarding the potential roles of the fibronectin-binding adhesins of $B$. burgdorferi. In addition to those described above, there are reports that $\mathrm{CspA}$, a complement regulatory protein, also binds other host molecules, including fibronectin (Hallstrom et al., 2010). One interesting consideration is whether the different fibronectinbinding proteins might have different affinities for soluble (plasma/serum) fibronectin vs. insoluble matrix 
fibronectin. Several pathogens are known to coat themselves with host molecules as a mechanism to evade host recognition, and it is possible that $B$. burgdorferi does this as well. However, this possibility remains to be experimentally addressed, a task made more difficult by the number of adhesins with apparently overlapping or redundant functions produced by $B$. burgdorferi and other spirochetes.

Bgp (Borrelia GAG-binding protein, BB0588) was the first $B$. burgdorferi GAG-binding adhesin identified, based on biochemical purification from the spirochetes (Leong et al., 1995; Parveen and Leong, 2000). Like intact $B$. burgdorferi, Bgp bound heparin and dermatan sulfate (Parveen and Leong, 2000). $\mathrm{Bgp}$ is a secreted protein that is found in the culture medium as well as on the surface of the spirochete (Parveen and Leong, 2000; Cluss et al., 2004). In addition to its GAG-binding properties, Bgp is a $5^{\prime}$ methylthioadenosine/S-adenosyl homocysteine nucleosidase (Pfs), which in other bacteria is important in elimination of toxic metabolic products and in nucleotide salvage (Winzer and Williams, 2001). Recombinant Bgp partially inhibits $B$. burgdorferi attachment to purified GAGs and to cultured mammalian cells, supporting it as a candidate adhesin, but the nonadherent $B$. burgdorferi strain B314 produces Bgp, indicating that Bgp is not sufficient to promote bacterial binding. $B$. burgdorferi bgp mutants retain the ability to infect mice (Parveen et al., 2006; Schlachter et al., 2018). A different protein, BB0210, also termed Lmp1, was selected for adhesion to the vasculature in living mice using phage display (Antonara et al., 2007), and subsequently shown to bind to the GAG chondroitin-6-sulfate (Yang et al., 2016). The middle region of this protein contains several repeats, at least some of which were included in all selected phage clones. This middle region is responsible for the adhesin activity, which can in itself promote $B$. burgdorferi infectivity (Yang et al., 2016).

Among the $B$. burgdorferi mutants that do not produce known GAG-binding adhesins, those that do not produce $d b p A B$ or $o s p C$ are most attenuated. Mutants in bbK32 and Imp1 are less attenuated, and bgp appears to play a very minor role in murine infection. Many of these proteins are multifunctional, and the roles of GAG binding, specifically, have been investigated only for DbpA, OspC, and BBK32 (Moriarty et al., 2012; Lin et al., 2014; Lin et al., 2015; Lin et al., 2020c). It remains possible that the other
GAG-binding adhesins play more significant roles in other vertebrate hosts.

\section{Integrin binding proteins}

Integrins are heterodimeric, integral membrane proteins produced by all mammalian cell types except erythrocytes. They perform a number of critical activities for the cell, including regulation of growth and morphology, adhesion to extracellular matrix, and bidirectional signaling in response to a variety of stimuli (Dustin and Springer; Larson and Springer, 1990; Hynes, 1992; Ruoslahti, 1996, 1997; Hynes, 2002; Bachmann et al., 2019; Humphries et al., 2019; Mohammed et al., 2019). Each integrin is composed of one alpha ( $\alpha$ ) subunit plus one beta $(\beta)$ subunit, with the primary subdivisions into families based on the $\beta$ subunit. There are two known $\beta_{3}$ chain integrins, $\alpha_{\| b} \beta_{3}$ and $\alpha_{v} \beta_{3}$, and $B$. burgdorferi has been shown to bind to both (Coburn et al., 1993; Coburn et al., 1994; Coburn et al., 1998; Coburn et al., 1999). Both of these integrins are rather promiscuous, meaning that they bind to several different mammalian proteins (ligands). B. burgdorferi is also known to bind to at least two $\beta_{1}$ chain integrins, $\alpha_{3} \beta_{1}$ and $\alpha_{5} \beta_{1}$, but interactions with other $\beta_{1}$ chain integrins and other integrin $\beta$ chain families have not been carefully investigated.

The integral outer membrane protein P66, which is also a porin, was the first integrin binding protein identified in $B$. burgdorferi. This was done using a functional phage display selection as opposed to homology or motif searching (Coburn et al., 1999). P66 binds primarily to the $\beta_{3}$ chain integrins, but also binds to integrins $\alpha_{3} \beta_{1}$ and $\alpha_{5} \beta_{1}$, showing that, like its integrin partners, P66 is promiscuous (Coburn et al., 1999; Coburn and Cugini, 2003). Subsequent studies demonstrated that P66 is essential for mammalian but not tick infection (Ristow et al., 2012), consistent with the observation that P66 is not detectable in the unfed tick (Cugini et al., 2003). The integrin binding activity has a specific role in facilitating dissemination and extravasation of the spirochete out of the vasculature and into perivascular connective tissue but is not essential for murine infection (Kumar et al., 2015; Ristow et al., 2015).

Leukocyte extravasation in the inflammatory response is a step-wise process in which leukocyte carbohydrates bind to endothelial cell selectins to capture the circulating cells, and leukocyte integrins then bind to endothelial cell ligands to form stationary adhesions (Lawrence and Springer, 1991; Lawrence 
et al., 1995). Further interactions and cellular changes at the chemical and mechanical levels promote leukocyte migration across the endothelium and basement membrane, which is critical to homing to sites of infection and inflammation. It is intriguing to note some conceptual similarities between leukocyte and $B$. burgdorferi extravasation, with the requirement for BBK32-host GAG interactions slowing the movement of the spirochetes in circulation and P66-host integrin and OspC-GAG interactions promoting extravasation.

Several candidate $B$. burgdorferi integrin ligands were identified by searching the genome for predicted proteins containing the RGD tripeptide, which is commonly found in mammalian $\beta_{1}$ and $\beta_{3}$ integrin ligands, and for possible secretion signals. Purified recombinant BBB07 promoted proinflammatory responses in synoviocytes through integrin $\alpha_{3} \beta_{1}$ (Behera et al., 2008), and transposon insertions showed mild defects in infectivity in mice (Lin et al., 2012). However, these results have not been connected experimentally, and at this point it is not clear that BBB07 is exposed on the surface of the $B$. burgdorferi cell and available to interact with host molecules. Further work regarding a different $B$. burgdorferi protein, BB0172, which in recombinant form also binds integrin $\alpha_{3} \beta_{1}$ (Wood et al., 2013) is also needed to determine relevance to $B$. burgdorferi infection and pathogenesis.

It is clear that $B$. burgdorferi encodes many adhesive proteins, and the roles in infection of mice for some are diagrammed in Figure 6. One might ask several questions: do all of the putative adhesins actually function as adhesins, and if so, why are so many needed? Several known adhesins have been shown to be essential to the ability of $B$. burgdorferi to cause infection in mice (e.g. OspC, P66) (Grimm et al., 2004b; Tilly et al., 2006; Ristow et al., 2012 ), while others contribute significantly to infection (BBK32, $\mathrm{DbpA}$ ), but are not absolutely essential ( $\mathrm{Li}$ et al., 2006; Seshu et al., 2006; Blevins et al., 2008; Hyde et al., 2011; Imai et al., 2013; Fortune et al., 2014). Others (e.g. Bgp) appear to make relatively minor contributions to infection and pathogenesis in laboratory mice (Parveen et al., 2006; Schlachter et al., 2018). It is certainly possible that, given the host range of $B$. burgdorferi in the natural infection cycle, some adhesins contribute more significantly to $B$. burgdorferi infection in natural reservoir hosts. It is also important to note that several of the $B$. burgdorferi adhesins (e.g., OspC, BBK32, P66,
BB0406) are multifunctional, and it is important to recognize that different functions may contribute to infectivity. In fact, this can and has been experimentally addressed (Seshu et al., 2006; Hyde et al., 2011; Ristow et al., 2012; Kumar et al., 2015; Lin et al., 2015; Ristow et al., 2015; Garcia et al., 2016; Caine et al., 2017; Lin et al., 2020c), but much remains to be done to fully understand the roles of each adhesin in B. burgdorferi infection.

As is the case for other pathogenic bacteria, it has been speculated that $B$. burgdorferi adhesins may play different roles in infection (Figure 6). In fact, evidence to date suggests that GAG binding by BBK32 is important for transient interactions with the vascular endothelium in vivo (Norman et al., 2008; Moriarty et al., 2012) and for colonization of joint tissue (Lin et al., 2015), while OspC GAG binding activity is required for extravasation and colonization of joint tissue, with associated joint swelling (Lin et al., 2020c). DbpA is also involved in colonization of joint tissue and promotes arthritis development in an allele-specific manner (Lin et al., 2014). P66 integrinbinding activity and OspC GAG-binding activity are required for extravasation in vivo (Kumar et al., 2015; Lin et al., 2020c). Since many of the B. burgdorferi adhesins bind glycosaminoglycans, one would think that they might be functionally redundant. However, since phenotypes seen in deletion mutant strains are decipherable, they are non-redundant, but in many cases the specific interactions that reveal the essential nature of each remain to be elucidated. The recognition of ECM components, such as Fn, collagen, or GAGs, which consist of repeating subunits of either protein or carbohydrate origin, may lead one to suspect that the corresponding $B$. burgdorferi adhesins might be recognizing diverse repeat structures with limited specificity, although specific roles for each have been demonstrated. Even interactions of relatively low affinity and specificity may promote bacterial binding to host components, which may then facilitate formation of more specific interactions mediated by other bacterial and host molecules. It is also possible that the relatively low affinities for human molecules may be higher for comparable molecules of other species. It is also important to remember that some of the extracellular matrix substrates for adhesion by $B$. burgdorferi also modulate immune responses by the host (e.g. (lozzo and Schaefer, 2010; Moreth et al., 2012; Frevert et al., 2018)), so the effects of $B$. burgdorferi-extracellular matrix interactions on the nature of the immune response remain to be 


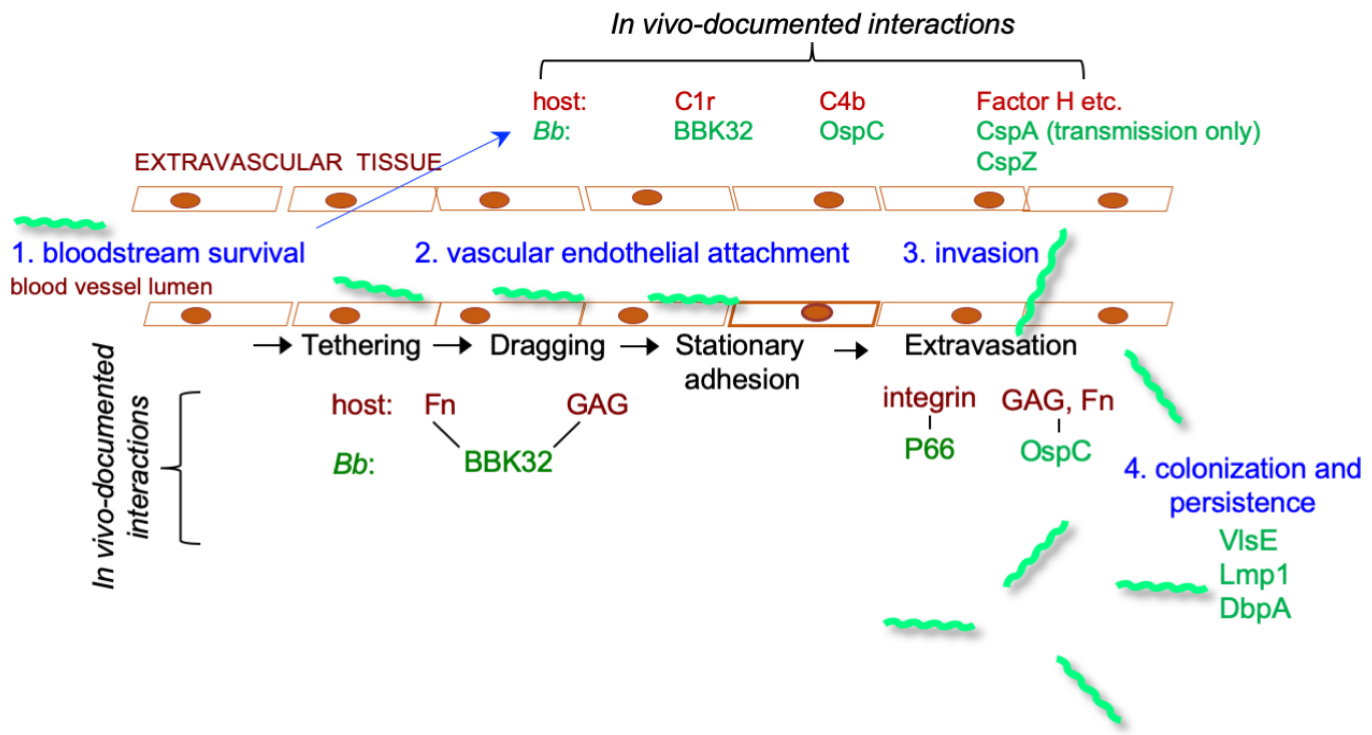

Figure 6. Borrelia burgdorferi-host interactions that contribute to infection. Shown are interactions between host molecules and $B$. burgdorferi virulence determinants that have been documented to influence infection in vivo in animal model(s). Many more await further characterization or have not yet been shown to make significant contributions in the mouse model of $B$. burgdorferi infection. Additional factors such as those involved in nutrient scavenging are not included here. Refer to Table 1 for a more complete summary of factors known to participate in $B$. burgdorferi survival in mice. Complement factors: $\mathrm{C} 1 \mathrm{r}$, C4b, Factor $\mathrm{H}$ (and related proteins). Adhesion substrates: $\mathrm{GAG}=$ glycosaminoglycan, $\mathrm{Fn}=$ fibronectin.

explored. The same is true of $B$. burgdorferi-integrin interactions, as integrins are also involved in shaping the immune response (Striz and Costabel, 1992; Gorfu et al., 2009; Nishimura, 2009; Verma and Kelleher, 2017; Thome et al., 2018). A difficult challenge, particularly in an experimental system with limited genetic tools, will be to systematically characterize each of the adherence pathways of $B$. burgdorferi, with respect to their biochemical functions, their effects on host cell biology and immune responses, and their roles during infection of mammals and ticks.

Roles of bacterial and host proteinases in dissemination and inflammation

In addition to binding to extracellular matrix proteins, $B$. burgdorferi needs a mechanism for breaking down the molecules in the extracellular matrix that impede its movement and that promote the inflammatory response that might clear the infection. $B$. burgdorferi appears to have adopted several strategies for accomplishing this, as reviewed in (Hu et al., 2001).
B. burgdorferi encodes a homolog of the high temperature requirement $A(H \operatorname{tr} A)$ family of proteins. $\mathrm{HtrA}$ in $B$. burgdorferi, an ortholog of DegP, a periplasmic chaperone and quality control protein, is bound to outer membranes and released into the milieu (Coleman et al., 2013; Russell et al., 2013; Backert et al., 2018). It has been shown to play a role in degradation of $B$. burgdorferi proteins such as the basic membrane protein, $\mathrm{BmpD}$, the chemotaxis phosphatase CheX, and outer membrane porin, P66, the monomeric but not polymerized form of flagellin, and the cellular fission protein BB0323 (Coleman et al., 2013; Kariu et al., 2013; Coleman et al., 2016; Ye et al., 2016; Coleman et al., 2018; Zhang et al., 2019). In vitro, HtrA also has aggrecanase activity and is able to degrade the extracellular matrix components fibronectin and aggrecan (Russell et al., 2013). An HtrA mutant is non-infectious in mice, but also exhibits significant growth defects in vitro (Ye et al., 2016), has decreased motility, and produces less pyruvate (Coleman et al., 2018). It is unclear whether the activity of $\mathrm{HtrA}$ on $B$. burgdorferi proteins and/or degradation of extracellular matrix proteins are 
important to the loss of infectivity of the HtrA mutant (Ye et al., 2016).

The Lon proteases are a group of ATP-dependent serine proteases ubiquitously distributed in the genomes sequenced to date. They fall into two major classes: LonA, encoded primarily in bacterial and eukaryotic genomes, and LonB, present in archaea. LonA proteases have generally been found to be localized in the cytoplasm and LonBs attached to the cytoplasmic membrane, but both groups appear to assure protein quality control. Most bacteria encode a single LonA, but Borrelia species encode two, Lon-1 (encoded by bb0253 in B. burgdorferi) and Lon-2 (encoded by bb0613 in B. burgdorferi). Both genes are expressed during mammalian infection (Mason et al., 2020; Thompson et al., 2020). The two $B$. burgdorferi proteins are functionally distinct, with different $\mathrm{N}$-terminal substrate-binding domains and different abilities to complement an E. coli lon mutant (Coleman et al., 2009), suggesting distinct activities. Individual knockout mutants have been generated and assessed for both in vitro and in vivo phenotypes. Inactivation of lon-1 results in reduced growth rate, reduced resilience to osmotic stress and oxidative stress, increased levels of OspC and RpoS in vitro, and markedly decreased infectivity (Thompson et al., 2020). The lon-2 mutant did not display an in vitro growth defect but did show reduced resistance to osmotic and oxidative stress in vitro and, as with lon-1 mutants, significantly reduced burdens in tissue samples from mice infected with a single dose (Mason et al., 2020). In this mutant, however, some reductions in in vitro levels of OspC and RpoS protein levels were noted.

Another strategy utilized by $B$. burgdorferi for breaking down extracellular matrix proteins is to exploit host proteases. B. burgdorferi has been shown to bind and stabilize plasmin, an important protease in the host fibrinolytic cascade (Coleman et al., 1995; Hu et al., 1995; Klempner et al., 1995; Klempner et al., 1996). A number of $B$. burgdorferi proteins have been found to bind plasminogen in vitro (Fuchs et al., 1994; Hu et al., 1997; Brissette et al., 2009b; Hallstrom et al., 2010; Floden et al., 2011; Onder et al., 2012; Toledo et al., 2012; Koenigs et al., 2013). The role that each plays in vivo has generally not been experimentally established, with one exception (Earnhart et al., 2014). The C-terminal 10 amino acids of OspC were shown to bind plasminogen but were found not to be required for $B$. burgdorferi infection. Plasmin is a broad-spectrum serine protease that, in addition to degrading fibrin, is capable of degrading extracellular matrix components such as elastin and laminin. Plasmin is also an important activator of other extracellular matrix degrading proteases such as matrix metalloproteinases (MMPs). Plasmin is produced by activation of its circulating zymogen form, plasminogen, through the action of activating proteases such as urokinase-type plasminogen activator (u-PA) and tissue-type plasminogen activator (t-PA). The presence of $B$. burgdorferi induces production of $\mathrm{u}-\mathrm{PA}$ and its receptor (CD87) by circulating monocytes (Fuchs et al., 1996; Coleman et al., 2001; Haile et al., 2006). CD87 can stabilize u-PA against degradation and inactivation by circulating inhibitors (e.g. plasminogen activator inhibitor-2, PAI-2), allowing it to efficiently convert plasminogen to plasmin. Urokinase also may bind directly to $B$. burgdorferi, which also protects it against inactivation (Klempner et al., 1996). The binding of plasmin to $B$. burgdorferi has been shown to increase the ability of the organism to pass through cell culture monolayers and to avoid inhibition by circulating inhibitors such as $\alpha_{2}$ antiplasmin (Coleman et al., 1995; Perides et al., 1996). In studies of plasminogen deficient mice, it was shown that plasmin was required for efficient dissemination of $B$. burgdorferi within the tick (i.e. from the midgut to the salivary glands) (Coleman et al., 1997). The presence of plasmin also enhanced spirochetemia following feeding of infected ticks on uninfected mice. However, it did not affect the spread of bacteria to distant sites in mice.

Other proteases appear to be involved in extracellular matrix degradation and dissemination by $B$. burgdorferi. MMPs are the major host enzymes in degradation of extracellular matrix proteins. They are involved in normal host processes such as tissue remodeling and wound healing and, as a family, can degrade every component of the extracellular matrix. Infection with $B$. burgdorferi has been shown to induce production of numerous MMPs (including MMP-1, MMP-3, MMP-9, MMP-13 and MMP-19) from different host tissues (keratinocytes, fibroblasts, astrocytes, PBMCs and chondrocytes) in cell culture (Perides et al., 1999; Gebbia et al., 2001; Lin et al., 2001a; Zhao et al., 2003; Behera et al., 2004; Gebbia et al., 2004; Behera et al., 2005; Grab et al., 2007). MMP-9 is up-regulated in erythema migrans skin lesions from infected patients (Zhao et al., 2003), and promotes development of arthritis but not $B$. 
burgdorferi dissemination, and does not increase bacterial loads in the joints (Heilpern et al., 2009). In vitro studies showed that MMP-9 can be activated by plasmin bound to $B$. burgdorferi and that activation of MMP-9 results in increased penetration of spirochetes through artificial barriers, including artificial blood-brain barrier models (Gebbia et al., 2001; Grab et al., 2005; Grab et al., 2007). MMP-9 also was found to be increased in the cerebrospinal fluid of patients with neuroborreliosis (Kirchner et al., 2000). Animal studies have shown that MMP-9 plays an important role in penetration of Streptococcus pneumonia through the blood brain barrier (Paul et al., 1998). However, studies of MMP-9 knockout mice in Lyme disease models have not shown any difference in dissemination of $B$. burgdorferi to distant sites, although it was important to the development of arthritis (Heilpern et al., 2009). However, because the MMPs show considerable overlap in their substrate specificity and because $B$. burgdorferi induces multiple MMPs from host tissues, it is possible that deficiency of any single MMP is compensated for by other induced enzymes.

While B. burgdorferi may co-opt host proteases to assist with dissemination, the induction and activation of MMPs resulting from the presence of $B$. burgdorferi contributes to some of the pathology associated with Lyme disease. In particular, MMPs have been closely associated with degradation of bone and cartilage in other forms of arthritis (e.g. rheumatoid arthritis). The collagenases MMP-1 and MMP-13, as well as stromelysins (MMP-3 and MMP-19), were found to be elevated in the synovial fluids of patients with Lyme arthritis and/or induced from cultured chondrocytes by the presence of $B$. burgdorferi (Hu et al., 2001; Lin et al., 2001a). Studies with monkey cartilage explants have shown that MMPs and a related metalloproteinase from the ADAMTS family ( $\underline{A}$ Disintegrin-like And Metallo-protease domain with Thrombospondin type I motifs), aggrecanase-1/ ADAMTS-4, play a key role in the degradation of articular cartilage after $B$. burgdorferi infection ( $\mathrm{Hu}$ et al., 2001; Behera et al., 2006). The specific MMPs induced by $B$. burgdorferi differ significantly between animals, as well as from tissue to tissue, and may be responsible for some of the differences in tissue-specific pathology. For example, the MMP-1, MMP-8 and MMP-13 collagenases are increased in human Lyme arthritis but not in joints of mouse strains infected with B. burgdorferi (Behera et al., 2005; Crandall et al., 2006). Irreparable cartilage damage occurs with the degradation of interstitial collagens by collagenases but not with degradation of other cartilage components (e.g. aggrecans, hyaluronans) mediated through MMPs in the noncollagenase families. It is possible that these differences explain the lack of permanent joint erosions in mouse models of Lyme arthritis compared with humans.

\section{Summary: Borrelia burgdorferi Biology Requires Multiple Virulence Determinants for Infection, Dissemination, Persistence, and Pathogenesis}

Dissemination of Borrelia species from the inoculation site to additional sites in an animal host and persistence in the skin are necessary for propagation in the natural tick-vertebrate infection cycle. While the focus in this review has been on consideration of these properties as virulence determinants, they are fundamental to the biology of $B$. burgdorferi. It is also important to remember that the focus of this review has been on features and questions that are experimentally tractable in mouse models of infection. B. burgdorferi has been shown by multiple groups to migrate in the skin following inoculation in humans (Berger et al., 1985; Berger et al., 1992; Mitchell et al., 1993), but not all $B$. burgdorferi strains cause disseminated infection in humans (Wang et al., 1999; Earnhart et al., 2005; Jones et al., 2006). In contrast, B. burgdorferi does generally spread to multiple diverse tissue sites as the infection proceeds in the laboratory mouse. The local spread, which is associated with the leading edge of the erythema migrans lesion in humans (Berger et al., 1985; Berger et al., 1992; Mitchell et al., 1993), is detectable in mice using microscopic imaging techniques including two photon and intravital microscopy (see the imaging section of this review and Radolf and Samuels, 2021), although mice do not develop erythema migrans. Dissemination through an entire animal (e.g. mouse) has been reliably followed over time and quantified using in vivo whole animal imaging, culture and qPCR, but these approaches are not possible, unethical, or more difficult in human patients. Once infection of most vertebrate hosts is established, it is maintained over long periods of time in the absence of antibiotic therapy.

Many researchers have contributed significantly to our understanding of Borrelia-host interactions in the mouse model. Spread through tissue matrices is 
thought to occur even between different tissue types, but the most efficient means of spread early after infection is likely through transient dissemination through the blood and/or lymphatic vascular systems. Imaging of lymphatic vessel involvement and blood vessel invasion has not yet been achieved, but i.v. inoculation of the bacteria has permitted intravital microscopic imaging of interactions with and extravasation from blood vessels (the vasculature) (Moriarty et al., 2008; Norman et al., 2008; Lee et al., 2010; Moriarty et al., 2012; Lee et al., 2014; Kumar et al., 2015; Lin et al., 2020c), and elucidation of specific roles in these processes for some adhesins. In order to even image such events, the bacteria must survive the innate host defenses in the circulation and in tissues, e.g. complement, ROS, and RNS, as discussed earlier in this review. In addition, the biosynthetically feeble Borrelia require nutrients supplied by the vertebrate host or through salvage pathways to survive and replicate, also as described earlier.

Despite the incredible amount of information clinical and basic science researchers have gained about $B$. burgdorferi and roles of some of its virulence determinants in infection, there are many interesting questions to be addressed in future research on the fundamental biology and virulence determinants of $B$, burgdorferi. For example, what is the mammalian host signal that activates switching at the v/s locus, and what signaling pathways in the Borrelia cell are involved? What are the specific mechanisms by which different adhesins contribute to dissemination, tissue colonization, intravascular interactions, and persistence in host animals? Are these the same or distinct in different vertebrate hosts? How is it that multiple adhesins that have similar binding activities in vitro have discernable roles in vivo? The same questions could be applied to complement regulatory proteins of Lyme disease Borrelia. How do the adhesins, complement regulators, and proteases collaborate during infection without inactivating each other? Why is $B$. burgdorferi infection associated with arthritis in humans and certain mouse strains, while $B$. garinii is associated with neuroborreliosis in humans? Are differences in bacterial components and host responses to these components each important in determining differential disease manifestations? What are the critical nutritional factors required by $B$. burgdorferi to replicate in the vertebrate host? Fortunately, there is an everexpanding and increasingly elegant genetic toolbox that facilitates research on the biology of $B$. burgdorferi, but the segmented genome and strainto-strain and species-to-species variations remain vexing. Importantly, mice are not tiny humans, and differences in how Borrelia species replicate, disseminate, are potentially cleared, or are pathogenic in different host species remain underexplored. Human infection is likely best recapitulated in non-human primate models of infection, but these require knowledge and resources not available to most researchers.

The human pathogenic spirochetes, Borrelia, Treponema, Leptospira, and Brachyspira, are all capable of causing long-term infections, although the sites of persistence and the means of acquisition vary dramatically. Perhaps further analysis of the expanding genomic information, and the expansion of genetic tools for all four genera will shed further light on commonalities and differences among the pathogens, and comparisons with the spirochete genera that are not pathogenic will illuminate convergent vs. divergent evolution and the features critical to maintenance of the unique lifestyles of each.

\section{Acknowledgements}

Work in the authors' laboratories was supported by the National Institutes of Health (US) awards K22 Al081730 (MWJ), R01 Al099094 (MWJ), R01 Al37277 (SJN), R01 Al59048 (SJN), R21 Al103905 (LTH), R21 Al111317 (LTH), R01 Al118799 (JC), R21 Al119821 (to JS), R01 Al121217 (JC), R01 Al121401 (JC and PK), R01 Al131656 (LTH and JS), R21 Al133367 (BG and JS), R21 Al140510 (JC), R56 Al146930 (BG and JS), R01 Al146930 (BG and JS), R21 NS102766 (BG), R21 NS104767 (BG), The National Research for Tick-Borne Diseases (MWJ), and the LOEWE Center DRUID Novel Drug Targets against Poverty-Related and Neglected Tropical Infectious Diseases, project C3 (PK).

The authors thank Dr. George Chaconas of the University of Calgary for insightful suggestions on the vIsE section, Valery Lozada-Fernandez, PhD candidate at the Medical College of Wisconsin, for generation of the 3D plot in Figure 1, Dr. Theresa C. Maatman at the Medical College of Wisconsin for assistance with the artwork in Figure 2, and Alexandra D. Powell, a PhD candidate at Texas A\&M University for assistance with Figure 4. 
Table 1. Information regarding known and potential virulence determinants of Borrelia burgdorferi (partial listing). Genes are sorted first according to their apparent major functions during the infectious cycle, then by genetic locus designation. In each section, those encoded on the chromosome are listed before those encoded on genomic plasmids. Note that some appear in more than one major function section. Chr= chromosome

\begin{tabular}{|c|c|c|c|}
\hline $\begin{array}{l}\text { Protein(s) and } \\
\text { gene(s) }\end{array}$ & $\begin{array}{l}\text { Gene } \\
\text { location(s) }\end{array}$ & Findings / evidence in vitro & Findings/evidence in vivo \\
\hline \multicolumn{4}{|l|}{ Regulation } \\
\hline $\operatorname{CsrA}(b b 0184)$ & $\operatorname{chr}$ & $\begin{array}{l}\text { Carbon storage regulator A controls expression of a number of infection- } \\
\text { relevant genes (Karna et al., 2011; Amold et al., 2018). }\end{array}$ & $\begin{array}{l}\text { A mutant lacking csrA is non-infectious in mice; however, complementation of the } \\
\text { mutant in trans does not restore the infectious phenotype (Karna et al., 2011). }\end{array}$ \\
\hline LtpA (bb0355) & chr & $\begin{array}{l}\text { CarD-like transcriptional regulator important for in vitro growth and cold } \\
\text { stress (Yang et al., 2008; Chen et al., 2018). }\end{array}$ & $\begin{array}{l}\text { An ItpA mutant demonstrates delayed infection in mice and reduced survival in } \\
\text { ticks (Chen et al., 2018). }\end{array}$ \\
\hline $\begin{array}{l}\text { BB0363 } \\
\text { (bb0363) }\end{array}$ & chr & $\begin{array}{l}\text { Cyclic di-GMP phosphodiesterase important for motility (Sultan et al., } \\
\text { 2010). }\end{array}$ & $\begin{array}{l}\text { Essential for infection of mice but dispensable for survival within ticks (Sultan et al., } \\
\text { 2010). }\end{array}$ \\
\hline LuxS (bb0377) & chr & $\begin{array}{l}\text { Potential involvement in quorum sensing (Stevenson and Babb, 2002; } \\
\text { Hubner et al., 2003; von Lackum et al., 2006; Riley et al., 2007). }\end{array}$ & Provides competitive advantage during mammalian infection (Arnold et al., 2015). \\
\hline Rrp1 (bb0419) & chr & $\begin{array}{l}\text { Two component response regulator, diguanylate cyclase (Rogers et al., } \\
\text { 2009) }\end{array}$ & $\begin{array}{l}\text { Required for survival in ticks (Caimano et al., 2011; He et al., 2011; Kostick et al., } \\
\text { 2011), inactivation of gene leads to attenuated virulence but overexpression leads } \\
\text { to avirulence in mice (Kostick et al., 2011) }\end{array}$ \\
\hline HK1 (bb0420) & chr & Two component response regulator, histidine kinase (Caimano et al., 2011) & Required for survival in ticks (Caimano et al., 2011) \\
\hline $\mathrm{RpoN}(b b 0450)$ & chr & $\begin{array}{l}\text { Sigma factor that regulates temperature- and pH-dependent gene } \\
\text { expression (Ouyang et al., 2008); RpoN activates rpoS (Smith et al., 2007; } \\
\text { Blevins et al., 2009), RpoS activates ospC promoter (Yang et al., 2003) }\end{array}$ & $\begin{array}{l}\text { Inactivation results in loss of tick to mouse transmission, mouse infectivity and } \\
\text { mammal-arthropod transmission, but does not affect survival in ticks (Caimano et } \\
\text { al., 2004; Ouyang et al., 2008). }\end{array}$ \\
\hline BosR (bb0647) & chr & $\begin{array}{l}\text { Regulatory protein that affects RpoS production and thus promotes } \\
\text { production of several known virulence determinants during transmission } \\
\text { from tick to mammal and early in mammalian infection, including OspC, } \\
\text { DbpAB (Hyde et al., 2009; Ouyang et al., 2011); involved in the oxidative } \\
\text { stress response (Boylan et al., 2003; Hyde et al., 2009); binds to regulatory } \\
\text { domains upstream of rpoS (Ouyang et al., 2011); exhibits post- } \\
\text { transcriptional regulation (Hyde et al., 2007) }\end{array}$ & $\begin{array}{l}\text { Required for infection in mice (Hyde et al., 2009; Ouyang et al., 2009b), including } \\
\text { transmission by tick or needle inoculation (Ouyang et al., 2009b) }\end{array}$ \\
\hline $\mathrm{PlzA}(\mathrm{bb0733)}$ & chr & $\begin{array}{l}\text { PilZ-domain containing protein that binds c-di-GMP, controls virulence gene } \\
\text { expression through RpoS and is important for motility (Pitzer et al., 2011; } \\
\text { He et al., 2014; Kostick-Dunn et al., 2018). }\end{array}$ & $\begin{array}{l}\text { PlzA contributes to survival in ticks and mouse infection by needle inoculation } \\
\text { (Pitzer et al., 2011; Kostick-Dunn et al., 2018). plzA mutant B. burgdorferi are non- } \\
\text { infectious by tick bite transmission (Pitzer et al., 2011). }\end{array}$ \\
\hline Rrp2 (bb0763) & chr & $\begin{array}{l}\text { Two component response regulator required for activation of rpoN } \\
\text { expression (Ouyang et al., 2008), is activated by acetyl phosphate (Xu et } \\
\text { al., 2010a) }\end{array}$ & $\begin{array}{l}\text { Inactivation by point mutation abrogates mouse infection (Boardman et al., 2008; } \\
\text { Ouyang et al., 2008). }\end{array}$ \\
\hline RpoS (bb0771) & chr & $\begin{array}{l}\text { Sigma factor that promotes production of several known virulence } \\
\text { determinants during transmission from tick to mammal and early in } \\
\text { mammalian infection, including OspC, DbpAB (Hubner et al., 2001; Eggers } \\
\text { et al., 2004; Yang et al., 2005), is regulated by small non-coding RNA } \\
\text { DsrABb (Lybecker and Samuels, 2007) and by BBD18 (Hayes et al., 2014) }\end{array}$ & $\begin{array}{l}\text { Required for infection and persistence in mice (Caimano et al., 2004; Xu et al., } \\
\text { 2012; Caimano et al., 2019), and for dissemination within feeding tick (Dunham- } \\
\text { Ems et al., 2012) }\end{array}$ \\
\hline $\operatorname{HrpA}(b b 0827)$ & chr & $\begin{array}{l}\text { ATP-dependent DEAH-box RNA helicase involved in RNA processing and } \\
\text { global gene regulation (Salman-Dilgimen et al., 2011; Salman-Dilgimen et } \\
\text { al., 2013). }\end{array}$ & $\begin{array}{l}\text { Required for mouse infection and tick transmission (Salman-Dilgimen et al., 2011; } \\
\text { Salman-Dilgimen et al., 2013). }\end{array}$ \\
\hline \multicolumn{4}{|c|}{ Basic cellular functions } \\
\hline RuvB (bb0022) & chr & $\begin{array}{l}\text { With RuvA, Holliday junction helicase/branch migrase (Dresser et al., 2009; } \\
\text { Lin et al., 2009) }\end{array}$ & $\begin{array}{l}\text { Required for vlsE recombination, therefore antigenic variation (Dresser et al., 2009; } \\
\text { Lin et al., 2009) }\end{array}$ \\
\hline RuvA (bb0023) & chr & $\begin{array}{l}\text { With RuvB, Holliday junction helicase/branch migrase (Dresser et al., 2009; } \\
\text { Lin et al., 2009) }\end{array}$ & $\begin{array}{l}\text { Required for vlsE recombination, therefore antigenic variation (Dresser et al., 2009; } \\
\text { Lin et al., 2009) }\end{array}$ \\
\hline $\mathrm{HtrA}(b b 0104)$ & chr & $\begin{array}{l}\text { A serine protease with a number of infection relevant target proteins } \\
\text { (Coleman et al., 2013; Gherardini, 2013; Kariu et al., 2013; Russell et al., } \\
\text { 2013; Russell and Johnson, 2013; Coleman et al., 2016, 2018). Induced } \\
\text { during stationary phase growth and at elevated temperatures (Ye et al., } \\
\text { 2016). Sensitive to inactivation by salt and zinc (Russell et al., 2016). } \\
\text { Important for spirochete growth and cellular organization at } 37^{\circ} \mathrm{C} \text { (Ye et al., } \\
\text { 2016). }\end{array}$ & Essential for establishment of mammalian infection (Ye et al., 2016). \\
\hline $\mathrm{BmtA}(\mathrm{bb0219)}$ & chr & Manganese transporter (Ouyang et al., 2009a) & Required for mammalian and tick infection (Ouyang et al., 2009a) \\
\hline Lon-1 (bb0253) & $\operatorname{chr}$ & $\begin{array}{l}\text { ATP- and Mg-dependent protease, does not complement } E \text {. coli lon } \\
\text { mutant (Coleman et al., 2009), slower growth in vitro and reduced } \\
\text { resistance to osmotic and oxidative stress, increased levels of OspC, } \\
\text { RpoS, BosR (Thompson et al., 2020) }\end{array}$ & $\begin{array}{l}\text { Significantly attenuated in mice at single dose and time point evaluated (Thompson } \\
\text { et al., 2020) }\end{array}$ \\
\hline $\begin{array}{l}\text { BB0318 } \\
\text { (bb0318) }\end{array}$ & chr & $\begin{array}{l}\text { ATPase component of a putative riboflavin ABC transport system (Deka et } \\
\text { al., 2013; Showman et al., 2016). }\end{array}$ & $\begin{array}{l}\text { Identified in IVET screen and is critical for resistance to oxidative stress, } \\
\text { macrophage killing and mouse infectivity (Ellis et al., 2013; Showman et al., 2016). }\end{array}$ \\
\hline
\end{tabular}




\begin{tabular}{|c|c|c|c|}
\hline Lon-2 (bb0613) & chr & $\begin{array}{l}\text { ATP- and Mg-dependent protease complements E. coli lon mutant } \\
\text { (Coleman et al., 2009), cotranscribed with tig, clpP, clpX, not required for } \\
\text { growth in culture, decreased resistance to osmotic and oxidative stress, } \\
\text { decreased OspC and RpoS levels (Mason et al., 2020). }\end{array}$ & Attenuated in mice at single dose and time point tested (Mason et al., 2020). \\
\hline PtsG (bb0645) & chr & $\begin{array}{l}\text { Putative glucose specific EllBC component of a phosphoenolpyruvate } \\
\text { phosphotransferase system and affects B. burgdorferi gene expression } \\
\text { (PEP-PTS) (Khajanchi et al., 2015). }\end{array}$ & $\begin{array}{l}\text { Critical for mouse infection by needle inoculation and tick bite transmission but } \\
\text { dispensible for survival in ticks (Khajanchi et al., 2015). }\end{array}$ \\
\hline $\operatorname{CoADR}(b b 0728)$ & chr & $\begin{array}{l}\text { Coenzyme A disulphide reductase likely important for intracellular redox } \\
\text { and the oxidative stress response(Boylan et al., 2006; Eggers et al., 2011) }\end{array}$ & $\begin{array}{l}\text { Required for infection of mice and important for survival in feeding nymphs (Eggers } \\
\text { et al., 2011) }\end{array}$ \\
\hline OppAV (bba34) & Ip56 & $\begin{array}{l}\text { Oligopeptide substrate binding protein component of the Opp ABC } \\
\text { transport system, regulated by RpoS (Kornacki and Oliver, 1998; Lin et al., } \\
2001 \text { b; Wang et al., 2002; Wang et al., 2004; Caimano et al., 2007; } \\
\text { Medrano et al., 2007; Dunham-Ems et al., 2012; Groshong et al., 2017; } \\
\text { Caimano et al., 2019). }\end{array}$ & Important for persistence in mice (Caimano et al., 2019). \\
\hline $\begin{array}{l}\text { GuaA and B } \\
\text { (bbb17,18) }\end{array}$ & cp26 & $\begin{array}{l}\text { GMP synthase and IMP dehydrogenase, respectively, involved in purine } \\
\text { salvage (Margolis et al., 1994; Jewett et al., 2009) }\end{array}$ & $\begin{array}{l}\text { Transposon mutagenesis suggested guaB is required for mouse infection (Botkin } \\
\text { et al., 2006), promote replication in tick, required for mouse infection via needle } \\
\text { inoculation and tick bite (Jewett et al., 2009) }\end{array}$ \\
\hline $\begin{array}{l}\text { BBB23, BBB23 } \\
(b b b 22,23)\end{array}$ & cp26 & $\begin{array}{l}\text { Purine permeases essential for hypoxanthine transport and critical for } \\
\text { adenine and guanine transport (Jain et al., 2012) }\end{array}$ & $\begin{array}{l}\text { Spirochetes lacking both bbb22 and bbb23 are non-infectious in mice. bbb22 alone } \\
\text { is sufficient to restore infectivity, but bbb23 alone is not (Jain et al., 2012). }\end{array}$ \\
\hline $\operatorname{PncA}(b b e 22)$ & Ip25 & Nicotinamidase involved in NAD metabolism (Purser et al., 2003) & Inactivation results in loss of infectivity in mice (Purser et al., 2003) \\
\hline AdeC (bbk17) & Ip36 & $\begin{array}{l}\text { Adenine deaminase; converts adenine to hypoxanthine. Involved in purine } \\
\text { interconversion (Jewett et al., 2007b). }\end{array}$ & Required for full infectivity in mice, but not in ticks (Jewett et al., 2007b) \\
\hline \multicolumn{4}{|c|}{ Hypothetical proteins of unknown function } \\
\hline $\begin{array}{l}\text { BB0238 } \\
(b b 0238)\end{array}$ & chr & $\begin{array}{l}\text { A tetratricopeptde repeat (TPR) domain containing protein that localizes to } \\
\text { the inner membrane (Groshong et al., 2014)). Interacts with the N-terminus } \\
\text { of BB0323 to promote posttranslational protein stability (Kariu et al., 2015). }\end{array}$ & $\begin{array}{l}\text { Critical for mammalian infection and persistence by promoting spirochete burden in } \\
\text { mouse tissues as well as heart and joint inflammation (Groshong et al., 2014; Kariu } \\
\text { et al., 2015). }\end{array}$ \\
\hline $\begin{array}{l}\text { BB0323 } \\
(b b 0323)\end{array}$ & chr & $\begin{array}{l}\text { A membrane-associated immunogenic protein that contains a C-terminal } \\
\text { LysM domain and is important for spirochete morphology and cell division } \\
\text { (Stewart et al., 2004; Zhang et al., 2009). The protein undergoes multiple } \\
\text { proteolysis events mediated by HtrA (BB0104) and interacts with BB0238 } \\
\text { (Kariu et al., 2015). }\end{array}$ & $\begin{array}{l}\text { Essential for infectivity and persistence in the mouse and transmission throughout } \\
\text { the enzootic cycle (Zhang et al., 2009). }\end{array}$ \\
\hline $\begin{array}{l}\text { BB0646 } \\
(b b 0646)\end{array}$ & chr & Lipolytic and hemolytic activities (Shaw et al., 2012) & Inactivation leads to reduced bacterial loads in mice (Shaw et al., 2012) \\
\hline $\begin{array}{l}\text { BB0744 } \\
(b b 0744)\end{array}$ & chr & Identified as possible adhesin but is subsurface (Wager et al., 2015) & Mutant is attenuated in mice (Wager et al., 2015) \\
\hline BBA03 (bba03) & Ip54 & Induced during tick feeding (Bestor et al., 2012). & Provides a competitive advantage during tick transmission (Bestor et al., 2012). \\
\hline BBA07 (bba07) & Ip54 & $\begin{array}{l}\text { A surface exposed lipoprotein that is induced during tick feeding (Xu et al., } \\
\text { 2010b). }\end{array}$ & Contribution to transmission by tick (Xu et al., 2010b). \\
\hline BBA64 (bba64) & Ip54 & $\begin{array}{l}\text { A surface exposed, immunogenic lipoprotein (Brooks et al., 2006; Nowalk } \\
\text { et al., 2006a; Barbour et al., 2008). }\end{array}$ & Contributes to transmission by tick (Gilmore et al., 2010; Patton et al., 2011). \\
\hline BBA66 (bba66) & Ip54 & $\begin{array}{l}\text { Surface exposed, immunogenic lipoprotein (Brooks et al., 2006; Nowalk et } \\
\text { al., 2006a; Barbour et al., 2008).. }\end{array}$ & Contributes to transmission by tick (Patton et al., 2013). \\
\hline$b b d 07$ & Ip17 & 317 bp intergenic transcript (Casselli et al., 2019) & $\begin{array}{l}\text { Contributes to colonization of mouse tissues as well as induction of carditis and } \\
\text { arthritis (Casselli et al., 2019). }\end{array}$ \\
\hline BBK13 (bbk13) & Ip36 & Non-surface exposed immunogenic protein (Aranjuez et al., 2019). & $\begin{array}{l}\text { Promotes B. burgdorferi proliferation and dissemination, especially in skin } \\
\text { (Aranjuez et al., 2019) }\end{array}$ \\
\hline \multicolumn{4}{|l|}{ Adhesion } \\
\hline Lmp1 (bb0210) & chr & $\begin{array}{l}\text { A surface localized membrane protein (Yang et al., 2009) that binds } \\
\text { chondroitin-6-sulfate (Yang et al., 2016) and undergoes proteolytic } \\
\text { processing mediated, in part, by HtrA (BB0104) (Zhuang X et al., } 2018 \text { doi: } \\
\text { 10.1111/cmi.12855). }\end{array}$ & $\begin{array}{l}\text { Selected using in vivo phage display for binding to the vascular endothelium } \\
\text { (Antonara et al., 2007), protects against host acquired immunity (Yang et al., 2009), } \\
\text { facilitates B. burgdorferi dissemination through ticks (Koci J. et al., } 2018 \text { doi: } \\
\text { 10.1038/s41598-018-20208-4) }\end{array}$ \\
\hline $\begin{array}{l}\text { BB0172 } \\
(b b 0172)\end{array}$ & chr & Recombinant protein binds integrin a331 (Wood et al., 2013) & $\begin{array}{l}\text { Immunization with BB0172 peptides protects mice against B. burgdorferi infection } \\
\text { (Small et al., 2014; Hassan et al., 2019) }\end{array}$ \\
\hline $\begin{array}{l}\text { BB0347 } \\
(b b 0347)\end{array}$ & chr & Binds fibronectin (Gaultney et al., 2013) & $\begin{array}{l}\text { Does not have a role in vascular interactions in skin (Moriarty et al., 2012), but } \\
\text { increases binding in mouse joint tissue } 1 \mathrm{hr} \text { post-inoculation (Caine and Coburn, } \\
\text { 2015) }\end{array}$ \\
\hline $\begin{array}{l}\operatorname{BmpA}(b b 0383), \\
\operatorname{BmpD}(b b 0385)\end{array}$ & chr & BmpA binds laminin (Verma et al., 2009) & $\begin{array}{l}\text { BmpABB contribute to joint persistence and arthritis (Pal et al., 2008), BmpD } \\
\text { selected using in vivo phage display for binding to the vascular endothelium } \\
\text { (Antonara et al., 2007) }\end{array}$ \\
\hline $\begin{array}{l}\text { BB0405, BB0406 } \\
\left(\begin{array}{l}\text { bb0405, } \\
\text { bb0406) }\end{array}\right.\end{array}$ & chr & Closely related, BB0406 binds laminin (Bista et al., 2020) & $\begin{array}{l}\text { Each is required for optimal infection in mice (Shrestha et al., 2017; Bista et al., } \\
\text { 2020) }\end{array}$ \\
\hline
\end{tabular}




\begin{tabular}{|c|c|c|c|}
\hline Bgp (bb0588) & chr & $\begin{array}{l}\text { Binds heparin, dermatan sulfate GAGs (Parveen et al., 2006), aggrecan } \\
\text { (Russell and Johnson, 2013), has nucleosidase activity (Parveen et al., } \\
\text { 2006) }\end{array}$ & $\begin{array}{l}\text { Not essential for infection of mice, but promotes colonization (Parveen et al., 2006; } \\
\text { Schlachter et al., 2018) }\end{array}$ \\
\hline $\begin{array}{l}\text { P66 } \\
(b b 0603)\end{array}$ & chr & $\begin{array}{l}\text { Porin (Skare et al., 1997; Pinne et al., 2007; Barcena-Uribari et al., 2010; } \\
\text { Barcena-Uribarri et al., 2013), binds certain integrins (Cobum et al., 1999; } \\
\text { Coburn and Cugini, 2003). Inactivation in noninfectious B. burgdorferi } \\
\text { reduces binding to integrins and eliminates specific channel forming activity } \\
\text { (Coburn and Cugini, 2003; Pinne et al., 2007). }\end{array}$ & $\begin{array}{l}\text { Selected using in vivo phage display for binding to the vascular endothelium } \\
\text { (Antonara et al., 2007), inactivation in infectious B. burgdorferi results in loss of } \\
\text { infectivity in mice (Ristow et al., 2012); disruption of integrin binding activity } \\
\text { decreases dissemination in mice (Ristow et al., 2015) and vascular transmigration } \\
\text { in mice (Kumar et al., 2015). }\end{array}$ \\
\hline $\begin{array}{l}\text { DbpAand B } \\
\text { (bba24, bba25) }\end{array}$ & Ip54 & $\begin{array}{l}\text { Binding to extracellular matrix (ECM) component decorin, GAGs (Guo et } \\
\text { al., 1998; Fischer et al., 2003), } 3 \text { critical lysines required for binding (Brown } \\
\text { et al., 1999), allelic variation influences binding to ECM and cells (Benoit et } \\
\text { al., 2011) }\end{array}$ & $\begin{array}{l}\text { Lack of expression of either dbpA or dbpB results in reduced virulence, (Blevins et } \\
\text { al., 2008; Hyde et al., 2011), less so when delivered by tick bite than by needle } \\
\text { inoculation of cultured bacteria (Blevins et al., 2008), effects seen primarily early in } \\
\text { infection (Weening et al., 2008; Imai et al., 2013) } 3 \text { critical lysines required for full } \\
\text { virulence (Fortune et al., 2014), promotes joint colonization and arthritis in mice (Lin } \\
\text { et al., 2014; Salo et al., 2015), allelic variation influences tissue tropism (Shi et al., } \\
\text { 2008; Lin et al., 2014) }\end{array}$ \\
\hline BBA33 (bba33) & Ip54 & Binds to collagen types IV and VI (Zhi et al., 2015) & $\begin{array}{l}\text { Transposon insertion attenuated in mice (Lin et al., 2012), targeted mutant cleared } \\
\text { from mice by day } 4 \text { (Zhi et al., 2015) }\end{array}$ \\
\hline OspC (bbb19) & cp26 & $\begin{array}{l}\text { Increased expression under mammalian tissue conditions }\left(37^{\circ} \mathrm{C} \text { ) (Schwan }\right. \\
\text { and Piesman, 2000), binds a tick salivary protein that inhibits complement } \\
\text { (Ramamoorthi et al., 2005; Schuijt et al., 2008), binds plasminogen (Lagal } \\
\text { et al., 2006), binds complement factor C4b and inhibits complement } \\
\text { cascade (Caine et al., 2017); binds fibrinogen (Bienwagen et al., 2019), } \\
\text { binds fibronectin and/or dermatan sulfate GAGs depending on type (Lin et } \\
\text { al., 2020c) }\end{array}$ & $\begin{array}{l}\text { Induced in midgut of feeding tick (Schwan et al., 1995; Schwan and Piesman, } \\
\text { 2000); required for early stages of infection (Grimm et al., 2004b; Stewart et al., } \\
\text { 2006; Tilly et al., 2006), antiphagocytic (Carrasco et al., 2015), promotes } \\
\text { bloodstream survival (Caine and Coburn, 2015; Caine et al., 2017), selected using } \\
\text { in vivo phage display for binding to the vascular endothelium (Antonara et al., } \\
\text { 2007); binding to dermatan sulfate GAG required for joint colonization; binding to } \\
\text { Fn and GAG required for infectivity (Lin et al., 2020c) }\end{array}$ \\
\hline BBK32 (bbk32) & Ip36 & $\begin{array}{l}\text { Binds to fibronectin and GAGs (Probert and Johnson, 1998; Probert et al., } \\
\text { 2001; Fischer et al., 2006); binds complement protein C1r and blocks } \\
\text { activation of complement C1r and thus C1s (Garcia et al., 2016) }\end{array}$ & $\begin{array}{l}\text { Quantifiable attenuation of bbk32 mutant on overall infectivity in mice (Hyde et al., } \\
\text { 2011) (Li et al., 2006; Seshu et al., 2006); mediates interactions with the } \\
\text { vasculature in mice (Moriarty et al., 2008; Norman et al., 2008; Moriarty et al., } \\
\text { 2012), affects tissue tropism in mice (Lin et al., 2015), GAG binding domain confers } \\
\text { bloodstream survival in mice (Caine and Coburn, 2015) and promotes joint } \\
\text { colonization (Lin et al., 2015) }\end{array}$ \\
\hline $\begin{array}{l}\operatorname{RevA}(b b m 27, \\
b b p 27)\end{array}$ & cp32s & Binds fibronectin, laminin (Brissette et al., 2009a; Moriarty et al., 2012) & $\begin{array}{l}\text { Promotes heart colonization (Lin et al., 2012; Byram et al., 2015); but gain of } \\
\text { function decreases bacterial binding in heart (Caine and Coburn, 2015), does not } \\
\text { have a role in vascular interactions in skin (Moriarty et al., 2012); }\end{array}$ \\
\hline \multicolumn{4}{|l|}{ Immune evasion } \\
\hline BBA57 (bba57) & Ip54 & $\begin{array}{l}\text { Lipoprotein originally of unknown function (Yang et al., 2013), modulates } \\
\text { expression of multiple infection relevant B. burgdorferi proteins (Bernard et } \\
\text { al., 2018) }\end{array}$ & $\begin{array}{l}\text { Supports survival during early infection by protecting against neutrophils, } \\
\text { suppressing host complement-mediated killing and regulating type l interferon and } \\
\text { triggers neutrophil chemotaxis and inflammation during late disseminated infection } \\
\text { (Yang et al., 2013; Bernard et al., 2018) }\end{array}$ \\
\hline $\begin{array}{l}\text { CspA(aka } \\
\text { CRASP-1) } \\
\text { (bba68) }\end{array}$ & Ip54 & $\begin{array}{l}\text { Complement regulator-acquiring surface protein-1, binds to complement } \\
\text { inhibitory factor H and FHL-1 (Kraiczy et al., 2001b; Kraiczy et al., 2001c); } \\
\text { binds terminal complement factor C7 and C9, blocks C9 polymerization } \\
\text { (Hallstrom et al., 2013), confers serum resistance (Brooks et al., 2005; } \\
\text { Kenedy et al., 2009; Hammerschmidt et al., 2014); inactivation of gene } \\
\text { decreases resistance to killing by normal human serum (Brooks et al., } \\
\text { 2005; Kenedy et al., 2009), binds plasminogen (Hallstrom et al., 2010) }\end{array}$ & $\begin{array}{l}\text { Produced during transmission/adaptation to mammal but not in tick (von Lackum et } \\
\text { al., 2005; Bykowski et al., 2007) required to survive in feeding nymphal ticks and for } \\
\text { transmission to mice (Hart et al., 2018) }\end{array}$ \\
\hline OspC (bbb19) & cp26 & $\begin{array}{l}\text { Increased expression under mammalian tissue conditions }\left(37^{\circ} \mathrm{C} \text { ) (Schwan }\right. \\
\text { and Piesman, 2000), binds a tick salivary protein that inhibits complement } \\
\text { (Ramamoorth i tal., 2005; Schuijt et al., 2008), binds plasminogen (Lagal } \\
\text { et al., 2006), binds complement factor C4b and inhibits complement } \\
\text { cascade (Caine et al., 2017); binds fibrinogen (Bierwagen et al., 2019), } \\
\text { binds fibronectin and/or dermatan sulfate GAGs depending on type (Lin et } \\
\text { al., 2020c) }\end{array}$ & $\begin{array}{l}\text { Induced in midgut of feeding tick (Schwan et al., 1995; Schwan and Piesman, } \\
\text { 2000); required for early stages of infection (Grimm et al., 2004b; Stewart et al., } \\
\text { 2006; Tilly et al., 2006), antiphagocytic (Carrasco et al., 2015), promotes } \\
\text { bloodstream survival (Caine and Coburn, 2015; Caine et al., 2017), selected using } \\
\text { in vivo phage display for binding to the vascular endothelium (Antonara et al., } \\
\text { 2007) }\end{array}$ \\
\hline VlsE (bbf32) & |p28-1 & $\begin{array}{l}\text { Antigenic variation system (Zhang et al., 1997; Zhang and Norris, 1998a, } \\
\text { b), unusual recombination requirements for RuvA-RuvB Holliday junction } \\
\text { helicase/branch migrase (Dresser et al., 2009; Lin et al., 2009; Castellanos } \\
\text { et al., 2018; Verhey et al., 2018b, a, 2019) (reviewed in (Norris, 2006; } \\
\text { Chaconas et al., 2020)) }\end{array}$ & $\begin{array}{l}\text { Antigenic variation system active during infection (Zhang and Norris, 1998b), } \\
\text { complete vls locus required for full capacity for recombination and therefore } \\
\text { evasion of adaptive immunity and persistence in immunocompetent mice (Zhang } \\
\text { et al., 1997; Zhang and Norris, 1998a, b; Bankhead and Chaconas, 2007), } \\
\text { changes recently tracked and quantified (Castellanos et al., 2018; Verhey et al., } \\
2018 b, a, 2019 \text { ) and locus calculated to encode on the order of } 10^{40} \text { variants, } \\
\text { selected using in vivo phage display for binding to the vascular endothelium } \\
\text { (Antonara et al., 2007) }\end{array}$ \\
\hline $\begin{array}{l}\text { Crasp2 (aka } \\
\text { Cspz) (bbh06) }\end{array}$ & |p28-3 & $\begin{array}{l}\text { Complement regulator-acquiring surface protein-2, binds to complement } \\
\text { inhibitory factors } \mathrm{H} \text { and FHL-1 (Hartmann et al., 2006; Haupt et al., 2007), } \\
\text { confers serum resistance (Hartmann et al., 2006). CspZ production is } \\
\text { induced by human blood leading to complement resistance (Marcinkiewicz } \\
\text { et al., 2019). }\end{array}$ & $\begin{array}{l}\text { Produced during mammalian infection but not in ticks (Bykowski et al., 2007; } \\
\text { Marcinkiewicz et al., 2019), inactivation reduces dissemination and colonization in } \\
\text { vertebrate and avian hosts (Marcinkiewicz et al., 2019) }\end{array}$ \\
\hline
\end{tabular}




\section{References}

Adams, P.P., Flores Avile, C., Popitsch, N., Bilusic, I., Schroeder, R. Lybecker, M., and Jewett, M.W. (2017). In vivo expression technology and 5 ' end mapping of the Borrelia burgdorferi transcriptome identify novel RNAs expressed during mammalian infection. Nucleic Acids Research 45, 775-792. https://doi.org/10.1093/nar/gkw1180

Aguirre, J.D., Clark, H.M., Mcllvin, M., Vazquez, C., Palmere, S.L., Grab, D.J., Seshu, J., Hart, P.J., Saito, M., and Culotta, V.C. (2013). A manganese-rich environment supports superoxide dismutase activity in a Lyme disease pathogen, Borrelia burgdorferi. The Journal of Biological Chemistry 288, 8468-8478. https://doi.org/10.1074/ jbc.M112.433540

Akins, D.R., Bourell, K.W., Caimano, M.J., Norgard, M.V., and Radolf, J.D. (1998). A new animal model for studying Lyme disease spirochetes in a mammalian host-adapted state. J Clin Invest 101, 2240-2250. https://doi.org/10.1172/JCI2325

Alitalo, A., Meri, T., Lankinen, H., Seppala, I., Lahdenne, P., Hefty, P.S., Akins, D., and Meri, S. (2002). Complement inhibitor factor $\mathrm{H}$ binding to Lyme disease spirochetes is mediated by inducible expression of multiple plasmid-encoded outer surface protein $E$ paralogs. J Immunol 169, 3847-3853.

Angel, T.E., Luft, B.J., Yang, X., Nicora, C.D., Camp, D.G., 2nd, Jacobs, J.M., and Smith, R.D. (2010). Proteome analysis of Borrelia burgdorferi response to environmental change. PLOS ONE 5, e13800. https://doi.org/10.1371/journal.pone.0013800

Antonara, S., Chafel, R.M., Lafrance, M., and Coburn, J. (2007). Borrelia burgdorferi adhesins identified using in vivo phage display. Molecular microbiology 66, 262-276.

Antonara, S., Ristow, L., and Coburn, J. (2011). Adhesion mechanisms of Borrelia burgdorferi. Adv Exp Med Biol 715, 35-49. https://doi.org/ 10.1007/978-94-007-0940-9 3

Aranjuez, G.F., Kuhn, H.W., Adams, P.P., and Jewett, M.W. (2019). Borrelia burgdorferi bbk13 is Critical for Spirochete Population Expansion in the Skin during Early Infection. Infect Immun 87. https:// doi.org/10.1128/IAl.00887-18

Archibald, F.S., and Fridovich, I. (1981). Manganese, superoxide dismutase, and oxygen tolerance in some lactic acid bacteria. Journal of bacteriology 146, 928-936.

Arnold, W.K., Savage, C.R., Antonicello, A.D., and Stevenson, B. (2015). Apparent role for Borrelia burgdorferi LuxS during mammalian infection. Infection and immunity 83, 1347-1353. https://doi.org/ 10.1128/IAI.00032-15

Arnold, W.K., Savage, C.R., Lethbridge, K.G., Smith, T.C., 2nd, Brissette, C.A., Seshu, J., and Stevenson, B. (2018). Transcriptomic insights on the virulence-controlling CsrA, BadR, RpoN, and RpoS regulatory networks in the Lyme disease spirochete. PLOS ONE 13, e0203286. https://doi.org/10.1371/journal.pone.0203286

Astrand, M., Cuellar, J., Hytonen, J., and Salminen, T.A. (2019). Predicting the ligand-binding properties of Borrelia burgdorferi s.s. Bmp proteins in light of the conserved features of related Borrelia proteins. J Theor Biol 462, 97-108. https://doi.org/10.1016/j.jtbi. 2018.11.004

Bachmann, M., Kukkurainen, S., Hytonen, V.P., and Wehrle-Haller, B. (2019). Cell Adhesion by Integrins. Physiological reviews 99, 1655-1699. https://doi.org/10.1152/physrev.00036.2018

Backert, S., Bernegger, S., Skorko-Glonek, J., and Wessler, S. (2018). Extracellular HtrA serine proteases: An emerging new strategy in bacterial pathogenesis. Cell Microbiol 20, e12845. https://doi.org/ 10.1111/cmi.12845

Bankhead, T., and Chaconas, G. (2007). The role of VlsE antigenic variation in the Lyme disease spirochete: persistence through a mechanism that differs from other pathogens. Mol Microbiol 65, 1547-1558. https://doi.org/10.1111/j.1365-2958.2007.05895.x
Barbour, A.G. (1991). Molecular biology of antigenic variation in Lyme borreliosis and relapsing fever: a comparative analysis. Scand J Infect Dis - Supplementum 77, 88-93.

Barbour, A.G., Carter, C.J., and Sohaskey, C.D. (2000). Surface protein variation by expression site switching in the relapsing fever agent Borrelia hermsii. Infection and immunity 68, 7114-7121.

Barbour, A.G., Jasinskas, A., Kayala, M.A., Davies, D.H., Steere, A.C., Baldi, P., and Felgner, P.L. (2008). A genome-wide proteome array reveals a limited set of immunogens in natural infections of humans and white-footed mice with Borrelia burgdorferi. Infect Immun 76 , 3374-3389. https://doi.org/10.1128/IAl.00048-08

Barcena-Uribarri, I., Thein, M., Sacher, A., Bunikis, I., Bonde, M., Bergstrom, S., and Benz, R. (2010). P66 porins are present in both Lyme disease and relapsing fever spirochetes: a comparison of the biophysical properties of P66 porins from six Borrelia species. Biochim Biophys Acta 1798, 1197-1203. https://doi.org/10.1016/ j.bbamem.2010.02.011

Barcena-Uribarri, I., Thein, M., Maier, E., Bonde, M., Bergstrom, S., and Benz, R. (2013). Use of nonelectrolytes reveals the channel size and oligomeric constitution of the Borrelia burgdorferi P66 porin. PLoS One 8, e78272. https://doi.org/10.1371/journal.pone.0078272

Barthold, S.W., Moody, K.D., Terwilliger, G.A., Duray, P.H., Jacoby, R.O., and Steere, A.C. (1988). Experimental Lyme arthritis in rats infected with Borrelia burgdorferi. J Infect Dis 157, 842-846.

Barthold, S.W., Persing, D.H., Armstrong, A.L., and Peeples, R.A. (1991). Kinetics of Borrelia burgdorferi dissemination and evolution of disease after intradermal inoculation of mice. Am J Pathol 139, 263-273.

Barthold, S.W., de Souza, M.S., Janotka, J.L., Smith, A.L., and Persing, D.H. (1993). Chronic Lyme borreliosis in the laboratory mouse. Am J Pathol 143, 959-971.

Battisti, J.M., Bono, J.L., Rosa, P.A., Schrumpf, M.E., Schwan, T.G., and Policastro, P.F. (2008). Outer surface protein A protects Lyme disease spirochetes from acquired host immunity in the tick vector. Infection and immunity $76,5228-5237$

Beckwith, J., and Silhavy, T.J. (1983). Genetic analysis of protein export in Escherichia coli. Methods in Enzymology 97, 3-11. https://doi.org/ 10.1016/0076-6879(83)97114-8

Behera, A.K., Thorpe, C.M., Kidder, J.M., Smith, W., Hildebrand, E., and $\mathrm{Hu}$, L.T. (2004). Borrelia burgdorferi-induced expression of matrix metalloproteinases from human chondrocytes requires mitogenactivated protein kinase and Janus kinase/signal transducer and activator of transcription signaling pathways. Infect Immun 72, 2864-2871. https://doi.org/10.1128/iai.72.5.2864-2871.2004

Behera, A.K., Hildebrand, E., Scagliotti, J., Steere, A.C., and Hu, L.T. (2005). Induction of host matrix metalloproteinases by Borrelia burgdorferi differs in human and murine lyme arthritis. Infect Immun 73, 126-134. https://doi.org/10.1128/IAl.73.1.126-134.2005

Behera, A.K., Hildebrand, E., Szafranski, J., Hung, H.H., Grodzinsky, A.J., Lafyatis, R., Koch, A.E., Kalish, R., Perides, G., Steere, A.C., et al. (2006). Role of aggrecanase 1 in Lyme arthritis. Arthritis Rheum 54, 3319-3329. https://doi.org/10.1002/art.22128

Behera, A.K., Durand, E., Cugini, C., Antonara, S., Bourassa, L., Hildebrand, E., Hu, L.T., and Coburn, J. (2008). Borrelia burgdorferi BBB07 interaction with integrin $\alpha 3 \beta 1$ stimulates production of proinflammatory mediators in primary human chondrocytes. Cell Microbiol 10, 320-331.

Benach, J.L., Fernandez Villar, B., Szczepanski, A., and Garcia Monco, J. (1991). Lyme borreliosis: non-specific interactions of the organism with the host. Scandinavian journal of infectious diseases Supplementum 77, 130-135.

Benoit, V.M., Fischer, J.R., Lin, Y.P., Parveen, N., and Leong, J.M. (2011). Allelic variation of the Lyme disease spirochete adhesin DbpA influences spirochetal binding to decorin, dermatan sulfate, and 
mammalian cells. Infect Immun 79, 3501-3509. https://doi.org/ 10.1128/IAI.00163-11

Berger, B.W., Kaplan, M.H., Rothenberg, I.R., and Barbour, A.G. (1985). Isolation and characterization of the Lyme disease spirochete from the skin of patients with erythema chronicum migrans. Journal of the American Academy of Dermatology 13, 444-449.

Berger, B.W., Johnson, R.C., Kodner, C., and Coleman, L. (1992). Cultivation of Borrelia burgdorferi from erythema migrans lesions and perilesional skin. Journal of clinical microbiology 30, 359-361.

Bernard, Q., Smith, A.A., Yang, X., Koci, J., Foor, S.D., Cramer, S.D., Zhuang, X., Dwyer, J.E., Lin, Y.P., Mongodin, E.F., et al. (2018). Plasticity in early immune evasion strategies of a bacterial pathogen. Proc Natl Acad Sci U S A 115, E3788-E3797. https://doi.org/10.1073/ pnas. 1718595115

Bestor, A., Rego, R.O., Tilly, K., and Rosa, P.A. (2012). Competitive advantage of Borrelia burgdorferi with outer surface protein BBA03 during tick-mediated infection of the mammalian host. Infection and immunity 80, 3501-3511. https://doi.org/10.1128/IAl.00521-12

Bierwagen, P., Szpotkowski, K., Jaskolski, M., and Urbanowicz, A. (2019). Borrelia outer surface protein $C$ is capable of human fibrinogen binding. FEBS J 286, 2415-2428. https://doi.org/10.1111/ febs. 14810

Bista, S., Singh, P., Bernard, Q., Yang, X., Hart, T., Lin, Y.P., Kitsou, C., Singh Rana, V., Zhang, F., Linhardt, R.J., et al. (2020). A Novel Laminin-Binding Protein Mediates Microbial-Endothelial Cell Interactions and Facilitates Dissemination of Lyme Disease Pathogens. J Infect Dis 221, 1438-1447. https://doi.org/10.1093/ infdis/jiz626

Bledsoe, H.A., Carroll, J.A., Whelchel, T.R., Farmer, M.A., Dorward, D.W., and Gherardini, F.C. (1994). Isolation and partial characterization of Borrelia burgdorferi inner and outer membranes by using isopycnic centrifugation. Journal of bacteriology 176, 7447-7455

Blevins, J.S., Revel, A.T., Smith, A.H., Bachlani, G.N., and Norgard, M.V. (2007). Adaptation of a luciferase gene reporter and lac expression system to Borrelia burgdorferi. Appl Environ Microbiol 73, 1501-1513. https://doi.org/10.1128/AEM.02454-06

Blevins, J.S., Hagman, K.E., and Norgard, M.V. (2008). Assessment of decorin-binding protein $A$ to the infectivity of Borrelia burgdorferi in the murine models of needle and tick infection. BMC Microbiol 8, 82 https://doi.org/10.1186/1471-2180-8-82

Blevins, J.S., Xu, H., He, M., Norgard, M.V., Reitzer, L., and Yang, X.F. (2009). Rrp2, a sigma54-dependent transcriptional activator of Borrelia burgdorferi, activates rpoS in an enhancer-independent manner. Journal of bacteriology 191, 2902-2905.

Boardman, B.K., He, M., Ouyang, Z., Xu, H., Pang, X., and Yang, X.F. (2008). Essential role of the response regulator Rrp2 in the infectious cycle of Borrelia burgdorferi. Infection and immunity 76, 3844-3853. https://doi.org/10.1128//Al.00467-08

Bockenstedt, L., Barthold, S., Deponte, K., Marcantonio, N., and Kantor, F. (1993). Borrelia burgdorferi infection and immunity in mice deficient in the fifth component of complement. Infection and immunity 61 , 2104-2107.

Bockenstedt, L.K., Gonzalez, D., Mao, J., Li, M., Belperron, A.A., and Haberman, A. (2014). What ticks do under your skin: two-photon intravital imaging of Ixodes scapularis feeding in the presence of the lyme disease spirochete. Yale J Biol Med 87, 3-13.

Botkin, D.J., Abbott, A.N., Stewart, P.E., Rosa, P.A., Kawabata, H., Watanabe, H., and Norris, S.J. (2006). Identification of potential virulence determinants by Himar1 transposition of infectious Borrelia burgdorferi B31. Infection and immunity 74, 6690-6699. https:// doi.org/10.1128//Al.00993-06

Bourret, T.J., Boylan, J.A., Lawrence, K.A., and Gherardini, F.C. (2011). Nitrosative damage to free and zinc-bound cysteine thiols underlies nitric oxide toxicity in wild-type Borrelia burgdorferi. Mol Microbiol 81 , 259-273. https://doi.org/10.1111/j.1365-2958.2011.07691.x

Bourret, T.J., Lawrence, K.A., Shaw, J.A., Lin, T., Norris, S.J., and Gherardini, F.C. (2016). The nucleotide excision repair pathway protects Borrelia burgdorferi from nitrosative stress in Ixodes scapularis ticks. Front Microbiol 7, 1397. https://doi.org/10.3389/ fmicb.2016.01397

Boylan, J.A., Posey, J.E., and Gherardini, F.C. (2003). Borrelia oxidative stress response regulator, BosR: a distinctive $\mathrm{Zn}$-dependent transcriptional activator. Proc Natl Acad Sci U S A 100, 11684-11689. https://doi.org/10.1073/pnas.2032956100

Boylan, J.A., Hummel, C.S., Benoit, S., Garcia-Lara, J., TreglownDowney, J., Crane, E.J., 3rd, and Gherardini, F.C. (2006). Borrelia burgdorferi bb0728 encodes a coenzyme A disulphide reductase whose function suggests a role in intracellular redox and the oxidative stress response. Molecular microbiology 59, 475-486. https://doi.org/ 10.1111/j.1365-2958.2005.04963.x

Boylan, J.A., and Gherardini, F.C. (2008). Determining the cellular targets of reactive oxygen species in Borrelia burgdorferi. Methods in molecular biology (Clifton, NJ 431, 213-221. https://doi.org/ 10.1007/978-1-60327-032-8 17

Boylan, J.A., Lawrence, K.A., Downey, J.S., and Gherardini, F.C. (2008). Borrelia burgdorferi membranes are the primary targets of reactive oxygen species. Mol Microbiol 68, 786-799. https://doi.org/10.1111/j. 1365-2958.2008.06204.x

Branda, J.A., Strle, K., Nigrovic, L.E., Lantos, P.M., Lepore, T.J., Damle, N.S., Ferraro, M.J., and Steere, A.C. (2017). Evaluation of Modified 2Tiered Serodiagnostic Testing Algorithms for Early Lyme Disease. Clin Infect Dis 64, 1074-1080. https://doi.org/10.1093/cid/cix043

Brissette, C.A., Bykowski, T., Cooley, A.E., Bowman, A., and Stevenson, B. (2009a). Borrelia burgdorferi RevA antigen binds host fibronectin. Infection and immunity $77,2802-2812$.

Brissette, C.A., Haupt, K., Barthel, D., Cooley, A.E., Bowman, A., Skerka, C., Wallich, R., Zipfel, P.F., Kraiczy, P., and Stevenson, B. (2009b). Borrelia burgdorferi infection-associated surface proteins ErpP, ErpA, and ErpC bind human plasminogen. Infect Immun 77 300-306. https://doi.org/10.1128/IAl.01133-08

Brissette, C.A., Verma, A., Bowman, A., Cooley, A.E., and Stevenson, B. (2009c). The Borrelia burgdorferi outer-surface protein ErpX binds mammalian laminin. Microbiology (Reading, England) 155, 863-872.

Brissette, C.A., and Gaultney, R.A. (2014). That's my story, and I'm sticking to it--an update on B. burgdorferi adhesins. Front Cell Infect Microbiol 4, 41. https://doi.org/10.3389/fcimb.2014.00041

Brooks, C.S., Hefty, P.S., Jolliff, S.E., and Akins, D.R. (2003). Global analysis of Borrelia burgdorferi genes regulated by mammalian hostspecific signals. Infect Immun 71, 3371-3383. https://doi.org/10.1128/ iai.71.6.3371-3383.2003

Brooks, C.S., Vuppala, S.R., Jett, A.M., Alitalo, A., Meri, S., and Akins, D.R. (2005). Complement regulator-acquiring surface protein 1 imparts resistance to human serum in Borrelia burgdorferi. $\mathrm{J}$ Immunol 175, 3299-3308.

Brooks, C.S., Vuppala, S.R., Jett, A.M., and Akins, D.R. (2006). Identification of Borrelia burgdorferi outer surface proteins. Infect Immun 74, 296-304. https://doi.org/10.1128/IAI.74.1.296-304.2006

Brown, C.R., and Reiner, S.L. (1999). Development of lyme arthritis in mice deficient in inducible nitric oxide synthase. J Infect Dis 179 , 1573-1576. https://doi.org/10.1086/314774

Brown, E.L., Guo, B.P., O'Neal, P., and Hook, M. (1999). Adherence of Borrelia burgdorferi. Identification of critical lysine residues in DbpA required for decorin binding. The Journal of biological chemistry 274 , 26272-26278.

Brown, E.L., Wooten, R.M., Johnson, B.J., Iozzo, R.V., Smith, A., Dolan, M.C., Guo, B.P., Weis, J.J., and Hook, M. (2001). Resistance to Lyme disease in decorin-deficient mice. J Clin Invest 107, 845-852. https:/l doi.org/10.1172/JCl11692 
Bunikis, J., Mirian, H., Bunikiene, E., and Barbour, A.G. (2001). Nonheritable change of a spirochaete's phenotype by decoration of the cell surface with exogenous lipoproteins. Molecular microbiology 40 , 387-396.

Burgdorfer, W., Barbour, A.G., Hayes, S.F., Benach, J.L., Grunwaldt, E. and Davis, J.P. (1982). Lyme disease-a tick-borne spirochetosis? Science (New York, NY 216, 1317-1319.

Burman, N., Bergstrom, S., Restrepo, B.I., and Barbour, A.G. (1990) The variable antigens Vmp7 and Vmp21 of the relapsing fever bacterium Borrelia hermsii are structurally analogous to the VSG proteins of the African trypanosome. Molecular microbiology 4, 1715-1726.

Bykowski, T., Woodman, M.E., Cooley, A.E., Brissette, C.A., Brade, V., Wallich, R., Kraiczy, P., and Stevenson, B. (2007). Coordinated expression of Borrelia burgdorferi complement regulator-acquiring surface proteins during the Lyme disease spirochete's mammal-tick infection cycle. Infect Immun 75, 4227-4236. https://doi.org/10.1128/ IAI.00604-07

Byram, R., Gaultney, R.A., Floden, A.M., Hellekson, C., Stone, B.L., Bowman, A., Stevenson, B., Johnson, B.J., and Brissette, C.A. (2015). Borrelia burgdorferi RevA Significantly Affects Pathogenicity and Host Response in the Mouse Model of Lyme Disease. Infection and immunity 83, 3675-3683. https://doi.org/10.1128//Al.00530-15

Caimano, M.J., Eggers, C.H., Hazlett, K.R., and Radolf, J.D. (2004). RpoS is not central to the general stress response in Borrelia burgdorferi but does control expression of one or more essential virulence determinants. Infect Immun 72, 6433-6445. https://doi.org/ 10.1128/IAI.72.11.6433-6445.2004

Caimano, M.J. (2005). Cultivation of Borrelia burgdorferi in dialysis membrane chambers in rat peritonea. Current protocols in microbiology Chapter 12, Unit 12C 13. https://doi.org/ 10.1002/9780471729259.mc12c03s00

Caimano, M.J., Iyer, R., Eggers, C.H., Gonzalez, C., Morton, E.A., Gilbert, M.A., Schwartz, I., and Radolf, J.D. (2007). Analysis of the RpoS regulon in Borrelia burgdorferi in response to mammalian host signals provides insight into RpoS function during the enzootic cycle. Mol Microbiol 65, 1193-1217. https://doi.org/10.1111/j. 1365-2958.2007.05860.x

Caimano, M.J., Kenedy, M.R., Kairu, T., Desrosiers, D.C., Harman, M., Dunham-Ems, S., Akins, D.R., Pal, U., and Radolf, J.D. (2011). The hybrid histidine kinase $\mathrm{Hk} 1$ is part of a two-component system that is essential for survival of Borrelia burgdorferi in feeding Ixodes scapularis ticks. Infect Immun 79, 3117-3130. https://doi.org/10.1128/ |AI.05136-11

Caimano, M.J., Groshong, A.M., Belperron, A., Mao, J., Hawley, K.L., Luthra, A., Graham, D.E., Earnhart, C.G., Marconi, R.T., Bockenstedt, L.K., et al. (2019). The RpoS Gatekeeper in Borrelia burgdorferi: An Invariant Regulatory Scheme That Promotes Spirochete Persistence in Reservoir Hosts and Niche Diversity. Front Microbiol 10, 1923. https://doi.org/10.3389/fmicb.2019.01923

Caine, J.A., and Coburn, J. (2015). A short-term Borrelia burgdorferi infection model identifies tissue tropisms and bloodstream survival conferred by adhesion proteins. Infect Immun 83, 3184-3194. https:// doi.org/10.1128/IAI.00349-15

Caine, J.A., Lin, Y.P., Kessler, J.R., Sato, H., Leong, J.M., and Coburn J. (2017). Borrelia burgdorferi outer surface protein C (OspC) binds complement component $\mathrm{C} 4 \mathrm{~b}$ and confers bloodstream survival. Cell Microbiol 19. https://doi.org/10.1111/cmi.12786

Carrasco, S.E., Troxell, B., Yang, Y., Brandt, S.L., Li, H., Sandusky, G.E., Condon, K.W., Serezani, C.H., and Yang, X.F. (2015). Outer surface protein $\mathrm{OspC}$ is an antiphagocytic factor that protects Borrelia burgdorferi from phagocytosis by macrophages. Infect Immun 83, 4848-4860. https://doi.org/10.1128/IAl.01215-15
Carroll, J.A., Garon, C.F., and Schwan, T.G. (1999). Effects of environmental $\mathrm{pH}$ on membrane proteins in Borrelia burgdorferi. Infection \& Immunity 67, 3181-3187.

Casjens, S., Palmer, N., van Vugt, R., Huang, W.M., Stevenson, B., Rosa, P., Lathigra, R., Sutton, G., Peterson, J., Dodson, R.J., et al. (2000). A bacterial genome in flux: the twelve linear and nine circular extrachromosomal DNAs in an infectious isolate of the Lyme disease spirochete Borrelia burgdorferi. Molecular microbiology 35, 490-516.

Casjens, S.R., Gilcrease, E.B., Vujadinovic, M., Mongodin, E.F., Luft, B.J., Schutzer, S.E., Fraser, C.M., and Qiu, W.G. (2017). Plasmid diversity and phylogenetic consistency in the Lyme disease agent Borrelia burgdorferi. BMC Genomics 18, 165. https://doi.org/10.1186/ s12864-017-3553-5

Casselli, T., and Bankhead, T. (2015). Use of in vivo Expression Technology for the Identification of Putative Host Adaptation Factors of the Lyme Disease Spirochete. Journal of molecular microbiology and biotechnology 25, 349-361. https://doi.org/10.1159/000439305

Casselli, T., Crowley, M.A., Highland, M.A., Tourand, Y., and Bankhead, T. (2019). A small intergenic region of Ip17 is required for evasion of adaptive immunity and induction of pathology by the Lyme disease spirochete. Cell Microbiol 21, e13029. https://doi.org/10.1111/cmi. 13029

Castellanos, M., Verhey, T.B., and Chaconas, G. (2018). A Borrelia burgdorferi mini-vls system that undergoes antigenic switching in mice: investigation of the role of plasmid topology and the long inverted repeat. Molecular microbiology 109, 710-721. https://doi.org/ 10.1111/mmi.14071

Chaconas, G., Castellanos, M., and Verhey, T.B. (2020). Changing of the guard: How the Lyme disease spirochete subverts the host immune response. The Journal of biological chemistry 295, 301-313. https://doi.org/10.1074/jbc.REV119.008583

Chao, M.C., Abel, S., Davis, B.M., and Waldor, M.K. (2016). The design and analysis of transposon insertion sequencing experiments. Nature reviews 14, 119-128. https://doi.org/10.1038/nrmicro.2015.7

Charon, N.W., Cockburn, A., Li, C., Liu, J., Miller, K.A., Miller, M.R., Motaleb, M.A., and Wolgemuth, C.W. (2012). The unique paradigm of spirochete motility and chemotaxis. Annu Rev Microbiol 66, 349-370. https://doi.org/10.1146/annurev-micro-092611-150145

Chen, T., Xiang, X., Xu, H., Zhang, X., Zhou, B., Yang, Y., Lou, Y., and Yang, X.F. (2018). LtpA, a CdnL-type CarD regulator, is important for the enzootic cycle of the Lyme disease pathogen. Emerg Microbes Infect 7, 126. https://doi.org/10.1038/s41426-018-0122-1

Cluss, R.G., Silverman, D.A., and Stafford, T.R. (2004). Extracellular secretion of the Borrelia burgdorferi Oms28 porin and Bgp, a glycosaminoglycan binding protein. Infection and immunity 72 6279-6286

Coburn, J., Leong, J., and Erban, J. (1993). Integrin allbß3 mediates binding of the Lyme disease agent, Borrelia burgdorferi, to human platelets. Proc Natl Acad Sci USA 90, 7058-7063.

Coburn, J., Barthold, S.W., and Leong, J.M. (1994). Diverse Lyme disease spirochetes bind integrin allb $\beta 3$ on human platelets. Infect Immunity 62, 5559-5567.

Coburn, J., Magoun, L., Bodary, S.C., and Leong, J.M. (1998). Integrins avß3 and a5 31 mediate attachment of lyme disease spirochetes to human cells. Infection and immunity 66, 1946-1952.

Coburn, J., Chege, W., Magoun, L., Bodary, S.C., and Leong, J.M. (1999). Characterization of a candidate Borrelia burgdorferi $\beta 3$-chain integrin ligand identified using a phage display library. Molecular microbiology $34,926-940$.

Coburn, J., and Cugini, C. (2003). Targeted mutation of the outer membrane protein P66 disrupts attachment of the Lyme disease spirochete, Borrelia burgdorferi, to integrin avß3. Proc Natl Acad Sci USA 100, 7301-7306.

Coburn, J., Fischer, J.R., and Leong, J.M. (2005). Solving a sticky problem: new genetic approaches to host cell adhesion by the Lyme 
disease spirochete. Mol Microbiol 57, 1182-1195. https://doi.org/ 10.1111/j.1365-2958.2005.04759.x

Coburn, J., Leong, J., and Chaconas, G. (2013). Illuminating the roles of the Borrelia burgdorferi adhesins. Trends Microbiol 21, 372-379. https://doi.org/10.1016/j.tim.2013.06.005

Coleman, A.S., Yang, X., Kumar, M., Zhang, X., Promnares, K., Shroder, D., Kenedy, M.R., Anderson, J.F., Akins, D.R., and Pal, U. (2008). Borrelia burgdorferi complement regulator-acquiring surface protein 2 does not contribute to complement resistance or host infectivity. PLoS One 3, 3010e. https://doi.org/10.1371/journal.pone.0003010

Coleman, J., Gebbia, J., Piesman, J., Degan, J., Bugge, T., and Benach, J. (1997). Plasminogen is required for efficient dissemination of Borrelia burgdorferi in ticks and for enhancement of spirochetemia in the vertebrate host. Cell 90, 1111-1119.

Coleman, J.L., Sellati, T.J., Testa, J.E., Kew, R.R., Furie, M.B., and Benach, J.L. (1995). Borrelia burgdorferi binds plasminogen, resulting in enhanced penetration of endothelial monolayers. Infection \& Immunity 63, 2478-2484.

Coleman, J.L., Gebbia, J.A., and Benach, J.L. (2001). Borrelia burgdorferi and other bacterial products induce expression and release of the urokinase receptor (CD87). J Immunol 166, 473-480. https://doi.org/10.4049/jimmunol.166.1.473

Coleman, J.L., Katona, L.I., Kuhlow, C., Toledo, A., Okan, N.A., Tokarz, R., and Benach, J.L. (2009). Evidence that two ATP-dependent (Lon) proteases in Borrelia burgdorferi serve different functions. PLOS Pathog 5, e1000676. https://doi.org/10.1371/journal.ppat.1000676

Coleman, J.L., Crowley, J.T., Toledo, A.M., and Benach, J.L. (2013). The HtrA protease of Borrelia burgdorferi degrades outer membrane protein $\mathrm{BmpD}$ and chemotaxis phosphatase CheX. Molecular microbiology 88, 619-633. https://doi.org/10.1111/mmi.12213

Coleman, J.L., Toledo, A., and Benach, J.L. (2016). Borrelia burgdorferi HtrA: evidence for twofold proteolysis of outer membrane protein $\mathrm{p} 66$. Mol Microbiol 99, 135-150. https://doi.org/10.1111/mmi.13221

Coleman, J.L., Toledo, A., and Benach, J.L. (2018). HtrA of Borrelia burgdorferi Leads to Decreased Swarm Motility and Decreased Production of Pyruvate. mBio 9. https://doi.org/10.1128/mBio. 01136-18

Coumou, J., Wagemakers, A., Narasimhan, S., Schuijt, T.J., Ersoz, J.I., Oei, A., de Boer, O.J., Roelofs, J., Fikrig, E., and Hovius, J.W. (2019). The role of mannose binding lectin in the immune response against Borrelia burgdorferi sensu lato. Sci Rep 9, 1431. https://doi.org/ 10.1038/s41598-018-37922-8

Coutte, L., Botkin, D.J., Gao, L., and Norris, S.J. (2009). Detailed analysis of sequence changes occurring during vlsE antigenic variation in the mouse model of Borrelia burgdorferi infection. PLOS Pathog 5, e1000293.

Cox, D.L., Akins, D.R., Bourell, K.W., Lahdenne, P., Norgard, M.V., and Radolf, J.D. (1996). Limited surface exposure of Borrelia burgdorferi outer surface lipoproteins. Proc Natl Acad Sci U S A 93, 7973-7978.

Craft, J.E., Fischer, D.K., Shimamoto, G.T., and Steere, A.C. (1986). Antigens of Borrelia burgdorferi recognized during Lyme disease. Appearance of a new immunoglobulin $\mathrm{M}$ response and expansion of the immunoglobulin $\mathrm{G}$ response late in the illness. Journal of Clinical Investigation 78, 934-939.

Crandall, H., Dunn, D.M., Ma, Y., Wooten, R.M., Zachary, J.F., Weis, J.H., Weiss, R.B., and Weis, J.J. (2006). Gene expression profiling reveals unique pathways associated with differential severity of lyme arthritis. J Immunol 177, 7930-7942. https://doi.org/10.4049/jimmunol. 177.11.7930

Crowley, J.T., Toledo, A.M., LaRocca, T.J., Coleman, J.L., London, E., and Benach, J.L. (2013). Lipid exchange between Borrelia burgdorferi and host cells. PLoS Pathog 9, e1003109. https://doi.org/10.1371/ journal.ppat.1003109

Cuellar, J., Astrand, M., Elovaara, H., Pietikainen, A., Siren, S., Liljeblad, A., Guedez, G., Salminen, T.A., and Hytonen, J. (2020). Structural and Biomolecular Analyses of Borrelia burgdorferi $\mathrm{BmpD}$ Reveal a Substrate-Binding Protein of an ABC-Type Nucleoside Transporter Family. Infection and immunity 88. https://doi.org/10.1128/IAI. 00962-19

Cugini, C., Medrano, M., Schwan, T.G., and Coburn, J. (2003). Regulation of expression of the Borrelia burgdorferi $\beta 3$-chain integrin ligand, P66, in ticks and in culture. Infection and immunity 71 , 1001-1007.

Dai, Q., Restrepo, B.I., Porcella, S.F., Raffel, S.J., Schwan, T.G., and Barbour, A.G. (2006). Antigenic variation by Borrelia hermsii occurs through recombination between extragenic repetitive elements on linear plasmids. Molecular microbiology 60, 1329-1343. https:/l doi.org/10.1111/j.1365-2958.2006.05177.x

De Silva, A.M., and Fikrig, E. (1995). Growth and migration of Borrelia burgdorferi in Ixodes ticks during blood feeding. American Journal of Tropical Medicine \& Hygiene 53, 397-404.

Deitsch, K.W., Lukehart, S.A., and Stringer, J.R. (2009). Common strategies for antigenic variation by bacterial, fungal and protozoan pathogens. Nature reviews 7, 493-503. https://doi.org/10.1038/ nrmicro2145

Deka, R.K., Brautigam, C.A., Biddy, B.A., Liu, W.Z., and Norgard, M.V. (2013). Evidence for an ABC-type riboflavin transporter system in pathogenic spirochetes. mBio 4, e00615-00612. https://doi.org/ 10.1128/mBio.00615-12

Dowdell, A.S., Murphy, M.D., Azodi, C., Swanson, S.K., Florens, L., Chen, S., and Zuckert, W.R. (2017). Comprehensive spatial analysis of the Borrelia burgdorferi lipoproteome reveals a compartmentalization bias toward the bacterial surface. J Bacteriol 199. https://doi.org/10.1128/JB.00658-16

Dresser, A.R., Hardy, P.O., and Chaconas, G. (2009). Investigation of the genes involved in antigenic switching at the vlsE locus in Borrelia burgdorferi: an essential role for the RuvAB branch migrase. PLoS Pathog 5, e1000680.

Dunham-Ems, S.M., Caimano, M.J., Eggers, C.H., and Radolf, J.D. (2012). Borrelia burgdorferi requires the alternative sigma factor RpoS for dissemination within the vector during tick-to-mammal transmission. PLoS Pathog 8, e1002532. https://doi.org/10.1371/ journal.ppat. 1002532

Dustin, M.L., and Springer, T.A. Role of lymphocyte adhesion receptors in transient interactions and cell locomotion. [Review]. Annual Review of Immunology 9:27-66, 1991.

Earnhart, C.G., Buckles, E.L., Dumler, J.S., and Marconi, R.T. (2005). Demonstration of OspC type diversity in invasive human Lyme disease isolates and identification of previously uncharacterized epitopes that define the specificity of the OspC murine antibody response. Infection and immunity 73, 7869-7877.

Earnhart, C.G., Rhodes, D.V., Smith, A.A., Yang, X., Tegels, B., Carlyon, J.A., Pal, U., and Marconi, R.T. (2014). Assessment of the potential contribution of the highly conserved C-terminal motif $(\mathrm{C} 10)$ of Borrelia burgdorferi outer surface protein $\mathrm{C}$ in transmission and infectivity. Pathogens and disease 70, 176-184. https://doi.org/ 10.1111/2049-632X.12119

Eggers, C.H., Caimano, M.J., and Radolf, J.D. (2004). Analysis of promoter elements involved in the transcriptional initiation of RpoSdependent Borrelia burgdorferi genes. J Bacteriol 186, 7390-7402 https://doi.org/10.1128/JB.186.21.7390-7402.2004

Eggers, C.H., Caimano, M.J., Malizia, R.A., Kariu, T., Cusack, B., Desrosiers, D.C., Hazlett, K.R., Claiborne, A., Pal, U., and Radolf, J.D. (2011). The coenzyme A disulphide reductase of Borrelia burgdorferi is important for rapid growth throughout the enzootic cycle and essential for infection of the mammalian host. Mol Microbiol 82 679-697. https://doi.org/10.1111/j.1365-2958.2011.07845.x

Eicken, C., Sharma, V., Klabunde, T., Lawrenz, M.B., Hardham, J.M., Norris, S.J., and Sacchettini, J.C. (2002). Crystal structure of Lyme 
disease variable surface antigen VIsE of Borrelia burgdorferi. J Biol Chem 277, 21691-21696. https://doi.org/10.1074/jbc.M201547200

Ellis, T.C., Jain, S., Linowski, A.K., Rike, K., Bestor, A., Rosa, P.A., Halpern, M., Kurhanewicz, S., and Jewett, M.W. (2013). In vivo expression technology identifies a novel virulence factor critical for Borrelia burgdorferi persistence in mice. PLoS Pathog 9, e1003567. https://doi.org/10.1371/journal.ppat.1003567

Emr, S.D., Hall, M.N., and Silhavy, T.J. (1980a). A mechanism of protein localization: the signal hypothesis and bacteria. The Journal of cell biology 86, 701-711. https://doi.org/10.1083/jcb.86.3.701

Emr, S.D., Hedgpeth, J., Clement, J.M., Silhavy, T.J., and Hofnung, M. (1980b). Sequence analysis of mutations that prevent export of lambda receptor, an Escherichia coli outer membrane protein. Nature 285, 82-85. https://doi.org/10.1038/285082a0

Esteve-Gassent, M.D., Elliott, N.L., and Seshu, J. (2009). sodA is essential for virulence of Borrelia burgdorferi in the murine model of Lyme disease. Molecular microbiology 71, 594-612.

Falkow, S. (1988). Molecular Koch's postulates applied to microbial pathogenicity. Rev Infect Dis 10 Suppl 2, S274-276.

Fischer, J.R., Parveen, N., Magoun, L., and Leong, J.M. (2003). Decorin-binding proteins $\mathrm{A}$ and $\mathrm{B}$ confer distinct mammalian cell typespecific attachment by Borrelia burgdorferi, the Lyme disease spirochete. Proc Natl Acad Sci U S A 100, 7307-7312. https://doi.org/ 10.1073/pnas.1231043100

Fischer, J.R., LeBlanc, K.T., and Leong, J.M. (2006). Fibronectin binding protein BBK32 of the Lyme disease spirochete promotes bacterial attachment to glycosaminoglycans. Infection and immunity 74 , 435-441.

Fisher, M.A., Grimm, D., Henion, A.K., Elias, A.F., Stewart, P.E., Rosa, P.A., and Gherardini, F.C. (2005). Borrelia burgdorferi sigma54 is required for mammalian infection and vector transmission but not for tick colonization. Proceedings of the National Academy of Sciences of the United States of America 102, 5162-5167. https://doi.org/10.1073/ pnas. 0408536102

Floden, A.M., Watt, J.A., and Brissette, C.A. (2011). Borrelia burgdorferi enolase is a surface-exposed plasminogen binding protein. PLOS One 6, e27502. https://doi.org/10.1371/journal.pone.0027502

Foley, J. (2015). Mini-review: Strategies for Variation and Evolution of Bacterial Antigens. Comput Struct Biotechnol J 13, 407-416. https:// doi.org/10.1016/j.csbj.2015.07.002

Fortune, D.E., Lin, Y.P., Deka, R.K., Groshong, A.M., Moore, B.P., Hagman, K.E., Leong, J.M., Tomchick, D.R., and Blevins, J.S. (2014). Identification of lysine residues in the Borrelia burgdorferi DbpA adhesin required for murine infection. Infect Immun 82, 3186-3198. https://doi.org/10.1128/IAI.02036-14

Fraser, C.M., Casjens, S., Huang, W.M., Sutton, G.G., Clayton, R., Lathigra, R., White, O., Ketchum, K.A., Dodson, R., Hickey, E.K., et al. (1997). Genomic sequence of a Lyme disease spirochaete, Borrelia burgdorferi Nature 390, 580-586.

Frevert, C.W., Felgenhauer, J., Wygrecka, M., Nastase, M.V., and Schaefer, L. (2018). Danger-Associated Molecular Patterns Derived From the Extracellular Matrix Provide Temporal Control of Innate Immunity. J Histochem Cytochem 66, 213-227. https://doi.org/ 10.1369/0022155417740880

Fuchs, H., Wallich, R., Simon, M.M., and Kramer, M.D. (1994). The outer surface protein A of the spirochete Borrelia burgdorferi is a plasmin(ogen) receptor. Proceedings of the National Academy of Sciences of the United States of America 91, 12594-12598.

Fuchs, H., Simon, M.M., Wallich, R., Bechtel, M., and Kramer, M.D. (1996). Borrelia burgdorferi induces secretion of pro-urokinase-type plasminogen activator by human monocytes. Infection and immunity 64, 4307-4312.

Garcia, B.L., Zhi, H., Wager, B., Hook, M., and Skare, J.T. (2016). Borrelia burgdorferi BBK32 inhibits the classical pathway by blocking activation of the $\mathrm{C} 1$ complement complex. PLOS Pathog 12, e1005404. https://doi.org/10.1371/journal.ppat.1005404

Gaultney, R.A., Gonzalez, T., Floden, A.M., and Brissette, C.A. (2013). BB0347, from the lyme disease spirochete Borrelia burgdorferi, is surface exposed and interacts with the CS1 heparin-binding domain of human fibronectin. PLoS One 8, e75643. https://doi.org/10.1371/ journal.pone.0075643

Gebbia, J.A., Coleman, J.L., and Benach, J.L. (2001). Borrelia spirochetes upregulate release and activation of matrix metalloproteinase gelatinase B (MMP-9) and collagenase 1 (MMP-1) in human cells. Infect Immun 69, 456-462. https://doi.org/10.1128/IAI 69.1.456-462.2001

Gebbia, J.A., Coleman, J.L., and Benach, J.L. (2004). Selective induction of matrix metalloproteinases by Borrelia burgdorferi via tolllike receptor 2 in monocytes. J Infect Dis 189, 113-119. https://doi.org/ 10.1086/380414

Gherardini, F.C. (2013). Borrelia burgdorferi HtrA may promote dissemination and irritation. Molecular microbiology 90, 209-213. https://doi.org/10.1111/mmi.12390

Gilmore, R.D., Jr., Howison, R.R., Dietrich, G., Patton, T.G., Clifton, D.R., and Carroll, J.A. (2010). The bba64 gene of Borrelia burgdorferi, the Lyme disease agent, is critical for mammalian infection via tick bite transmission. Proc Natl Acad Sci U S A 107, 7515-7520. https://doi.org/10.1073/pnas.1000268107

Gorfu, G., Rivera-Nieves, J., and Ley, K. (2009). Role of $\beta 7$ integrins in intestinal lymphocyte homing and retention. Curr Mol Med 9, 836-850. https://doi.org/10.2174/156652409789105525

Grab, D.J., Perides, G., Dumler, J.S., Kim, K.J., Park, J., Kim, Y.V., Nikolskaia, O., Choi, K.S., Stins, M.F., and Kim, K.S. (2005). Borrelia burgdorferi, host-derived proteases, and the blood-brain barrier Infection and immunity 73, 1014-1022.

Grab, D.J., Nyarko, E., Barat, N.C., Nikolskaia, O.V., and Dumler, J.S. (2007). Chemokine, cytokine and matrix metalloprotease expression by human brain microvascular endothelial cells is enhanced with Anaplasma phagocytophilum-Borrelia burgdorferi coinfection. Clin Vaccine Immunol.

Grimm, D., Eggers, C.H., Caimano, M.J., Tilly, K., Stewart, P.E., Elias, A.F., Radolf, J.D., and Rosa, P.A. (2004a). Experimental assessment of the roles of linear plasmids Ip25 and Ip28-1 of Borrelia burgdorfer throughout the infectious cycle. Infect Immun 72, 5938-5946. https:/l doi.org/10.1128/IAl.72.10.5938-5946.2004

Grimm, D., Tilly, K., Byram, R., Stewart, P.E., Krum, J.G., Bueschel, D.M., Schwan, T.G., Policastro, P.F., Elias, A.F., and Rosa, P.A. (2004b). Outer-surface protein $C$ of the Lyme disease spirochete: a protein induced in ticks for infection of mammals. Proc Natl Acad Sci U S A 101, 3142-3147. https://doi.org/10.1073/pnas.0306845101

Groshong, A.M., Fortune, D.E., Moore, B.P., Spencer, H.J., Skinner, R.A., Bellamy, W.T., and Blevins, J.S. (2014). BB0238, a presumed tetratricopeptide repeat-containing protein, is required during Borrelia burgdorferi mammalian infection. Infection and immunity 82 , 4292-4306. https://doi.org/10.1128/IAl.01977-14

Groshong, A.M., Dey, A., Bezsonova, I., Caimano, M.J., and Radolf, J.D. (2017). Peptide Uptake Is Essential for Borrelia burgdorferi Viability and Involves Structural and Regulatory Complexity of its Oligopeptide Transporter. mBio 8. https://doi.org/10.1128/mBio.02047-17

Guo, B.P., Brown, E.L., Dorward, D.W., Rosenberg, L.C., and Hook, M. (1998). Decorin-binding adhesins from Borrelia burgdorferi. Molecular microbiology 30, 711-723.

Haile, W.B., Coleman, J.L., and Benach, J.L. (2006). Reciprocal upregulation of urokinase plasminogen activator and its inhibitor, PAI-2, by Borrelia burgdorferi affects bacterial penetration and hostinflammatory response. Cell Microbiol 8, 1349-1360. https://doi.org/ 10.1111/j.1462-5822.2006.00717.x 
Hall, M.N., Emr, S.D., and Silhavy, T.J. (1980). Genetic studies on mechanisms of protein localization in Escherichia coli K-12. J Supramol Struct 13, 147-163. https://doi.org/10.1002/jss.400130203

Hallstrom, T., Haupt, K., Kraiczy, P., Hortschansky, P., Wallich, R., Skerka, C., and Zipfel, P.F. (2010). Complement regulator-acquiring surface protein 1 of Borrelia burgdorferi binds to human bone morphogenic protein 2, several extracellular matrix proteins, and plasminogen. J Infect Dis 202, 490-498. https://doi.org/ $10.1086 / 653825$

Hallstrom, T., Siegel, C., Morgelin, M., Kraiczy, P., Skerka, C., and Zipfel, P.F. (2013). CspA from Borrelia burgdorferi inhibits the terminal complement pathway. MBio 4. https://doi.org/10.1128/mBio.00481-13

Hammerschmidt, C., Koenigs, A., Siegel, C., Hallstrom, T., Skerka, C., Wallich, R., Zipfel, P.F., and Kraiczy, P. (2014). Versatile roles of CspA orthologs in complement inactivation of serum-resistant Lyme disease spirochetes. Infect Immun 82, 380-392. https://doi.org/10.1128/IAI. 01094-13

Hammerschmidt, C., Klevenhaus, Y., Koenigs, A., Hallstrom, T., Fingerle, V., Skerka, C., Pos, K.M., Zipfel, P.F., Wallich, R., and Kraiczy, P. (2016). BGA66 and BGA71 facilitate complement resistance of Borrelia bavariensis by inhibiting assembly of the membrane attack complex. Mol Microbiol 99, 407-424. https://doi.org/ 10.1111/mmi.13239

Harman, M.W., Dunham-Ems, S.M., Caimano, M.J., Belperron, A.A., Bockenstedt, L.K., Fu, H.C., Radolf, J.D., and Wolgemuth, C.W. (2012). The heterogeneous motility of the Lyme disease spirochete in gelatin mimics dissemination through tissue. Proc Natl Acad Sci U S A 109, 3059-3064. https://doi.org/10.1073/pnas.1114362109

Hart, T., Nguyen, N.T.T., Nowak, N.A., Zhang, F., Linhardt, R.J., DiukWasser, M., Ram, S., Kraiczy, P., and Lin, Y.P. (2018). Polymorphic factor $\mathrm{H}$-binding activity of CspA protects Lyme borreliae from the host complement in feeding ticks to facilitate tick-to-host transmission. PLoS Pathog 14, e1007106. https://doi.org/10.1371/journal.ppat. 1007106

Hartmann, K., Corvey, C., Skerka, C., Kirschfink, M., Karas, M., Brade, V., Miller, J.C., Stevenson, B., Wallich, R., Zipfel, P.F., et al. (2006). Functional characterization of BbCRASP-2, a distinct outer membrane protein of Borrelia burgdorferi that binds host complement regulators factor $\mathrm{H}$ and FHL-1. Mol Microbiol 61, 1220-1236. https:// doi.org/10.1111/j.1365-2958.2006.05318.x

Hassan, W.S., Giaretta, P.R., Rech, R., Ollivault-Shiflett, M., and EsteveGasent, M.D. (2019). Enhanced protective efficacy of Borrelia burgdorferi BB0172 derived-peptide based vaccine to control Lyme disease. Vaccine 37, 5596-5606. https://doi.org/10.1016/j.vaccine. 2019.07.092

Haupt, K., Kraiczy, P., Wallich, R., Brade, V., Skerka, C., and Zipfel, P.F. (2007). Binding of human factor $\mathrm{H}$-related protein 1 to serum-resistant Borrelia burgdorferi is mediated by borrelial complement regulatoracquiring surface proteins. J Infect Dis 196, 124-133.

Hayes, B.M., Dulebohn, D.P., Sarkar, A., Tilly, K., Bestor, A., Ambroggio, X., and Rosa, P.A. (2014). Regulatory protein BBD18 of the lyme disease spirochete: essential role during tick acquisition? $\mathrm{mBio} 5$, e01017-01014. https://doi.org/10.1128/mBio.01017-14

He, M., Ouyang, Z., Troxell, B., Xu, H., Moh, A., Piesman, J., Norgard, M.V., Gomelsky, M., and Yang, X.F. (2011). Cyclic di-GMP is essential for the survival of the Lyme disease spirochete in ticks. PLoS Pathog 7, e1002133. https://doi.org/10.1371/journal.ppat.1002133

He, M., Zhang, J.J., Ye, M., Lou, Y., and Yang, X.F. (2014). Cyclic DiGMP receptor PlzA controls virulence gene expression through RpoS in Borrelia burgdorferi. Infect Immun 82, 445-452. https://doi.org/ 10.1128/IAI.01238-13

Hefty, P.S., Jolliff, S.E., Caimano, M.J., Wikel, S.K., and Akins, D.R. (2002). Changes in temporal and spatial patterns of outer surface lipoprotein expression generate population heterogeneity and antigenic diversity in the Lyme disease spirochete, Borrelia burgdorferi. Infect Immun 70, 3468-3478.

Heilpern, A.J., Wertheim, W., He, J., Perides, G., Bronson, R.T., and Hu, L.T. (2009). Matrix metalloproteinase 9 plays a key role in Lyme arthritis but not in dissemination of Borrelia burgdorferi. Infect Immun 77, 2643-2649. https://doi.org/10.1128/IAl.00214-09

Hu, L.T., Perides, G., Noring, R., and Klempner, M.S. (1995). Binding of human plasminogen to Borrelia burgdorferi. Infection \& Immunity 63 , 3491-3496.

Hu, L.T., Pratt, S.D., Perides, G., Katz, L., Rogers, R.A., and Klempner, M.S. (1997). Isolation, cloning, and expression of a 70-kilodalton plasminogen binding protein of Borrelia burgdorferi. Infection and immunity $65,4989-4995$.

Hu, L.T., Eskildsen, M.A., Masgala, C., Steere, A.C., Arner, E.C., Pratta, M.A., Grodzinsky, A.J., Loening, A., and Perides, G. (2001). Host metalloproteinases in Lyme arthritis. Arthritis Rheum 44, 1401-1410. https://doi.org/10.1002/1529-0131(200106)44:6<1401::AIDART234>3.0.CO;2-S

Hubner, A., Yang, X., Nolen, D.M., Popova, T.G., Cabello, F.C., and Norgard, M.V. (2001). Expression of Borrelia burgdorferi OspC and DbpA is controlled by a RpoN-RpoS regulatory pathway. Proc Natl Acad Sci U S A 98, 12724-12729. https://doi.org/10.1073/pnas. 231442498

Hubner, A., Revel, A.T., Nolen, D.M., Hagman, K.E., and Norgard, M.V. (2003). Expression of a luxS gene is not required for Borrelia burgdorferi infection of mice via needle inoculation. Infect Immun 71 , 2892-2896. https://doi.org/10.1128/iai.71.5.2892-2896.2003

Hudson, C.R., Frye, J.G., Quinn, F.D., and Gherardini, F.C. (2001). Increased expression of Borrelia burgdorferi vlsE in response to human endothelial cell membranes. Molecular microbiology 41 , 229-239.

Humphries, J.D., Chastney, M.R., Askari, J.A., and Humphries, M.J. (2019). Signal transduction via integrin adhesion complexes. Current opinion in cell biology 56, 14-21. https://doi.org/10.1016/j.ceb. 2018.08.004

Hyde, J.A., Trzeciakowski, J.P., and Skare, J.T. (2007). Borrelia burgdorferi alters its gene expression and antigenic profile in response to $\mathrm{CO} 2$ levels. Journal of bacteriology $189,437-445$. https:/l doi.org/10.1128/JB.01109-06

Hyde, J.A., Shaw, D.K., Smith lii, R., Trzeciakowski, J.P., and Skare, J.T. (2009). The BosR regulatory protein of Borrelia burgdorferi interfaces with the RpoS regulatory pathway and modulates both the oxidative stress response and pathogenic properties of the Lyme disease spirochete. Mol Microbiol 74, 1344-1355. https://doi.org/10.1111/j. 1365-2958.2009.06951.x

Hyde, J.A., Weening, E.H., Chang, M., Trzeciakowski, J.P., Hook, M., Cirillo, J.D., and Skare, J.T. (2011). Bioluminescent imaging of Borrelia burgdorferi in vivo demonstrates that the fibronectin-binding protein BBK32 is required for optimal infectivity. Mol Microbiol 82 , 99-113. https://doi.org/10.1111/j.1365-2958.2011.07801.x

Hynes, R.O. (1992). Integrins: versatility, modulation, and signaling in cell adhesion. Cell 69, 11-25.

Hynes, R.O. (2002). Integrins: bidirectional, allosteric signaling machines. Cell 110, 673-687.

Imai, D.M., Samuels, D.S., Feng, S., Hodzic, E., Olsen, K., and Barthold, S.W. (2013). The early dissemination defect attributed to disruption of decorin-binding proteins is abolished in chronic murine Lyme borreliosis. Infection and immunity 81, 1663-1673. https:/l doi.org/10.1128//Al.01359-12

Indest, K.J., Howell, J.K., Jacobs, M.B., Scholl-Meeker, D., Norris, S.J., and Philipp, M.T. (2001). Analysis of Borrelia burgdorferi vlsE gene expression and recombination in the tick vector. Infection and immunity $69,7083-7090$. https://doi.org/10.1128//AI. $69.11 .7083-7090.2001$ 
Iozzo, R.V., and Schaefer, L. (2010). Proteoglycans in health and disease: novel regulatory signaling mechanisms evoked by the small leucine-rich proteoglycans. FEBS J 277, 3864-3875. https://doi.org/ 10.1111/j.1742-4658.2010.07797.x

Iyer, R., Kalu, O., Purser, J., Norris, S., Stevenson, B., and Schwartz, I. (2003). Linear and circular plasmid content in Borrelia burgdorferi clinical isolates. Infect Immun 71, 3699-3706. https://doi.org/10.1128/ iai.71.7.3699-3706.2003

lyer, R., Caimano, M.J., Luthra, A., Axline, D., Jr., Corona, A., lacobas, D.A., Radolf, J.D., and Schwartz, I. (2015). Stage-specific global alterations in the transcriptomes of Lyme disease spirochetes during tick feeding and following mammalian host adaptation. Mol Microbiol 95, 509-538. https://doi.org/10.1111/mmi.12882

Jacobs, J.M., Yang, X., Luft, B.J., Dunn, J.J., Camp, D.G., 2nd, and Smith, R.D. (2005). Proteomic analysis of Lyme disease: global protein comparison of three strains of Borrelia burgdorferi. Proteomics 5, 1446-1453.

Jain, S., Sutchu, S., Rosa, P.A., Byram, R., and Jewett, M.W. (2012). Borrelia burgdorferi harbors a transport system essential for purine salvage and mammalian infection. Infection and immunity 80 , 3086-3093. https://doi.org/10.1128/IAI.00514-12

Jain, S., Showman, A.C., and Jewett, M.W. (2015). Molecular dissection of a Borrelia burgdorferi in vivo essential purine transport system. Infection and immunity 83, 2224-2233. https://doi.org/10.1128/IAl. 02859-14

Jewett, M.W., Byram, R., Bestor, A., Tilly, K., Lawrence, K., Burtnick, M.N., Gherardini, F., and Rosa, P.A. (2007a). Genetic basis for retention of a critical virulence plasmid of Borrelia burgdorferi. Molecular microbiology 66, 975-990.

Jewett, M.W., Lawrence, K., Bestor, A.C., Tilly, K., Grimm, D., Shaw, P. VanRaden, M., Gherardini, F., and Rosa, P.A. (2007b). The critical role of the linear plasmid Ip36 in the infectious cycle of Borrelia burgdorferi. Molecular microbiology 64, 1358-1374.

Jewett, M.W., Lawrence, K.A., Bestor, A., Byram, R., Gherardini, F., and Rosa, P.A. (2009). GuaA and GuaB are essential for Borrelia burgdorferi survival in the tick-mouse infection cycle. Journal of bacteriology 191, 6231-6241.

Jones, K.L., Glickstein, L.J., Damle, N., Sikand, V.K., McHugh, G., and Steere, A.C. (2006). Borrelia burgdorferi genetic markers and disseminated disease in patients with early Lyme disease. $\mathrm{J}$ Clin Microbiol 44, 4407-4413. https://doi.org/10.1128/JCM.01077-06

Kariu, T., Yang, X., Marks, C.B., Zhang, X., and Pal, U. (2013). Proteolysis of BB0323 results in two polypeptides that impact physiologic and infectious phenotypes in Borrelia burgdorferi. Molecular microbiology 88, 510-522. https://doi.org/10.1111/mmi. 12202

Kariu, T., Sharma, K., Singh, P., Smith, A.A., Backstedt, B., Buyuktanir, O., and Pal, U. (2015). BB0323 and novel virulence determinant BB0238: Borrelia burgdorferi proteins that interact with and stabilize each other and are critical for infectivity. J Infect Dis 211, 462-471. https://doi.org/10.1093/infdis/jiu460

Karna, S.L., Sanjuan, E., Esteve-Gassent, M.D., Miller, C.L., Maruskova, M., and Seshu, J. (2011). CsrA modulates levels of lipoproteins and key regulators of gene expression critical for pathogenic mechanisms of Borrelia burgdorferi. Infection and immunity $79,732-744$. https:// doi.org/10.1128/IAI.00882-10

Kawabata, H., Myouga, F., Inagaki, Y., Murai, N., and Watanabe, H. (1998). Genetic and immunological analyses of VIs (VMP-like sequences) of Borrelia burgdorferi. Microbial pathogenesis 24, 155-166. https://doi.org/10.1006/mpat.1997.0183

Kawabata, H., Norris, S.J., and Watanabe, H. (2004). BBE02 disruption mutants of Borrelia burgdorferi B31 have a highly transformable, infectious phenotype. Infection and immunity 72, 7147-7154.

Kenedy, M.R., Vuppala, S.R., Siegel, C., Kraiczy, P., and Akins, D.R. (2009). CspA-mediated binding of human factor $H$ inhibits complement deposition and confers serum resistance in Borrelia burgdorferi. Infect Immun 77, 2773-2782. https://doi.org/10.1128/IAI. 00318-09

Kenedy, M.R., Luthra, A., Anand, A., Dunn, J.P., Radolf, J.D., and Akins, D.R. (2014). Structural modeling and physicochemical characterization provide evidence that P66 forms a beta-barrel in the Borrelia burgdorferi outer membrane. J Bacteriol 196, 859-872. https://doi.org/10.1128/JB.01236-13

Khajanchi, B.K., Odeh, E., Gao, L., Jacobs, M.B., Philipp, M.T., Lin, T., and Norris, S.J. (2015). Phosphoenolpyruvate Phosphotransferase System Components Modulate Gene Transcription and Virulence of Borrelia burgdorferi. Infect Immun 84, 754-764. https://doi.org/ 10.1128/IAI.00917-15

Kirchner, A., Koedel, U., Fingerle, V., Paul, R., Wilske, B., and Pfister, H.W. (2000). Upregulation of matrix metalloproteinase-9 in the cerebrospinal fluid of patients with acute Lyme neuroborreliosis. $J$ Neurol Neurosurg Psychiatry 68, 368-371. https://doi.org/10.1136/ jnnp.68.3.368

Klempner, M.S., Noring, R., Epstein, M.P., McCloud, B., Hu, R. Limentani, S.A., and Rogers, R.A. (1995). Binding of human plasminogen and urokinase-type plasminogen activator to the Lyme disease spirochete, Borrelia burgdorferi. J Infect Dis 171, 1258-1265.

Klempner, M.S., Noring, R., Epstein, M.P., McCloud, B., and Rogers, R.A. (1996). Binding of human urokinase type plasminogen activator and plasminogen to Borrelia species. Journal of Infectious Diseases 174, 97-104.

Knirel, Y.A., Sun, Q., Senchenkova, S.N., Perepelov, A.V., Shashkov, A.S., and $\mathrm{Xu}$, J. (2015). O-antigen modifications providing antigenic diversity of Shigella flexneri and underlying genetic mechanisms Biochemistry Biokhimiia 80, 901-914. https://doi.org/10.1134/ S0006297915070093

Koenigs, A., Hammerschmidt, C., Jutras, B.L., Pogoryelov, D., Barthel, D., Skerka, C., Kugelstadt, D., Wallich, R., Stevenson, B., Zipfel, P.F., et al. (2013). BBA70 of Borrelia burgdorferi is a novel plasminogenbinding protein. J Biol Chem 288, 25229-25243. https://doi.org/ 10.1074/jbc.M112.413872

Kornacki, J.A., and Oliver, D.B. (1998). Lyme disease-causing Borrelia species encode multiple lipoproteins homologous to peptide-binding proteins of ABC-type transporters. Infection and immunity 66 4115-4122.

Kostick-Dunn, J.L., Izac, J.R., Freedman, J.C., Szkotnicki, L.T., Oliver, L.D., Jr., and Marconi, R.T. (2018). The Borrelia burgdorferi c-di-GMP binding receptors, $\mathrm{PlzA}$ and $\mathrm{PlzB}$, are functionally distinct. Front Cell Infect Microbiol 8, 213. https://doi.org/10.3389/fcimb.2018.00213

Kostick, J.L., Szkotnicki, L.T., Rogers, E.A., Bocci, P., Raffaelli, N., and Marconi, R.T. (2011). The diguanylate cyclase, Rrp1, regulates critical steps in the enzootic cycle of the Lyme disease spirochetes. Mol Microbiol 81, 219-231. https://doi.org/10.1111/j.1365-2958.2011.07687.x Kraiczy, P., Skerka, C., Brade, V., and Zipfel, P.F. (2001a). Further characterization of complement regulator-acquiring surface proteins of Borrelia burgdorferi. Infection and immunity 69, 7800-7809.

Kraiczy, P., Skerka, C., Kirschfink, M., Brade, V., and Zipfel, P.F. (2001b). Immune evasion of Borrelia burgdorferi by acquisition of human complement regulators $\mathrm{FHL}-1 /$ reconectin and Factor $\mathrm{H}$. Eur J Immunol 31, 1674-1684. https://doi.org/10.1002/1521-4141(200106)31:6\&\#60; 1674::AID-IMMU1674\&\#62;3.0.CO;2-2

Kraiczy, P., Skerka, C., Kirschfink, M., Zipfel, P.F., and Brade, V. (2001c). Mechanism of complement resistance of pathogenic Borrelia burgdorferi isolates. Int Immunopharmacol 1, 393-401.

Kraiczy, P., Hellwage, J., Skerka, C., Kirschfink, M., Brade, V., Zipfel, P.F., and Wallich, R. (2003). Immune evasion of Borrelia burgdorferi: mapping of a complement-inhibitor factor $\mathrm{H}$-binding site of BbCRASP-3, a novel member of the Erp protein family. Eur $\mathrm{J}$ Immunol 33, 697-707. https://doi.org/10.1002/eji.200323571 
Kraiczy, P., and Stevenson, B. (2013). Complement regulator-acquiring surface proteins of Borrelia burgdorferi: Structure, function and regulation of gene expression. Ticks Tick Borne Dis 4, 26-34. https:// doi.org/10.1016/j.ttbdis.2012.10.039

Kraiczy, P. (2016a). Travelling between two worlds: complement as a gatekeeper for an expanded host range of Lyme disease spirochetes. Vet Sci 3. https://doi.org/10.3390/vetsci3020012

Kraiczy, P. (2016b). Hide and seek: how Lyme disease spirochetes overcome complement attack. Front Immunol 7, 385. https://doi.org/ 10.3389/fimmu.2016.00385

Kumar, D., Ristow, L.C., Shi, M., Mukherjee, P., Caine, J.A., Lee, W.Y., Kubes, P., Coburn, J., and Chaconas, G. (2015). Intravital Imaging of Vascular Transmigration by the Lyme Spirochete: Requirement for the Integrin Binding Residues of the B. burgdorferi P66 Protein. PLoS Pathog 11, e1005333. https://doi.org/10.1371/journal.ppat.1005333

Kurtenbach, K., De Michelis, S., Etti, S., Schafer, S.M., Sewell, H.S. Brade, V., and Kraiczy, P. (2002). Host association of Borrelia burgdorferi sensu lato--the key role of host complement. Trends Microbiol 10, 74-79.

Kuthejlova, M., Kopecky, J., Stepanova, G., and Macela, A. (2001). Tick salivary gland extract inhibits killing of Borrelia afzelii spirochetes by mouse macrophages. Infection and immunity 69, 575-578. https:/l doi.org/10.1128/IAl.69.1.575-578.2001

Labandeira-Rey, M., Seshu, J., and Skare, J.T. (2003). The absence of linear plasmid 25 or 28-1 of Borrelia burgdorferi dramatically alters the kinetics of experimental infection via distinct mechanisms. Infect Immun 71, 4608-4613.

Lagal, V., Portnoi, D., Faure, G., Postic, D., and Baranton, G. (2006). Borrelia burgdorferi sensu stricto invasiveness is correlated with OspC-plasminogen affinity. Microbes Infect 8, 645-652. https://doi.org/ 10.1016/j.micinf.2005.08.017

Larson, R.S., and Springer, T.A. (1990). Structure and function of leukocyte integrins. Immunol Rev 114, 181-217. https://doi.org/ 10.1111/j.1600-065x.1990.tb00565.x

Lawrence, M.B., and Springer, T.A. (1991). Leukocytes roll on a selectin at physiologic flow rates: distinction from and prerequisite for adhesion through integrins. Cell 65, 859-873.

Lawrence, M.B., Berg, E.L., Butcher, E.C., and Springer, T.A. (1995). Rolling of lymphocytes and neutrophils on peripheral node addressin and subsequent arrest on ICAM-1 in shear flow. European journal of immunology 25, 1025-1031.

Lawrenz, M.B., Kawabata, H., Purser, J.E., and Norris, S.J. (2002) Decreased electroporation efficiency in Borrelia burgdorferi containing linear plasmids Ip25 and Ip56: impact on transformation of infectious B. burgdorferi. Infection and immunity 70, 4798-4804.

Lawrenz, M.B., Wooten, R.M., Zachary, J.F., Drouin, S.M., Weis, J.J., Wetsel, R.A., and Norris, S.J. (2003). Effect of complement component $\mathrm{C} 3$ deficiency on experimental Lyme borreliosis in mice. Infection and immunity $71,4432-4440$.

Lawrenz, M.B., Wooten, R.M., and Norris, S.J. (2004). Effects of vlsE complementation on the infectivity of Borrelia burgdorferi lacking the linear plasmid Ip28-1. Infection and immunity 72, 6577-6585. https:// doi.org/10.1128/IAI.72.11.6577-6585.2004

Lee, W.Y., Moriarty, T.J., Wong, C.H., Zhou, H., Strieter, R.M., van Rooijen, N., Chaconas, G., and Kubes, P. (2010). An intravascular immune response to Borrelia burgdorferi involves Kupffer cells and iNKT cells. Nat Immunol 11, 295-302. https://doi.org/10.1038/ni.1855

Lee, W.Y., Sanz, M.J., Wong, C.H., Hardy, P.O., Salman-Dilgimen, A. Moriarty, T.J., Chaconas, G., Marques, A., Krawetz, R., Mody, C.H., et al. (2014). Invariant natural killer T cells act as an extravascular cytotoxic barrier for joint-invading Lyme Borrelia. Proceedings of the National Academy of Sciences of the United States of America 111, 13936-13941. https://doi.org/10.1073/pnas.1404769111

Leong, J.M., Morrissey, P.E., Ortega-Barria, E., Pereira, M.E., and Coburn, J. (1995). Hemagglutination and proteoglycan binding by the
Lyme disease spirochete, Borrelia burgdorferi. Infection \& Immunity 63, 874-883.

Li, X., Liu, X., Beck, D.S., Kantor, F.S., and Fikrig, E. (2006). Borrelia burgdorferi lacking BBK32, a fibronectin-binding protein, retains full pathogenicity. Infect Immun 74, 3305-3313. https://doi.org/10.1128/ IAl.02035-05

Li, X., Pal, U., Ramamoorthi, N., Liu, X., Desrosiers, D.C., Eggers, C.H., Anderson, J.F., Radolf, J.D., and Fikrig, E. (2007). The Lyme disease agent Borrelia burgdorferi requires BB0690, a Dps homologue, to persist within ticks. Mol Microbiol 63,694-710. https://doi.org/10.1111/ j.1365-2958.2006.05550.x

Lin, B., Kidder, J.M., Noring, R., Steere, A.C., Klempner, M.S., and Hu, L.T. (2001a). Differences in synovial fluid levels of matrix metalloproteinases suggest separate mechanisms of pathogenesis in Lyme arthritis before and after antibiotic treatment. J Infect Dis 184, 174-180. https://doi.org/10.1086/322000

Lin, B., Short, S.A., Eskildsen, M., Klempner, M.S., and Hu, L.T. (2001b). Functional testing of putative oligopeptide permease (Opp) proteins of Borrelia burgdorferi: a complementation model in opp(-) Escherichia coli. Biochimica et biophysica acta 1499, 222-231.

Lin, T., Gao, L., Edmondson, D.G., Jacobs, M.B., Philipp, M.T., and Norris, S.J. (2009). Central role of the holliday junction helicase RuvAB in vlsE recombination and infectivity of Borrelia burgdorferi. PLoS Pathog 5, e1000679.

Lin, T., Gao, L., Zhang, C., Odeh, E., Jacobs, M.B., Coutte, L., Chaconas, G., Philipp, M.T., and Norris, S.J. (2012). Analysis of an ordered, comprehensive STM mutant library in infectious Borrelia burgdorferi: insights into the genes required for mouse infectivity. PLoS One 7, e47532. https://doi.org/10.1371/journal.pone.0047532

Lin, Y.P., Benoit, V., Yang, X., Martinez-Herranz, R., Pal, U., and Leong, J.M. (2014). Strain-specific variation of the decorin-binding adhesin DbpA influences the tissue tropism of the lyme disease spirochete. PLoS Pathog 10, e1004238. https://doi.org/10.1371/journal.ppat. 1004238

Lin, Y.P., Chen, Q., Ritchie, J.A., Dufour, N.P., Fischer, J.R., Coburn, J., and Leong, J.M. (2015). Glycosaminoglycan binding by Borrelia burgdorferi adhesin BBK32 specifically and uniquely promotes joint colonization. Cell Microbiol 17, 860-875. https://doi.org/10.1111/cmi. 12407

Lin, Y.P., Diuk-Wasser, M.A., Stevenson, B., and Kraiczy, P. (2020a). Complement Evasion Contributes to Lyme Borreliae-Host Associations. Trends in parasitology. https://doi.org/10.1016/j.pt. 2020.04.011

Lin, Y.P., Frye, A.M., Nowak, T.A., and Kraiczy, P. (2020b). New Insights Into CRASP-Mediated Complement Evasion in the Lyme Disease Enzootic Cycle. Frontiers in cellular and infection microbiology 10, 1. https://doi.org/10.3389/fcimb.2020.00001

Lin, Y.P., Tan, X., Caine, J.A., Castellanos, M., Chaconas, G., Coburn, J., and Leong, J.M. (2020c). Strain-specific joint invasion and colonization by Lyme disease spirochetes is promoted by outer surface protein C. PLoS Pathog 16, e1008516. https://doi.org/ 10.1371/journal.ppat.1008516

Lipsett, S.C., Branda, J.A., and Nigrovic, L.E. (2019). Evaluation of the Modified Two-Tiered Testing Method for Diagnosis of Lyme Disease in Children. Journal of clinical microbiology 57. https://doi.org/10.1128/ JCM.00547-19

Liveris, D., Mulay, V., Sandigursky, S., and Schwartz, I. (2008). Borrelia burgdorferi vlsE antigenic variation is not mediated by RecA. Infection and immunity 76, 4009-4018. https://doi.org/10.1128//Al.00027-08

Lone, A.G., and Bankhead, T. (2020). The Borrelia burgdorferi VIsE Lipoprotein Prevents Antibody Binding to an Arthritis-Related Surface Antigen. Cell Rep 30, 3663-3670 e3665. https://doi.org/10.1016/ j.celrep.2020.02.081 
Lybecker, M.C., and Samuels, D.S. (2007). Temperature-induced regulation of RpoS by a small RNA in Borrelia burgdorferi. Molecular microbiology 64, 1075-1089

Magnarelli, L.A., Anderson, J.F., and Barbour, A.G. (1989). Enzymelinked immunosorbent assays for Lyme disease: reactivity of subunits of Borrelia burgdorferi. Journal of Infectious Diseases 159, 43-49.

Mahan, M.J., Slauch, J.M., Hanna, P.C., Camilli, A., Tobias, J.W. Waldor, M.K., and Mekalanos, J.J. (1993a). Selection for bacterial genes that are specifically induced in host tissues: the hunt for virulence factors. [Review]. Infectious Agents \& Disease 2, 263-268.

Mahan, M.J., Slauch, J.M., and Mekalanos, J.J. (1993b). Selection of bacterial virulence genes that are specifically induced in host tissues [see comments]. Science (New York, NY 259, 686-688.

Marcinkiewicz, A.L., Dupuis, A.P., 2nd, Zamba-Campero, M., Nowak, N., Kraiczy, P., Ram, S., Kramer, L.D., and Lin, Y.P. (2019). Blood treatment of Lyme borreliae demonstrates the mechanism of CspZmediated complement evasion to promote systemic infection in vertebrate hosts. Cell Microbiol 21, e12998. https://doi.org/10.1111/ cmi.12998

Margolis, N., Hogan, D., Tilly, K., and Rosa, P. (1994). Plasmid location of Borrelia purine biosynthesis gene homologs. Journal of bacteriology 176, 6427-6432.

Marques, A.R. (2018). Revisiting the Lyme Disease Serodiagnostic Algorithm: the Momentum Gathers. Journal of clinical microbiology 56. https://doi.org/10.1128/JCM.00749-18

Mason, C., Thompson, C., and Ouyang, Z. (2020). The Lon-2 protease of Borrelia burgdorferi is critical for infection in the mammalian host. Molecular microbiology. https://doi.org/10.1111/mmi.14460

McDowell, J.V., Sung, S.Y., Hu, L.T., and Marconi, R.T. (2002). Evidence that the variable regions of the central domain of VlsE are antigenic during infection with lyme disease spirochetes. Infection and immunity 70, 4196-4203.

McDowell, J.V., Hovis, K.M., Zhang, H., Tran, E., Lankford, J., and Marconi, R.T. (2006). Evidence that the BBA68 protein (BbCRASP-1) of the Lyme disease spirochetes does not contribute to factor $\mathrm{H}$ mediated immune evasion in humans and other animals. Infect Immun 74, 3030-3034. https://doi.org/10.1128//AI. 74.5.3030-3034.2006

Medrano, M.S., Ding, Y., Wang, X.G., Lu, P., Coburn, J., and Hu, L.T. (2007). Regulators of expression of the oligopeptide permease $A$ proteins of Borrelia burgdorferi. Journal of bacteriology 189, 2653-2659.

Metts, M.S., McDowell, J.V., Theisen, M., Hansen, P.R., and Marconi, R.T. (2003). Analysis of the OspE determinants involved in binding of factor $\mathrm{H}$ and OspE-targeting antibodies elicited during Borrelia burgdorferi infection in mice. Infect Immun 71, 3587-3596.

Mitchell, P.D., Reed, K.D., Vandermause, M.F., and Melski, J.W. (1993). Isolation of Borrelia burgdorferi from skin biopsy specimens of patients with erythema migrans. Am J Clin Pathol 99, 104-107. https:// doi.org/10.1093/ajcp/99.1.104

Mohammed, D., Versaevel, M., Bruyere, C., Alaimo, L., Luciano, M. Vercruysse, E., Proces, A., and Gabriele, S. (2019). Innovative Tools for Mechanobiology: Unraveling Outside-In and Inside-Out Mechanotransduction. Front Bioeng Biotechnol 7, 162. https://doi.org/ 10.3389/fbioe.2019.00162

Moreth, K., Iozzo, R.V., and Schaefer, L. (2012). Small leucine-rich proteoglycans orchestrate receptor crosstalk during inflammation. Cell cycle (Georgetown, Tex 11, 2084-2091. https://doi.org/10.4161/ cc.20316

Moriarty, T.J., Norman, M.U., Colarusso, P., Bankhead, T., Kubes, P., and Chaconas, G. (2008). Real-time high resolution 3D imaging of the Lyme disease spirochete adhering to and escaping from the vasculature of a living host. PLoS Pathog 4, e1000090. https:// doi.org/10.1371/journal.ppat.1000090
Moriarty, T.J., Shi, M., Lin, Y.P., Ebady, R., Zhou, H., Odisho, T., Hardy, P.O., Salman-Dilgimen, A., Wu, J., Weening, E.H., et al. (2012). Vascular binding of a pathogen under shear force through mechanistically distinct sequential interactions with host macromolecules. Mol Microbiol 86, 1116-1131. https://doi.org/10.1111/ mmi.12045

Narasimhan, S., Sukumaran, B., Bozdogan, U., Thomas, V., Liang, X., DePonte, K., Marcantonio, N., Koski, R.A., Anderson, J.F., Kantor, F. et al. (2007). A tick antioxidant facilitates the Lyme disease agent's successful migration from the mammalian host to the arthropod vector. Cell Host Microbe 2, 7-18. https://doi.org/10.1016/j.chom 2007.06.001

Nishimura, S.L. (2009). Integrin-mediated transforming growth factorbeta activation, a potential therapeutic target in fibrogenic disorders Am J Pathol 175, 1362-1370. https://doi.org/10.2353/ajpath. 2009.090393

Norman, M.U., Moriarty, T.J., Dresser, A.R., Millen, B., Kubes, P., and Chaconas, G. (2008). Molecular mechanisms involved in vascular interactions of the Lyme disease pathogen in a living host. PLoS Pathog 4, e1000169. https://doi.org/10.1371/journal.ppat.1000169

Norris, S.J. (2006). Antigenic variation with a twist--the Borrelia story. Mol Microbiol 60, 1319-1322. https://doi.org/10.1111/j. 1365-2958.2006.05204.x

Norris, S.J. (2014). vls antigenic variation systems of Lyme disease Borrelia: eluding host immunity through both random, segmental gene conversion and framework heterogeneity. Microbiol Spectr 2. https:// doi.org/10.1128/microbiolspec.MDNA3-0038-2014

Nowalk, A.J., Gilmore, R.D., Jr., and Carroll, J.A. (2006a). Serologic proteome analysis of Borrelia burgdorferi membrane-associated proteins. Infect Immun 74, 3864-3873. https://doi.org/10.1128/IAI. 00189-06

Nowalk, A.J., Nolder, C., Clifton, D.R., and Carroll, J.A. (2006b). Comparative proteome analysis of subcellular fractions from Borrelia burgdorferi by NEPHGE and IPG. Proteomics 6, 2121-2134.

Obergfell, K.P., and Seifert, H.S. (2015). Mobile DNA in the Pathogenic Neisseria. Microbiol Spectr 3, MDNA3-0015-2014. https://doi.org/ 10.1128/microbiolspec.MDNA3-0015-2014

Ojaimi, C., Brooks, C., Casjens, S., Rosa, P., Elias, A., Barbour, A. Jasinskas, A., Benach, J., Katona, L., Radolf, J., et al. (2003) Profiling of temperature-induced changes in Borrelia burgdorferi gene expression by using whole genome arrays. Infect Immun 71 $1689-1705$

Onder, O., Humphrey, P.T., McOmber, B., Korobova, F., Francella, N., Greenbaum, D.C., and Brisson, D. (2012). OspC is potent plasminogen receptor on surface of Borrelia burgdorferi. J Biol Chem 287, 16860-16868. https://doi.org/10.1074/jbc.M111.290775

Ouyang, Z., Blevins, J.S., and Norgard, M.V. (2008). Transcriptional interplay among the regulators Rrp2, RpoN and RpoS in Borrelia burgdorferi. Microbiology (Reading, England) 154, 2641-2658.

Ouyang, Z., He, M., Oman, T., Yang, X.F., and Norgard, M.V. (2009a). A manganese transporter, BB0219 (BmtA), is required for virulence by the Lyme disease spirochete, Borrelia burgdorferi. Proceedings of the National Academy of Sciences of the United States of America 106, 3449-3454. https://doi.org/10.1073/pnas.0812999106

Ouyang, Z., Kumar, M., Kariu, T., Haq, S., Goldberg, M., Pal, U., and Norgard, M.V. (2009b). BosR (BB0647) governs virulence expression in Borrelia burgdorferi. Mol Microbiol 74, 1331-1343. https://doi.org/ 10.1111/j.1365-2958.2009.06945.x

Ouyang, Z., Deka, R.K., and Norgard, M.V. (2011). BosR (BB0647) controls the RpoN-RpoS regulatory pathway and virulence expression in Borrelia burgdorferi by a novel DNA-binding mechanism. PLoS Pathog 7, e1001272. https://doi.org/10.1371/journal.ppat.1001272

Pal, U., Wang, P., Bao, F., Yang, X., Samanta, S., Schoen, R., Wormser, G.P., Schwartz, I., and Fikrig, E. (2008). Borrelia burgdorferi basic membrane proteins $A$ and $B$ participate in the genesis of Lyme 
arthritis. J Exp Med 205, 133-141. https://doi.org/10.1084/jem. 20070962

Parveen, N., and Leong, J.M. (2000). Identification of a candidate glycosaminoglycan-binding adhesin of the Lyme disease spirochete Borrelia burgdorferi. Molecular microbiology 35, 1220-1234.

Parveen, N., Cornell, K.A., Bono, J.L., Chamberland, C., Rosa, P., and Leong, J.M. (2006). Bgp, a secreted glycosaminoglycan-binding protein of Borrelia burgdorferi strain N40, displays nucleosidase activity and is not essential for infection of immunodeficient mice. Infection and immunity 74, 3016-3020.

Patton, T.G., Dietrich, G., Dolan, M.C., Piesman, J., Carroll, J.A., and Gilmore, R.D., Jr. (2011). Functional analysis of the Borrelia burgdorferi bba64 gene product in murine infection via tick infestation. PLOS ONE 6, e19536. https://doi.org/10.1371/journal.pone.0019536

Patton, T.G., Brandt, K.S., Nolder, C., Clifton, D.R., Carroll, J.A., and Gilmore, R.D. (2013). Borrelia burgdorferi bba66 gene inactivation results in attenuated mouse infection by tick transmission. Infect Immun 81, 2488-2498. https://doi.org/10.1128//AI.00140-13

Paul, R., Lorenzl, S., Koedel, U., Sporer, B., Vogel, U., Frosch, M., and Pfister, H.W. (1998). Matrix metalloproteinases contribute to the blood-brain barrier disruption during bacterial meningitis. Annals of neurology 44, 592-600. https://doi.org/10.1002/ana.410440404

Perides, G., Noring, R., and Klempner, M.S. (1996). Inhibition of Borrelia burgdorferi-bound fibrinolytic enzymes by alpha2-antiplasmin, PAl-1 and PAI-2. Biochemical \& Biophysical Research Communications 219, 690-695.

Perides, G., Tanner-Brown, L.M., Eskildsen, M.A., and Klempner, M.S (1999). Borrelia burgdorferi induces matrix metalloproteinases by neural cultures. Journal of neuroscience research 58, 779-790. https://doi.org/10.1002/(sici)1097-4547(19991215)58:6<779::aidjnr5>3.0.co;2-I

Phelan, J.P., Kern, A., Ramsey, M.E., Lundt, M.E., Sharma, B., Lin, T., Gao, L., Norris, S.J., Hyde, J.A., Skare, J.T., et al. (2019). Genomewide screen identifies novel genes required for Borrelia burgdorferi survival in its Ixodes tick vector. PLoS Pathog 15, e1007644. https:// doi.org/10.1371/journal.ppat.1007644

Phillips, Z.N., Tram, G., Seib, K.L., and Atack, J.M. (2019). Phasevariable bacterial loci: how bacteria gamble to maximise fitness in changing environments. Biochemical Society transactions 47 1131-1141. https://doi.org/10.1042/BST20180633

Pickering, M.C., Cook, H.T., Warren, J., Bygrave, A.E., Moss, J., Walport, M.J., and Botto, M. (2002). Uncontrolled C3 activation causes membranoproliferative glomerulonephritis in mice deficient in complement factor $H$. Nature genetics 31, 424-428.

Pinne, M., Thein, M., Denker, K., Benz, R., Coburn, J., and Bergstrom, S. (2007). Elimination of channel-forming activity by insertional inactivation of the p66 gene in Borrelia burgdorferi. FEMS Microbiol Lett 266, 241-249. https://doi.org/10.1111/j.1574-6968.2006.00529.x

Pitzer, J.E., Sultan, S.Z., Hayakawa, Y., Hobbs, G., Miller, M.R., and Motaleb, M.A. (2011). Analysis of the Borrelia burgdorferi cyclic-diGMP-binding protein PlzA reveals a role in motility and virulence. Infect Immun 79, 1815-1825. https://doi.org/10.1128/IAI.00075-11

Plasterk, R.H., Simon, M.I., and Barbour, A.G. (1985). Transposition of structural genes to an expression sequence on a linear plasmid causes antigenic variation in the bacterium Borrelia hermsii. Nature 318, 257-263

Posey, J.E., and Gherardini, F.C. (2000). Lack of a role for iron in the Lyme disease pathogen. Science 288, 1651-1653.

Probert, W.S., and Johnson, B.J. (1998). Identification of a $47 \mathrm{kDa}$ fibronectin-binding protein expressed by Borrelia burgdorferi isolate B31. Molecular microbiology 30, 1003-1015.

Probert, W.S., Kim, J.H., Hook, M., and Johnson, B.J.B. (2001). Mapping the ligand-binding region of the Borrelia burgdorferi fibronectin-binding protein BBK32. Infection \& Immunity 69, 4129-4133.
Purser, J.E., Lawrenz, M.B., Caimano, M.J., Howell, J.K., Radolf, J.D., and Norris, S.J. (2003). A plasmid-encoded nicotinamidase (PncA) is essential for infectivity of Borrelia burgdorferi in a mammalian host. Mol Microbiol 48, 753-764.

Radolf, J.D., Goldberg, M.S., Bourell, K., Baker, S.I., Jones, J.D., and Norgard, M.V. (1995). Characterization of outer membranes isolated from Borrelia burgdorferi, the Lyme disease spirochete. Infection \& Immunity 63, 2154-2163.

Radolf J.D. and Samuels, D.S. (2021). Lyme Disease and Relapsing Fever Spirochetes: Genomics, Molecular Biology, Host Interactions and Disease Pathogenesis (Norfolk, UK: Caister Academic Press). https://doi.org/10.21775/9781913652616

Raffel, S.J., Battisti, J.M., Fischer, R.J., and Schwan, T.G. (2014). Inactivation of genes for antigenic variation in the relapsing fever spirochete Borrelia hermsii reduces infectivity in mice and transmission by ticks. PLoS Pathog 10, e1004056. https://doi.org/ 10.1371/journal.ppat.1004056

Ramamoorthi, N., Narasimhan, S., Pal, U., Bao, F., Yang, X.F., Fish, D., Anguita, J., Norgard, M.V., Kantor, F.S., Anderson, J.F., et al. (2005). The Lyme disease agent exploits a tick protein to infect the mammalian host. Nature 436, 573-577. https://doi.org/10.1038/ nature03812

Ramsey, M.E., Hyde, J.A., Medina-Perez, D.N., Lin, T., Gao, L., Lundt, M.E., Li, X., Norris, S.J., Skare, J.T., and Hu, L.T. (2017). A highthroughput genetic screen identifies previously uncharacterized Borrelia burgdorferi genes important for resistance against reactive oxygen and nitrogen species. PLoS Pathog 13, e1006225. https:// doi.org/10.1371/journal.ppat.1006225

Revel, A.T., Talaat, A.M., and Norgard, M.V. (2002). DNA microarray analysis of differential gene expression in Borrelia burgdorferi, the Lyme disease spirochete. Proc Natl Acad Sci U S A 99, 1562-1567. https://doi.org/10.1073/pnas.032667699

Revel, A.T., Blevins, J.S., Almazan, C., Neil, L., Kocan, K.M., de la Fuente, J., Hagman, K.E., and Norgard, M.V. (2005). bptA (bbe16) is essential for the persistence of the Lyme disease spirochete, Borrelia burgdorferi, in its natural tick vector. Proc Natl Acad Sci U S A 102 6972-6977. https://doi.org/10.1073/pnas.0502565102

Ribeiro, J.M., Weis, J.J., and Telford, S.R., 3rd (1990). Saliva of the tick Ixodes dammini inhibits neutrophil function. Exp Parasitol 70, 382-388. https://doi.org/10.1016/0014-4894(90)90121-r

Riley, S.P., Bykowski, T., Babb, K., von Lackum, K., and Stevenson, B. (2007). Genetic and physiological characterization of the Borrelia burgdorferi ORF BB0374-pfs-metK-luxS operon. Microbiology (Reading, England) 153, 2304-2311.

Ristow, L.C., Miller, H.E., Padmore, L.J., Chettri, R., Salzman, N., Caimano, M.J., Rosa, P.A., and Coburn, J. (2012). The $\beta 3$-integrin ligand of Borrelia burgdorferi is critical for infection of mice but not ticks. Molecular microbiology 85, 1105-1118. https://doi.org/10.1111/j. 1365-2958.2012.08160.x

Ristow, L.C., Bonde, M., Lin, Y.P., Sato, H., Curtis, M., Wesley, E., Hahn, B.L., Fang, J., Wilcox, D.A., Leong, J.M., et al. (2015). Integrin binding by Borrelia burgdorferi P66 facilitates dissemination but is not required for infectivity. Celular Microbiology 17, 1021-1036. https:/l doi.org $/ 10.1111 / \mathrm{cmi} .12418$

Rogers, E.A., Terekhova, D., Zhang, H.M., Hovis, K.M., Schwartz, I., and Marconi, R.T. (2009). Rrp1, a cyclic-di-GMP-producing response regulator, is an important regulator of Borrelia burgdorferi core cellular functions. Mol Microbiol 71, 1551-1573. https://doi.org/10.1111/j. 1365-2958.2009.06621.x

Rogovskyy, A.S., and Bankhead, T. (2013). Variable VIsE is critical for host reinfection by the Lyme disease spirochete. PLoS One 8, e61226. https://doi.org/10.1371/journal.pone.0061226

Rogovskyy, A.S., Casselli, T., Tourand, Y., Jones, C.R., Owen, J.P., Mason, K.L., Scoles, G.A., and Bankhead, T. (2015). Evaluation of the Importance of VIsE Antigenic Variation for the Enzootic Cycle of 
Borrelia burgdorferi. PLoS One 10, e0124268. https://doi.org/10.1371/ journal.pone. 0124268

Rosa, P.A. (1997). Microbiology of Borrelia burgdorferi. Seminars in neurology 17, 5-10. https://doi.org/10.1055/s-2008-1040906

Rossmann, E., Kitiratschky, V., Hofmann, H., Kraiczy, P., Simon, M.M., and Wallich, R. (2006). Borrelia burgdorferi complement regulatoracquiring surface protein 1 of the Lyme disease spirochetes is expressed in humans and induces antibody responses restricted to nondenatured structural determinants. Infection and immunity 74 , 7024-7028. https://doi.org/10.1128/IAl.01028-06

Ruoslahti, E. (1996). Integrin signaling and matrix assembly. [Review] [44 refs]. Tumour Biology 17, 117-124.

Ruoslahti, E. (1997). Integrins as signaling molecules and targets for tumor therapy. [Review] [44 refs]. Kidney international 51, 1413-1417.

Russell, T.M., Delorey, M.J., and Johnson, B.J. (2013). Borrelia burgdorferi BbHtrA degrades host ECM proteins and stimulates release of inflammatory cytokines in vitro. Molecular microbiology 90 , 241-251. https://doi.org/10.1111/mmi.12377

Russell, T.M., and Johnson, B.J. (2013). Lyme disease spirochaetes possess an aggrecan-binding protease with aggrecanase activity. Mol Microbiol 90, 228-240. https://doi.org/10.1111/mmi.12276

Russell, T.M., Tang, X., Goldstein, J.M., Bagarozzi, D., and Johnson, B.J. (2016). The salt-sensitive structure and zinc inhibition of Borrelia burgdorferi protease BbHtrA. Molecular microbiology 99, 586-596. https://doi.org/10.1111/mmi.13251

Salman-Dilgimen, A., Hardy, P.O., Dresser, A.R., and Chaconas, G. (2011). HrpA, a DEAH-box RNA helicase, is involved in global gene regulation in the Lyme disease spirochete. PLoS ONE 6, e22168. https://doi.org/10.1371/journal.pone.0022168

Salman-Dilgimen, A., Hardy, P.O., Radolf, J.D., Caimano, M.J., and Chaconas, G. (2013). HrpA, an RNA helicase involved in RNA processing, is required for mouse infectivity and tick transmission of the Lyme disease spirochete. PLoS Pathog 9, e1003841. https:// doi.org/10.1371/journal.ppat.1003841

Salo, J., Jaatinen, A., Soderstrom, M., Viljanen, M.K., and Hytonen, J. (2015). Decorin binding proteins of Borrelia burgdorferi promote arthritis development and joint specific post-treatment DNA persistence in mice. PLoS One 10, e0121512. https://doi.org/10.1371/ journal.pone. 0121512

Samuels, D.S. (2011). Gene regulation in Borrelia burgdorferi. Annu Rev Microbiol 65, 479-499. https://doi.org/10.1146/annurev.micro. 112408.134040

Schlachter, S., Seshu, J., Lin, T., Norris, S., and Parveen, N. (2018). The Borrelia burgdorferi Glycosaminoglycan Binding Protein Bgp in the B31 Strain Is Not Essential for Infectivity despite Facilitating Adherence and Tissue Colonization. Infection and immunity 86 . https://doi.org/10.1128/IAl.00667-17

Schopf, J.W. (2000). Solution to Darwin's dilemma: discovery of the missing Precambrian record of life. Proceedings of the National Academy of Sciences of the United States of America 97, 6947-6953. https://doi.org/10.1073/pnas.97.13.6947

Schuijt, T.J., Hovius, J.W., van Burgel, N.D., Ramamoorthi, N., Fikrig, E., and van Dam, A.P. (2008). The tick salivary protein Salp15 inhibits the killing of serum-sensitive Borrelia burgdorferi sensu lato isolates. Infect Immun 76, 2888-2894. https://doi.org/10.1128/IAI.00232-08

Schuiit, T.J., Coumou, J., Narasimhan, S., Dai, J., Deponte, K., Wouters, D., Brouwer, M., Oei, A., Roelofs, J.J., van Dam, A.P., et al. (2011). A tick mannose-binding lectin inhibitor interferes with the vertebrate complement cascade to enhance transmission of the lyme disease agent. Cell Host Microbe 10, 136-146. https://doi.org/10.1016/j.chom. 2011.06.010

Schulze, R.J., and Zuckert, W.R. (2006). Borrelia burgdorferi lipoproteins are secreted to the outer surface by default. Mol Microbiol 59, 1473-1484. https://doi.org/10.1111//.1365-2958.2006.05039.x
Schwan, T.G., Piesman, J., Golde, W.T., Dolan, M.C., and Rosa, P.A. (1995). Induction of an outer surface protein on Borrelia burgdorferi during tick feeding. Proc Natl Acad Sci U S A 92, 2909-2913.

Schwan, T.G., and Hinnebusch, B.J. (1998). Bloodstream- versus tickassociated variants of a relapsing fever bacterium. Science (New York, NY 280, 1938-1940.

Schwan, T.G., and Piesman, J. (2000). Temporal changes in outer surface proteins $A$ and $C$ of the lyme disease-associated spirochete, Borrelia burgdorferi, during the chain of infection in ticks and mice. Journal of clinical microbiology 38, 382-388.

Schwan, T.G., Raffel, S.J., and Battisti, J.M. (2020). Transgenic functional complementation with a transmission -associated protein restores spirochete infectivity by tick bite. Ticks and tick-borne diseases 11, 101377. https://doi.org/10.1016/j.ttbdis.2020.101377

Seiler, K.P., Vavrin, Z., Eichwald, E., Hibbs, J.B., Jr., and Weis, J.J. (1995). Nitric oxide production during murine Lyme disease: lack of involvement in host resistance or pathology. Infection \& Immunity 63 , 3886-3895

Seshu, J., Boylan, J.A., Gherardini, F.C., and Skare, J.T. (2004). Dissolved oxygen levels alter gene expression and antigen profiles in Borrelia burgdorferi. Infection and immunity 72, 1580-1586.

Seshu, J., Esteve-Gassent, M.D., Labandeira-Rey, M., Kim, J.H., Trzeciakowski, J.P., Hook, M., and Skare, J.T. (2006). Inactivation of the fibronectin-binding adhesin gene bbk32 significantly attenuates the infectivity potential of Borrelia burgdorferi. Mol Microbiol 59 1591-1601. https://doi.org/10.1111/j.1365-2958.2005.05042.x

Setubal, J.C., Reis, M., Matsunaga, J., and Haake, D.A. (2006). Lipoprotein computational prediction in spirochaetal genomes. Microbiology 152, 113-121. https://doi.org/10.1099/mic.0.28317-0

Shaw, D.K., Hyde, J.A., and Skare, J.T. (2012). The BB0646 protein demonstrates lipase and haemolytic activity associated with Borrelia burgdorferi, the aetiological agent of Lyme disease. Molecular microbiology 83, 319-334. https://doi.org/10.1111/j.1365-2958.2011.07932.x

Shi, Y., Xu, Q., McShan, K., and Liang, F.T. (2008). Both decorin-binding proteins $A$ and $B$ are critical for the overall virulence of Borrelia burgdorferi. Infect Immun 76, 1239-1246. https://doi.org/10.1128/IAI. 00897-07

Showman, A.C., Aranjuez, G., Adams, P.P., and Jewett, M.W. (2016). Gene bb0318 Is Critical for the Oxidative Stress Response and Infectivity of Borrelia burgdorferi. Infection and immunity 84, 3141-3151. https://doi.org/10.1128/IAI.00430-16

Shrestha, B., Kenedy, M.R., and Akins, D.R. (2017). Outer Membrane Proteins BB0405 and BB0406 Are Immunogenic, but Only BB0405 Is Required for Borrelia burgdorferi Infection. Infection and immunity 85 . https://doi.org/10.1128//Al.00803-16

Siegel, C., Schreiber, J., Haupt, K., Skerka, C., Brade, V., Simon, M.M., Stevenson, B., Wallich, R., Zipfel, P.F., and Kraiczy, P. (2008). Deciphering the ligand-binding sites in the Borrelia burgdorferi complement regulator-acquiring surface protein 2 required for interactions with the human immune regulators factor $\mathrm{H}$ and factor $\mathrm{H}$ like protein 1 . The Journal of biological chemistry 283, 34855-34863.

Siegel, C., Hallstrom, T., Skerka, C., Eberhardt, H., Uzonyi, B., Beckhaus, T., Karas, M., Wallich, R., Stevenson, B., Zipfel, P.F., et al. (2010). Complement factor H-related proteins CFHR2 and CFHR5 represent novel ligands for the infection-associated CRASP proteins of Borrelia burgdorferi. PLoS ONE 5, e13519. https://doi.org/10.1371/ journal.pone.0013519

Skare, J.T., Mirzabekov, T.A., Shang, E.S., Blanco, D.R., ErdjumentBromage, H., Bunikis, J., Bergstrom, S., Tempst, P., Kagan, B.L., Miller, J.N., et al. (1997). The Oms66 (p66) protein is a Borrelia burgdorferi porin. Infect Immun 65, 3654-3661.

Skare, J.T., Shaw, D.K., Trzeciakowski, J.P., and Hyde, J.A. (2016). in vivo imaging demonstrates that Borrelia burgdorferi ospC is uniquely expressed temporally and spatially throughout experimental infection. 
PLoS One 11, e0162501. https://doi.org/10.1371/journal.pone. 0162501

Skare, J.T., and Garcia, B.L. (2020). Complement Evasion by Lyme Disease Spirochetes. Trends in microbiology. https://doi.org/10.1016/ j.tim.2020.05.004

Small, C.M., Ajithdoss, D.K., Rodrigues Hoffmann, A., Mwangi, W., and Esteve-Gassent, M.D. (2014). Immunization with a Borrelia burgdorferi BB0172-derived peptide protects mice against lyme disease. PLoS ONE 9, e88245. https://doi.org/10.1371/journal.pone. 0088245

Smith, A.H., Blevins, J.S., Bachlani, G.N., Yang, X.F., and Norgard, M.V. (2007). Evidence that RpoS (sigmaS) in Borrelia burgdorferi is controlled directly by RpoN (sigma54/sigmaN). Journal of bacteriology 189, 2139-2144.

Stevenson, B., and Babb, K. (2002). LuxS-mediated quorum sensing in Borrelia burgdorferi, the lyme disease spirochete. Infection and immunity 70, 4099-4105. https://doi.org/10.1128/iai. 70.8.4099-4105.2002

Stevenson, B., El-Hage, N., Hines, M.A., Miller, J.C., and Babb, K. (2002). Differential binding of host complement inhibitor factor $\mathrm{H}$ by Borrelia burgdorferi Erp surface proteins: a possible mechanism underlying the expansive host range of Lyme disease spirochetes. Infect Immun 70, 491-497.

Stewart, P.E., Hoff, J., Fischer, E., Krum, J.G., and Rosa, P.A. (2004) Genome-wide transposon mutagenesis of Borrelia burgdorferi for identification of phenotypic mutants. Applied and environmental microbiology 70, 5973-5979. https://doi.org/10.1128/AEM. 70.10.5973-5979.2004

Stewart, P.E., Wang, X., Bueschel, D.M., Clifton, D.R., Grimm, D., Tilly, K., Carroll, J.A., Weis, J.J., and Rosa, P.A. (2006). Delineating the requirement for the Borrelia burgdorferi virulence factor OspC in the mammalian host. Infect Immun 74, 3547-3553. https://doi.org/ 10.1128/IAI.00158-06

Striz, I., and Costabel, U. (1992). The role of integrins in the immune response. Sarcoidosis 9 , 88-94.

Sultan, S.Z., Pitzer, J.E., Miller, M.R., and Motaleb, M.A. (2010). Analysis of a Borrelia burgdorferi phosphodiesterase demonstrates a role for cyclicdi-guanosine monophosphate in motility and virulence. Mol Microbiol 77, 128-142. https://doi.org/10.1111/j.1365-2958.2010.07191.x

Sung, S.Y., McDowell, J.V., and Marconi, R.T. (2001). Evidence for the contribution of point mutations to vlsE variation and for apparent constraints on the net accumulation of sequence changes in vlsE during infection with Lyme disease spirochetes. Journal of bacteriology 183, 5855-5861.

Thome, S., Begandt, D., Pick, R., Salvermoser, M., and Walzog, B. (2018). Intracellular $\beta 2$ integrin (CD11/CD18) interacting partners in neutrophil trafficking. European journal of clinical investigation 48 Suppl 2, e12966. https://doi.org/10.1111/eci.12966

Thompson, C., Mason, C., Parrilla, S., and Ouyang, Z. (2020). The Lon-1 protease is required by Borrelia burgdorferi to infect the mammalian host. Infection and immunity. https://doi.org/10.1128//Al. 00951-19

Tilly, K., Krum, J.G., Bestor, A., Jewett, M.W., Grimm, D., Bueschel, D., Byram, R., Dorward, D., Vanraden, M.J., Stewart, P., et al. (2006). Borrelia burgdorferi OspC protein required exclusively in a crucial early stage of mammalian infection. Infect Immun 74, 3554-3564. https://doi.org/10.1128/IAI.01950-05

Tilly, K., Bestor, A., and Rosa, P.A. (2013). Lipoprotein succession in Borrelia burgdorferi: similar but distinct roles for OspC and VIsE at different stages of mammalian infection. Mol Microbiol 89, 216-227. https://doi.org/10.1111/mmi.12271

Tokarz, R., Anderton, J.M., Katona, L.I., and Benach, J.L. (2004). Combined effects of blood and temperature shift on Borrelia burgdorferi gene expression as determined by whole genome DNA array. Infect Immun 72, 5419-5432. https://doi.org/10.1128/IAI 72.9.5419-5432.2004

Toledo, A., Coleman, J.L., Kuhlow, C.J., Crowley, J.T., and Benach, J.L. (2012). The enolase of Borrelia burgdorferi is a plasminogen receptor released in outer membrane vesicles. Infect Immun 80, 359-368. https://doi.org/10.1128//Al.05836-11

Troxell, B., Xu, H., and Yang, X.F. (2012). Borrelia burgdorferi, a pathogen that lacks iron, encodes manganese-dependent superoxide dismutase essential for resistance to streptonigrin. The Journal of biological chemistry 287, 19284-19293. https://doi.org/10.1074/ jbc.M112.344903

Troxell, B., and Yang, X.F. (2013). Metal-dependent gene regulation in the causative agent of Lyme disease. Frontiers in cellular and infection microbiology 3, 79. https://doi.org/10.3389/fcimb.2013.00079

Troxell, B., Ye, M., Yang, Y., Carrasco, S.E., Lou, Y., and Yang, X.F. (2013). Manganese and zinc regulate virulence determinants in Borrelia burgdorferi. Infection and immunity 81, 2743-2752. https:// doi.org/10.1128/IAl.00507-13

Troy, E.B., Lin, T., Gao, L., Lazinski, D.W., Camilli, A., Norris, S.J., and $\mathrm{Hu}$, L.T. (2013). Understanding barriers to Borrelia burgdorferi dissemination during infection using massively parallel sequencing. Infect Immun 81, 2347-2357. https://doi.org/10.1128/IAI.00266-13

Troy, E.B., Lin, T., Gao, L., Lazinski, D.W., Lundt, M., Camilli, A., Norris, S.J., and Hu, L.T. (2016). Global Tn-seq analysis of carbohydrate utilization and vertebrate infectivity of Borrelia burgdorferi. Mol Microbiol 101, 1003-1023. https://doi.org/10.1111/mmi.13437

van Burgel, N.D., Balmus, N.C., Fikrig, E., and van Dam, A.P. (2011) Infectivity of Borrelia burgdorferi sensu lato is unaltered in C3deficient mice. Ticks Tick Borne Dis 2, 20-26. https://doi.org/10.1016/ j.ttbdis.2010.10.003

van der Woude, M.W., and Baumler, A.J. (2004). Phase and antigenic variation in bacteria. Clin Microbiol Rev 17, 581-611, table of contents. https://doi.org/10.1128/CMR.17.3.581-611.2004

Verhey, T.B., Castellanos, M., and Chaconas, G. (2018a). Analysis of recombinational switching at the antigenic variation locus of the Lyme spirochete using a novel PacBio sequencing pipeline. Molecular microbiology 108, 461. https://doi.org/10.1111/mmi.13969

Verhey, T.B., Castellanos, M., and Chaconas, G. (2018b). Antigenic Variation in the Lyme Spirochete: Insights into Recombinational Switching with a Suggested Role for Error-Prone Repair. Cell Rep 23 2595-2605. https://doi.org/10.1016/j.celrep.2018.04.117

Verhey, T.B., Castellanos, M., and Chaconas, G. (2019). Antigenic variation in the Lyme spirochete: detailed functional assessment of recombinational switching at vlsE in the JD1 strain of Borrelia burgdorferi. Mol Microbiol 111, 750-763. https://doi.org/10.1111/mmi. 14189

Verma, A., Brissette, C.A., Bowman, A., and Stevenson, B. (2009). Borrelia burgdorferi BmpA is a laminin-binding protein. Infection and immunity $77,4940-4946$.

Verma, N.K., and Kelleher, D. (2017). Not Just an Adhesion Molecule: LFA-1 Contact Tunes the T Lymphocyte Program. J Immunol 199, 1213-1221. https://doi.org/10.4049/jimmunol.1700495

Vink, C., Rudenko, G., and Seifert, H.S. (2012). Microbial antigenic variation mediated by homologous DNA recombination. FEMS microbiology reviews 36, 917-948. https://doi.org/10.1111/j. 1574-6976.2011.00321.x

von Lackum, K., Miller, J.C., Bykowski, T., Riley, S.P., Woodman, M.E., Brade, V., Kraiczy, P., Stevenson, B., and Wallich, R. (2005). Borrelia burgdorferi regulates expression of complement regulator-acquiring surface protein 1 during the mammal-tick infection cycle. Infection and immunity $73,7398-7405$.

von Lackum, K., Babb, K., Riley, S.P., Wattier, R.L., Bykowski, T., and Stevenson, B. (2006). Functionality of Borrelia burgdorferi LuxS: the Lyme disease spirochete produces and responds to the pheromone 
autoinducer-2 and lacks a complete activated-methyl cycle. Int J Med Microbiol 296 Suppl 40, 92-102.

Wager, B., Shaw, D.K., Groshong, A.M., Blevins, J.S., and Skare, J.T. (2015). BB0744 affects tissue tropism and spatial distribution of Borrelia burgdorferi. Infect Immun 83, 3693-3703. https://doi.org/ 10.1128/IAI.00828-15

Wagh, D., Pothineni, V.R., Inayathullah, M., Liu, S., Kim, K.M., and Rajadas, J. (2015). Borreliacidal activity of Borrelia metal transporter $\mathrm{A}(\mathrm{BmtA})$ binding small molecules by manganese transport inhibition. Drug Des Devel Ther 9, 805-816. https://doi.org/10.2147/ DDDT.S77063

Walter, L., Surth, V., Rottgerding, F., Zipfel, P.F., Fritz-Wolf, K., and Kraiczy, P. (2019). Elucidating the Immune Evasion Mechanisms of Borrelia mayonii, the Causative Agent of Lyme Disease. Front Immunol 10, 2722. https://doi.org/10.3389/fimmu.2019.02722

Wang, D., Botkin, D.J., and Norris, S.J. (2003). Characterization of the vls antigenic variation loci of the Lyme disease spirochaetes Borrelia garinii Ip90 and Borrelia afzelii ACAI. Molecular microbiology 47, 1407-1417.

Wang, G., van Dam, A.P., Schwartz, I., and Dankert, J. (1999). Molecular typing of Borrelia burgdorferi sensu lato: taxonomic, epidemiological, and clinical implications. Clin Microbiol Rev 12, 633-653.

Wang, G., van Dam, A.P., and Dankert, J. (2001). Analysis of a VMP-like sequence (vIs) locus in Borrelia garinii and Vls homologues among four Borrelia burgdorferi sensu lato species. FEMS microbiology letters 199, 39-45.

Wang, P., Lutton, A., Olesik, J., Vali, H., and Li, X. (2012). A novel ironand copper-binding protein in the Lyme disease spirochaete. Molecular microbiology 86, 1441-1451. https://doi.org/10.1111/mmi. 12068

Wang, X.G., Lin, B., Kidder, J.M., Telford, S., and Hu, L.T. (2002). Effects of environmental changes on expression of the oligopeptide permease (opp) genes of Borrelia burgdorferi. Journal of bacteriology 184, 6198-6206

Wang, X.G., Kidder, J.M., Scagliotti, J.P., Klempner, M.S., Noring, R., and $\mathrm{Hu}$, L.T. (2004). Analysis of differences in the functional properties of the substrate binding proteins of the Borrelia burgdorferi oligopeptide permease (Opp) operon. Journal of bacteriology 186, 51-60.

Weening, E.H., Parveen, N., Trzeciakowski, J.P., Leong, J.M., Hook, M., and Skare, J.T. (2008). Borrelia burgdorferi lacking DbpBA exhibits an early survival defect during experimental infection. Infect Immun 76 , 5694-5705. https://doi.org/10.1128//Al.00690-08

Winzer, K., and Williams, P. (2001). Quorum sensing and the regulation of virulence gene expression in pathogenic bacteria.PG - 131-43. Int J Med Microbiol 291.

Wood, E., Tamborero, S., Mingarro, I., and Esteve-Gassent, M.D. (2013). BB0172, a Borrelia burgdorferi outer membrane protein that binds integrin a3ß1. Journal of bacteriology 195, 3320-3330. https:// doi.org/10.1128/JB.00187-13

Woodman, M.E., Cooley, A.E., Miller, J.C., Lazarus, J.J., Tucker, K., Bykowski, T., Botto, M., Hellwage, J., Wooten, R.M., and Stevenson, B. (2007). Borrelia burgdorferi binding of host complement regulator factor $\mathrm{H}$ is not required for efficient mammalian infection. Infect Immun 75, 3131-3139. https://doi.org/10.1128//Al.01923-06

Wormser, G.P., Molins, C.R., Levin, A., Lipsett, S.C., Nigrovic, L.E., Schriefer, M.E., and Branda, J.A. (2018). Evaluation of a sequential enzyme immunoassay testing algorithm for Lyme disease demonstrates lack of test independence but high diagnostic specificity. Diagnostic microbiology and infectious disease 91, 217-219. https://doi.org/10.1016/j.diagmicrobio.2018.02.006

Xie, J., Zhi, H., Garrigues, R.J., Keightley, A., Garcia, B.L., and Skare, J.T. (2019). Structural determination of the complement inhibitory domain of Borrelia burgdorferi BBK32 provides insight into classical pathway complement evasion by Lyme disease spirochetes. PLoS Pathog 15, e1007659. https://doi.org/10.1371/journal.ppat.1007659

Xu, H., Caimano, M.J., Lin, T., He, M., Radolf, J.D., Norris, S.J., Gherardini, F., Wolfe, A.J., and Yang, X.F. (2010a). Role of acetylphosphate in activation of the Rrp2-RpoN-RpoS pathway in Borrelia burgdorferi. PLoS Pathog 6, e1001104. https://doi.org/10.1371/ journal.ppat. 1001104

$\mathrm{Xu}, \mathrm{H} ., \mathrm{He}, \mathrm{M} ., \mathrm{He}$, J.J., and Yang, X.F. (2010b). Role of the surface lipoprotein BBA07 in the enzootic cycle of Borrelia burgdorferi. Infection and immunity 78, 2910-2918. https://doi.org/10.1128/IAI. 00372-10

Xu, Q., Seemanapalli, S.V., McShan, K., and Liang, F.T. (2006). Constitutive expression of outer surface protein $\mathrm{C}$ diminishes the ability of Borrelia burgdorferi to evade specific humoral immunity. Infection and immunity 74, 5177-5184.

Xu, Q., Shi, Y., Dadhwal, P., and Liang, F.T. (2012). RpoS regulates essential virulence factors remaining to be identified in Borrelia burgdorferi. PLoS ONE 7, e53212. https://doi.org/10.1371/ journal.pone.0053212

Yang, X., Coleman, A.S., Anguita, J., and Pal, U. (2009). A chromosomally encoded virulence factor protects the Lyme disease pathogen against host-adaptive immunity. PLoS Pathog 5, e1000326.

Yang, X., Qin, J., Promnares, K., Kariu, T., Anderson, J.F., and Pal, U. (2013). Novel microbial virulence factor triggers murine lyme arthritis. $\mathrm{J}$ Infect Dis 207, 907-918. https://doi.org/10.1093/infdis/jis930

Yang, X., Smith, A.A., Williams, M.S., and Pal, U. (2014). A dityrosine network mediated by dual oxidase and peroxidase influences the persistence of Lyme disease pathogens within the vector. The Journal of biological chemistry 289, 12813-12822. https://doi.org/10.1074/ jbc.M113.538272

Yang, X., Lin, Y.P., Heselpoth, R.D., Buyuktanir, O., Qin, J., Kung, F., Nelson, D.C., Leong, J.M., and Pal, U. (2016). Middle region of the Borrelia burgdorferi surface-located protein 1 (Lmp1) interacts with host chondroitin-6-sulfate and independently facilitates infection. Cell Microbiol 18, 97-110. https://doi.org/10.1111/cmi.12487

Yang, X.F., Alani, S.M., and Norgard, M.V. (2003). The response regulator Rrp2 is essential for the expression of major membrane lipoproteins in Borrelia burgdorferi. Proc Natl Acad Sci U S A 100, 11001-11006. https://doi.org/10.1073/pnas. 1834315100

Yang, X.F., Lybecker, M.C., Pal, U., Alani, S.M., Blevins, J., Revel, A.T., Samuels, D.S., and Norgard, M.V. (2005). Analysis of the ospC regulatory element controlled by the RpoN-RpoS regulatory pathway in Borrelia burgdorferi. J Bacteriol 187, 4822-4829. https://doi.org/ 10.1128/JB.187.14.4822-4829.2005

Yang, X.F., Goldberg, M.S., He, M., Xu, H., Blevins, J.S., and Norgard, M.V. (2008). Differential expression of a putative CarD-like transcriptional regulator, LtpA, in Borrelia burgdorferi. Infection and immunity $76,4439-4444$.

Ye, M., Sharma, K., Thakur, M., Smith, A.A., Buyuktanir, O., Xiang, X., Yang, X., Promnares, K., Lou, Y., Yang, X.F., et al. (2016). HtrA, a Temperature- and Stationary Phase-Activated Protease Involved in Maturation of a Key Microbial Virulence Determinant, Facilitates Borrelia burgdorferi Infection in Mammalian Hosts. Infection and immunity 84, 2372-2381. https://doi.org/10.1128/IAl.00360-16

Zambrano, M.C., Beklemisheva, A.A., Bryksin, A.V., Newman, S.A., and Cabello, F.C. (2004). Borrelia burgdorferi binds to, invades, and colonizes native type I collagen lattices. Infect Immun 72, 3138-3146. https://doi.org/10.1128/IAl.72.6.3138-3146.2004

Zhang, J.R., Hardham, J.M., Barbour, A.G., and Norris, S.J. (1997). Antigenic variation in Lyme disease borreliae by promiscuous recombination of VMP-like sequence cassettes. Cell 89, 275-285.

Zhang, J.R., and Norris, S.J. (1998a). Genetic variation of the Borrelia burgdorferi gene vlsE involves cassette-specific, segmental gene conversion. Infection and immunity 66, 3698-3704. 
Zhang, J.R., and Norris, S.J. (1998b). Kinetics and in vivo induction of genetic variation of vIsE in Borrelia burgdorferi. Infection and immunity 66, 3689-3697.

Zhang, K., Qin, Z., Chang, Y., Liu, J., Malkowski, M.G., Shipa, S., Li, L., Qiu, W., Zhang, J.R., and Li, C. (2019). Analysis of a flagellar filament cap mutant reveals that HtrA serine protease degrades unfolded flagellin protein in the periplasm of Borrelia burgdorferi. Molecular microbiology 111, 1652-1670. https://doi.org/10.1111/mmi.14243

Zhang, X., Yang, X., Kumar, M., and Pal, U. (2009). BB0323 function is essential for Borrelia burgdorferi virulence and persistence through tick-rodent transmission cycle. J Infect Dis 200, 1318-1330. https:// doi.org/10.1086/605846

Zhao, Z., Chang, H., Trevino, R.P., Whren, K., Bhawan, J., and Klempner, M.S. (2003). Selective up-regulation of matrix metalloproteinase-9 expression in human erythema migrans skin lesions of acute lyme disease. J Infect Dis 188, 1098-1104. https:/ doi.org/10.1086/379039
Zhi, H., Weening, E.H., Barbu, E.M., Hyde, J.A., Hook, M., and Skare, J.T. (2015). The BBA33 lipoprotein binds collagen and impacts Borrelia burgdorferi pathogenesis. Mol Microbiol 96, 68-83. https:// doi.org/10.1111/mmi.12921

Zhi, H., Xie, J., and Skare, J.T. (2018). The classical complement pathway Is required to control Borrelia burgdorferi levels during experimental infection. Front Immunol 9, 959. https://doi.org/10.3389/ fimmu.2018.00959

Zipfel, P.F., and Skerka, C. (2009). Complement regulators and inhibitory proteins. Nature reviews Immunology 9, 729-740. https:/l doi.org/10.1038/nri2620

Zuckert, W.R., Lloyd, J.E., Stewart, P.E., Rosa, P.A., and Barbour, A.G. (2004). Cross-species surface display of functional spirochetal lipoproteins by recombinant Borrelia burgdorferi. Infect Immun 72 1463-1469. https://doi.org/10.1128/iai.72.3.1463-1469.2004

Zuckert, W.R. (2019). Protein secretion in spirochetes. Microbiol Spectr 7. https://doi.org/10.1128/microbiolspec.PSIB-0026-2019 